\title{
On the weighty issue of obesity : physiological, behavioural and genetic aspects
}

Citation for published version (APA):

Vogels, N. (2006). On the weighty issue of obesity : physiological, behavioural and genetic aspects. [Doctoral Thesis, Maastricht University]. Universitaire Pers Maastricht. https://doi.org/10.26481/dis.20060922nv

Document status and date:

Published: 01/01/2006

DOI:

10.26481/dis.20060922nv

Document Version:

Publisher's PDF, also known as Version of record

\section{Please check the document version of this publication:}

- A submitted manuscript is the version of the article upon submission and before peer-review. There can be important differences between the submitted version and the official published version of record. People interested in the research are advised to contact the author for the final version of the publication, or visit the DOI to the publisher's website.

- The final author version and the galley proof are versions of the publication after peer review.

- The final published version features the final layout of the paper including the volume, issue and page numbers.

Link to publication

\footnotetext{
General rights rights.

- You may freely distribute the URL identifying the publication in the public portal. please follow below link for the End User Agreement:

www.umlib.nl/taverne-license

Take down policy

If you believe that this document breaches copyright please contact us at:

repository@maastrichtuniversity.nl

providing details and we will investigate your claim.
}

Copyright and moral rights for the publications made accessible in the public portal are retained by the authors and/or other copyright owners and it is a condition of accessing publications that users recognise and abide by the legal requirements associated with these

- Users may download and print one copy of any publication from the public portal for the purpose of private study or research.

- You may not further distribute the material or use it for any profit-making activity or commercial gain

If the publication is distributed under the terms of Article $25 \mathrm{fa}$ of the Dutch Copyright Act, indicated by the "Taverne" license above, 


\section{On the weighty issue of obesity:}

Physiological, behavioral and genetic aspects 


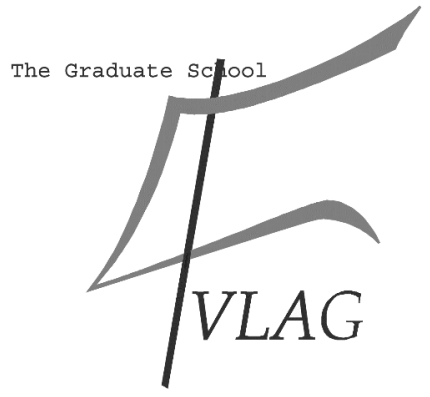

The studies presented in this thesis were performed at the Nutrition and Toxicology Research Institute Maastricht (NUTRIM), which participates in the graduate school VLAG (Food Technology, Agrobiotechnology, Nutrition and Health Sciences), accredited by the Royal Netherlands Academy of Arts and Sciences.

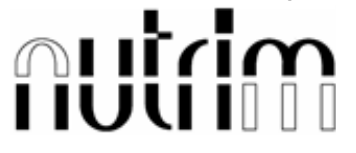

Printing of this thesis was financially supported by the Netherlands Association for the Study van Obesity (NASO).

Financial support from the Netherlands Heart Foundation and the Dutch Diabetes Research Foundation for the publication of this thesis is gratefully acknowledged.

Cover design: Bram Bollen (www.brambollen.be)

Cover:

Layout:

Derived from MN SOPHE

Printed by: Datawyse, Universitaire Pers Maastricht

(c) N.Vogels, Maastricht 2006

ISBN-10 90-5278-556-2

ISBN-13 97890-5278-556-1 


\title{
On the weighty issue of obesity:
}

\section{Physiological, behavioral and genetic aspects}

\author{
PROEFSCHRIFT \\ ter verkrijging van de graad van doctor \\ aan de Universiteit Maastricht, \\ op gezag van de Rector Magnificus, \\ Prof. mr. G.P.M.F. Mols, \\ volgens het besluit van het College van Decanen, \\ in het openbaar te verdedigen \\ op vrijdag 22 september 2006 om 14:00 uur \\ door

\section{Neeltje Vogels}

geboren te Veghel op 23 december 1978

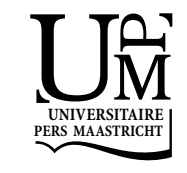




\section{Promotores}

Prof. dr. M.S. Westerterp-Plantenga

Prof. dr. E.C.M. Mariman

\section{Beoordelingscommissie}

Prof. dr. ir. P.A. van den Brandt (voorzitter)

Prof. dr. R.A.H. Adan (Utrecht Universiteit)

Prof. dr. R-J.M. Brummer

Prof. dr. W.J.M. Gerver

Prof. dr. M.W. deVries 


\section{CONTENTS}

\section{Chapter 1}

Introduction

\section{Chapter 2}

Determinants of overweight in a Dutch children cohort

\section{Chapter 3}

Daily physical activity and activity-counts in lean and overweight Dutch children

\section{Chapter 4}

Predictors of long-term weight maintenance

\section{Chapter 5}

Categorical strategies based on subject specific characteristics of dietray restraint and physical activity, for weight maintenance

\section{Chapter 6}

Successful long-term weight maintenance, a $2 y$ follow-up

\section{Chapter 7}

Relation of weight maintenance and dietary restraint with peroxisome proliferatie-activated $\gamma 2$, glucocorticoid receptor and ciliary neurotrophic factor polymorphisms

\section{Chapter 8}

Discussion

Summary

Samenvatting

Dankwoord

Publications 

1

Introduction 


\section{OBESITY AND ITS HEALTH CONSEQUENCES}

Obesity is a complex multi-factorial chronic disorder that develops from an interaction of genotype and the environment $(1,2)$. Our understanding of why and how obesity develops is still incomplete, but involves the integration of behavioral, social, cultural, metabolic, physiological and genetic factors (3). Obesity is characterized by an excess accumulation of body fat that clearly results from a chronic imbalance between energy intake and expenditure (4). For energy balance, energy intake must equal energy expenditure (5). Body mass index (BMI) is commonly used to classify overweight and obesity (6). According to the WHO (2000), the cut-off point for adult overweight is at a BMI of 25.0. A BMI between 18.5 and 24.9 is defined as normal weight, a BMI between 25.0 and 29.9 as pre-obese, and a BMI above 30 as obese (Table 1).

Table 1: The WHO classification of body mass index (BMI) for adults (6).

\begin{tabular}{lll}
\hline BMI $\left(\mathrm{kg} / \mathrm{m}^{2}\right)$ & Classification & Associated health risks \\
\hline$<18.5$ & Underweight & Low (but risks of other clinical problems increased) \\
$18.5-24.9$ & Normal weight & Average \\
$\geq 25.0$ & Overweight & \\
$25.0-29.9$ & Pre-obese & Increased \\
$30.0-34.9$ & Obese class I & Moderately increased \\
$35.0-39.9$ & Obese class II & Severely increased \\
$\geq 40.0$ & Obese class III & Very severely increased \\
\hline
\end{tabular}

Obese individuals and even individuals with mild to moderate overweight have increased risk for health problems (Table 1). Of these, most are associated with a relatively high rate of morbidity and mortality, such as type 2 diabetes, hypertension, coronary heart disease (6-8), and the so-called 'metabolic syndrome' (9).

\section{PREVALENCE OF OBESITY IN ADULTS AND CHILDREN}

Obesity is a fast-growing worldwide epidemic (6) and is recognized as a major public health problem. Secular increases in the prevalence of obesity are widely reported (6) and appear to have more than doubled in the last 2 decades $(9,10)$. There is a wide variation in the prevalence of obesity among and within countries. The prevalence is the highest in Western countries, where it ranges from $10-30 \%$ (11). The prevalence is still the highest in the United States; nearly two thirds of the adult population is now overweight (12), of which about $30 \%$ is obese $(3,10,13,14)$. Also, in the Netherlands the prevalence is slowly increasing; almost $40 \%$ of the adult population is now overweight and $10 \%$ is obese (15). Obesity is usually more frequent in regions with a relative low socio-economic status and is especially evident in some minority groups, as well as in those with lower incomes and less education (3). The prevalence is usually higher in women than in men (16). This may be explained by the fact that the social pressure to thinness seems to be more intense in women than in men, or a more biological reason that energy reserves are more required in women for pregnancy and lactation (16). Finally, obesity increases with age until about 60-70 years of age, after 
which it declines (17). Reasons for this may be selective survival (where the obese have died earlier), cohort-effect (where older people come from cohorts in which obesity was less common) and the simple fact that older people eat less and therefore start to loose weight after the age of 60 years $(17,18)$.

The increase in the prevalence of overweight and obesity may be even more striking among children $(9,14)$. Childhood obesity is associated with several obesity-related health problems, such as cardiovascular disease and type 2 diabetes (19). Moreover, the majority of obese children remains obese as adults (20), where the fattest children have the highest risks of adult obesity (21). Reasons for a family association can be partly explained by genetic factors and partly by shared lifestyles (i.e. diet and patterns of activity). The prevalence of childhood obesity increases in both developed and developing countries (22). Figure 1 shows the prevalence of childhood overweight and obesity worldwide and per different region.

Like in adults, the prevalence of childhood obesity in the United States is the highest; with over $30 \%$ overweight children and about $10 \%$ obese children (23). In the Netherlands, the prevalence is relatively low; about $12 \%$ of the children are overweight and $1 \%$ is obese (24). Comparison of prevalence data on obesity in children is difficult because of the lack of standardization and interpretation of indicators of being overweight or obese in these age groups. BMI in childhood changes substantially with age. Usually, percentile distributions of weight for age, weight for height or BMI for age are used (25). Recently, Cole et al. (2000) developed age and sex specific cut off points for BMI for overweight and obesity in children, using dataset specific centiles linked to adult cut off points (26). These cut off points are nowadays used as the international standards to define overweight and obesity in children (22).

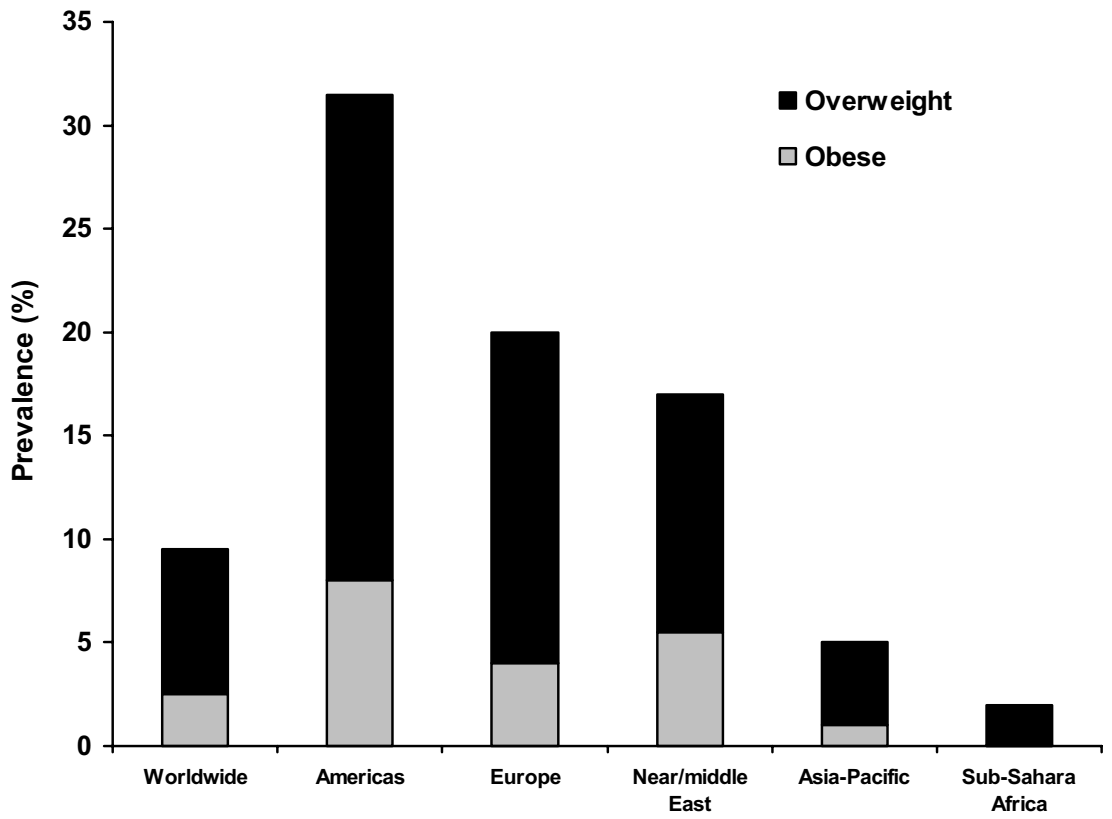

Figure 1: Prevalence of overweight and obesity among school-age children (5-17 years) in global regions. Based on surveys in different years after 1990. Source: IOTF (22). 


\section{OBESITY, WEIGHT LOSS AND THE METABOLIC SYNDROME}

Obesity and overweight are linked with a cluster of metabolic and vascular disorders that have been termed the metabolic syndrome (27). There is no common definition of the metabolic syndrome. It encompasses a cluster of disorders, which include visceral obesity, insulin resistance, alterations in glucose and lipid metabolism and increased blood pressure (28-30). Insulin resistance is probably the most frequently associated factor to the components of the syndrome. However, visceral obesity seems to be the main driving factor by means of the increased production of free fatty acids whose activity, in turn, might interfere with the action of insulin. Figure 2 shows the development of the metabolic syndrome, in which an upper body, or masculine, fat distribution plays a central role (29).

A genetic predisposition clearly underlies susceptibility to the metabolic syndrome (31). Together with different environmental factors, such as social economic status and education level, they determine the individual's physical activity level and total energy intake that in turn will influence the total fat storage.

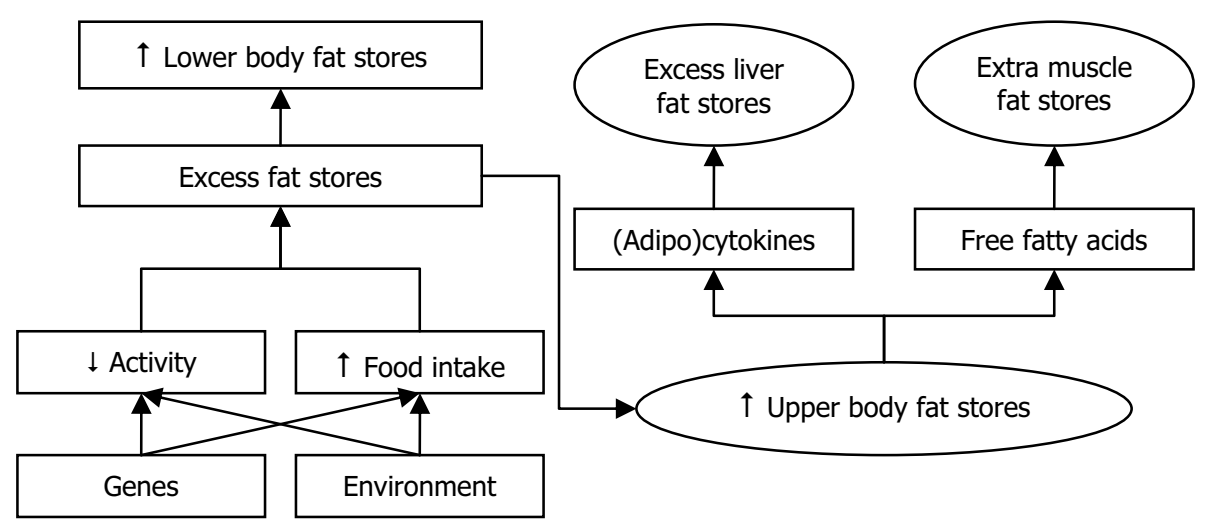

Figure 2: Development of the metabolic syndrome (31).

The extra stored fat increases the size of fat cells and raises the levels of circulating free fatty acids (FFA). Exposure to increased FFA levels by itself can produce insulin resistance, which is one characteristic of the metabolic syndrome. The mechanisms by which FFA's produce insulin resistance are still not clear. (Adipo)cytokines are the second secretory product of the fat cells that may play an important role in some features of the metabolic syndrome. Larger fat cells will secrete increased amounts of interleukine- 6 and other cytokines, which enter the portal circulation and transit to the liver, where they can enhance the production and release of inflammatory markers (31).

Weight gain has been shown to be a strong predictor of the metabolic syndrome (32). Interventions to treat visceral obesity by means of losing weight, which is at best mainly (visceral) fat mass $(33,34)$, seem to be the most effective way to treat the metabolic syndrome (29). Clinical studies suggest that a sustained weight loss of 5 to $10 \%$ can already reduce or eliminate obesity-related health problems $(3,35)$. A weight loss of 
approximately $10 \%$ or less improves for example insulin sensitivity (36), hypertension (37), and cardiovascular risk, the latter predominantly by increasing HDL cholesterol (38).

\section{DETERMINANTS OF WEIGHT LOSS AND WEIGHT MAINTENANCE}

A variety of factors are known to have an influence on energy balance. Different physiological, behavioral and genetic determinants affecting weight loss and weight maintenance are discussed below.

\section{Physiology and behavior}

\section{Eating behavior}

Eating behavior, for example how much, why and how people eat, is associated with weight gain, weight loss or weight maintenance. Eating behavior with respect to dieting can be determined using relatively simple questionnaires like the Three Factor Eating Questionnaire (TFEQ) (39) and the Herman-Polivy restrained eating questionnaire (40). The TFEQ is a self-report measure of eating behaviors that are believed to be particularly relevant to the development and maintenance of obesity. The TFEQ has been widely used in obesity treatment and includes three subscales: cognitive dietary restraint (Factor 1), inhibition of dietary restraint and emotional eating (Factor 2) and hunger (Factor 3$)(39,41)$. The factor cognitive dietary restraint is regarded as the best tool available for the psychometric assessment of restrained eating (42). It determines control over food intake to influence body weight and body shape (e.g. "I consciously hold back at meals to keep from gaining weight") (43). It was observed that restrained eaters consumed less energy, took fewer meals, and showed higher preferences for lowcalorie foods than did the complementarily defined unrestrained group (44, 45). Furthermore, it has been shown that an increased dietary restraint score during weight loss is related to successful weight maintenance thereafter (46-50). The factor inhibition of restraint eating (disinhibition) refers to the tendency to lose control over eating when feeling hungry or when exposed to external stimuli (e.g. "Sometimes when I start eating, I just can't seem to stop") and emotional eating refers to the propensity to overeat in relation to negative mood states, for example when feeling lonely, anxious, or depressed (43). The factor hunger measures a person's general subjective feeling of hunger. Chronic dieting behavior and body weight concern can be measured with the Herman-Polivy questionnaire (40). Frequency of dieting, also described as weight cycling or the yo-yo effect, has been put forward as an important predictor for weight regain (48, 51-53). The TFEQ addresses diet concern, while the Herman-Polivy is focused particularly on weight concern. The two questionnaires are not necessarily correlated.

\section{Energy expenditure}

A stable body weight requires energy balance. A positive energy balance can be prevented by increasing energy expenditure, while maintaining energy intake at the usual, lower level. Average daily metabolic rate (ADMR) consists of basal metabolic rate (which is the sleeping metabolic rate plus arousal), diet-induced thermogenesis, and activity-induced energy expenditure. The basal metabolic rate (BMR) is often measured by indirect calorimetry, which is the measurement of heat production by measuring 
oxygen consumption and/or carbohydrate production. BMR is the component of energy expenditure that explains the largest proportion of an individual's total daily energy expenditure. A low BMR therefore may explain why some individuals are more prone to gain weight over time than others $(54,55)$. The BMR declines when people lose weight (56). The decline in BMR after a period of dieting has been shown to be associated with unsuccessful weight maintenance (48). A reduced diet-induced thermogenesis (DIT) has been shown to be a contributor to maintain the obese state (57), but contradictory results have also been reported (58). The most variable component of the daily energy expenditure is the activity induced energy expenditure (AEE). The doubly labeled water method has provided quantitative estimates of $A E E$ in daily life $(5,59)$. A frequently used method to quantify physical activity is by expressing ADMR as a multiple of BMR (ADMR/BMR) (5). This ratio is known as the physical activity level (PAL). An estimation of the physical activity level can be determined using the validated Baecke questionnaire (60), which consists of a work, sports and leisure time index. Another way to assess physical activity very accurately is by measuring body movements with accelerometers (e.g. the tri-axial accelerometer for movement registration, TRACMOR) by measuring accelerations in the antero-posterior, medio-lateral and longitudinal axis of the trunk (61).

\section{Body composition}

During energy balance the body mass may be relatively stable, but the composition of the body is subject to a gradual change. Modification of body composition is influenced by age, partly genetically determined, and environmental factors such as the quality and quantity of food. Determination of body composition is necessary for the assessment of the nutritional status of the body, in many physiological measurements on energy and substrate metabolism and for monitoring the effect of treatment or interventions (62). The general model used is the two-compartment model, which assumes that the body consists of fat mass and fat free mass. Frequently used techniques to measure this are the underwater weighing technique and isotope dilution techniques.

On a diet, people lose weight, which is usually composed about $25-30 \%$ of fat free mass and $70-75 \%$ of fat mass (63). During weight loss the body composition may change continuously into a leaner composition (64), in which the body loses mainly fat mass and consequently spares its fat free mass. Yet, this is not always the case $(65,66)$.

\section{Leptin and body fat}

The adipocyte-derived hormone leptin is a critical mediator of energy balance that interacts with specific receptors in the brain $(12,67)$. The hormone functions as the afferent signal in a negative feedback loop regulating energy expenditure and energy intake (68). Serum leptin concentration is highly correlated with BMI, percentage body fat and fat mass and decreases in both humans and animals after weight loss (68-71). Soon after its discovery, leptin appeared to be the long-sought hormone with great prospects clarifying the obesity problem. The increasing leptin concentrations with increasing adiposity would generate a signal to the brain that excess energy is stored as fat. This in turn would allow the brain to implement appropriate adaptations such as an increase in energy expenditure and a reduction in appetite (72) in order to limit further weight gain. Reduced fat stores would then lead to a decrease in leptin concentration, which the brain would perceive as a signal of starvation and subsequently a trigger to increase weight (72). However, resistance in both animal and human studies to the proposed anti-obesity action of leptin is observed. To illustrate, obese subjects generally 
have high leptin concentrations $(69,71)$. This suggests that in most cases human obesity is likely to be associated with insensitivity to leptin $(68,73)$, comparably to insulin resistance in type 2 diabetes. In addition, it has recently been suggested that lower leptin concentrations exist in reduced-obese subjects as compared to control subjects and may therefore be a factor in the propensity to regain weight (74). Leptin drops with weight loss, and the initial drop may be greater than the drop in fat mass (75). The important question for weight loss maintenance may be whether the relationship between circulating leptin concentrations and fat mass is altered significantly from baseline after weight loss and weight stabilization (76).

To summarize, leptin is currently considered to have a broader physiological role, where both the intrinsic sensitivity to leptin and its rate of production vary and both appear to contribute to differences in body weight (68). However, the precise mechanism remains unclear.

\section{Genetic determinants}

Energy balance components are affected by genetic and environmental factors $(77,78)$. The genetic profile of most populations is quite stable and has not changed dramatically over recent decades (i.e. the period during which the obesity epidemic has merged). This same period of time is characterized by important environmental changes influencing diet and activity behaviors (4). The apparent dominance of environmental factors to explain the obesity epidemic does not imply that genetic differences are not playing a role in the proneness towards obesity. Indeed, different studies suggested the existence of significant gene-environment interaction effects $(77,79)$. Despite the likely validity of the gene-environment interaction concept, it has been difficult to identify genes and sequence variants involved, and determine the mechanisms by which these exert their influence (1). The literature suggests a role of many different genes in the etiology of obesity (80). In this thesis we focused on three strong candidate polymorphisms: the glucocorticoid receptor (GRL), the peroxisome proliferated-activated receptor $\gamma 2$ (PPAR $\gamma 2$ ), and the ciliary neurotrophic factor (CNTF). The GRL gene has an important role in the (hormone regulated) metabolism of adipose tissue and in the regulation of abdominal fat distribution. PPAR $\gamma 2$ is mainly expressed in adipose tissue, where it modulates the expression of target genes involved in adipocyte differentiation. CNTF exerts its multiple effects through a receptor complex whose sequence, localization and mode of signal transduction share remarkable similarities with the receptor for leptin (81-85). Variation in the abovementioned genes may therefore be related to fat mass regulation and storage. However, in most cases, genes involved in weight gain do not directly cause obesity but they increase the susceptibility to fat gain in individuals exposed to a specific environment (78).

\section{CHILDHOOD OBESITY}

Like in adults, overweight in children is a very rapidly growing health problem $(6,86)$. The prevalence of childhood obesity is dramatically higher in economically developed regions, but is rising significantly in most parts of the world (22). Next to the earlier described determinants associated with overweight in adults, literature provides some parameters related predominantly with overweight in children. Parental obesity might be 
the most important risk factor for children to become obese (78). It is likely that the family association is due partly to genetic factors and partly to shared lifestyles (i.e. diets and patterns of activity). Early experiences with food, feeding practices and family food choices affect children's nutritional habits $(78,87)$. Parental obesity may influence tracking of obesity, which is much stronger if both parents are obese (88). Tracking is defined as the maintenance of a relative position in the population over time and has important implications in terms of disease causality determination as well as for the prevention of future-related morbidity and mortality $(89,90)$. BMI tracking during childhood and from childhood into adulthood have been frequently reported $(88,89,91$ 93) and all confirm a moderate to strong positive significant correlation. Other factors related with childhood obesity are for example smoking in pregnancy, no or only very short breast-feeding, a very high or very low birth weight, early large catch-up growth and no or low physical activity (94-97). For the latter, it is important to find out whether the children move less because they are overweight, or the opposite, that they become overweight because they move less. In other words, is inactivity the cause or the consequence of being overweight? The same holds true for eating behavior.

\section{OUTLINE OF THE THESIS}

According to the first law of thermodynamics, obesity is necessarily the consequence of a long-term imbalance between energy intake and energy expenditure (4). Various aspects influence the individual level of energy intake and energy expenditure. The studies described in this thesis encompass different physiological, behavioral and genetic determinants associated with the etiology, prevention and treatment of obesity in both adults and children.

From a large cohort of Dutch Caucasian children born between 1990 and 1993 valuable anthropometrical data from birth till seven years of age were available as well as information about breastfeeding. To evaluate the development of obesity and related parameters, a follow-up study was performed in 2004, when the children had the mean age of 12 years. $15 \%$ of the children were classified as overweight and $85 \%$ as lean. Chapter 2 presents different physiological and behavioral predictors of overweight in this Dutch children cohort. In addition, daily physical activities were measured with the validated Beacke questionnaire as well as with validated tri-axial accelerometers (Tracmor-4). The overweight children and a matched group of lean controls wore the Tracmor-4 for one week in the daily living environment. Besides, a sports afternoon was organized where the children performed exactly the same activities according to a structured protocol. The results of this study are described in chapter 3.

The MWMS (Maastricht Weight Maintenance Study) is an ongoing longitudinal study of healthy men and women living in the south of the Netherlands. The subjects followed a Very Low Calorie Diet (VLCD) in order to lose weight. After a follow-up of at least 2 years 91 subjects were re-measured. Chapter 4 shows the possible physiological and behavioral determinants predisposing to long-term weight maintenance (2-8 years) after a period of weight loss in the MWMS.

To investigate the effect of subject specific strategies for weight maintenance, 120 overweight subjects followed a VLCD for six weeks in a free-living situation. During the 1-year weight maintenance period that follows, subjects received guidelines (dietary, activity or placebo), according to their capability measured during weight loss and their preference for particular guidelines. In Chapter 5 the effect of these subjects specific 
guidelines are discussed. Also, valuable physiological and behavioral determinants for successful weight maintenance after one year are presented. To find predictors for longterm weight maintenance, the same subjects were measured again after two years follow-up. Chapter 6 illustrates the outcome of this two years follow-up and additionally compares them with the 1-year results. The role of three relevant genetic polymorphisms related to obesity is presented in chapter 7 . These results are subsequently linked with the physiological and behavioral findings described in the previous chapters. Finally, chapter 8 provides a general discussion that deals with the effects of different physiological, behavioral and genetic determinants associated with overweight in both adults and children, and addresses future directions for research within this field. 


\section{REFERENCES}

1. Tremblay A, Bouchard L, Bouchard C, Despres JP, Drapeau V, Perusse L. Long-term adiposity changes are related to a glucocorticoid receptor polymorphism in young females. J Clin Endocrinol Metab 2003;88:3141-5.

2. Hill JO, Wyatt HR, Melanson EL. Genetic and environmental contributions to obesity. Med Clin North Am 2000;84:333-46.

3. Pi-Sunyer FX, Becker DM, Bouchard C, et al. Clinical Guidelines on the Identification, Evaluation, and Treatment of Overweight and Obesity in Adults--The Evidence Report. National Institutes of Health. Obes Res 1998;6 Suppl 2:51S-209S.

4. Tremblay A, Perusse L, Bouchard C. Energy balance and body-weight stability: impact of gene-environment interactions. Br J Nutr 2004;92 Suppl 1:S63-6.

5. Westerterp-Plantenga MS, Steffens A, Tremblay A. Regulation of food intake and energy expenditure. Milano: EDRA, 1999.

6. WHO. Obesity: preventing and managing the global epidemic. Report of a WHO consultation. World Health Organ Tech Rep Ser 2000;894:i-xii, 1-253.

7. Burton BT, Foster WR. Health implications of obesity: an NIH Consensus Development Conference. J Am Diet Assoc 1985;85:1117-21.

8. Pi-Sunyer FX, Becker DM, Bouchard C, al. e. NHLBI Obesity education initiative expert panel on the identification, evaluation, and treatment of overweight and obesity in adults. Obes Res 1998;6:51S-209S.

9. Proietto J, Baur LA. 10: Management of obesity. Med J Aust 2004;180:474-80.

10. Gregg EW, Cheng YJ, Cadwell BL, et al. Secular Trends in Cardiovascular Disease Risk Factors According to Body Mass Index in U.S. Adults. Obstet Gynecol Surv 2005;60:660661.

11. James PT. Obesity: the worldwide epidemic. Clin Dermatol 2004;22:276-80.

12. Wisse BE. The inflammatory syndrome: the role of adipose tissue cytokines in metabolic disorders linked to obesity. J Am Soc Nephrol 2004;15:2792-800.

13. Flegal KM, Carroll MD, Ogden CL, Johnson CL. Prevalence and trends in obesity among US adults, 1999-2000. Jama 2002;288:1723-7.

14. Hill JO, Thompson $\mathrm{H}$, Wyatt $\mathrm{H}$. Weight maintenance: what's missing? J Am Diet Assoc 2005;105:S63-6.

15. Visscher TL, Kromhout D, Seidell JC. Long-term and recent time trends in the prevalence of obesity among Dutch men and women. Int J Obes Relat Metab Disord 2002;26:121824.

16. Seidell JC. Prevalence and time trends of obesity in Europe. J Endocrinol Invest 2002;25:816-22.

17. Seidell JC, Visscher TL. Body weight and weight change and their health implications for the elderly. Eur J Clin Nutr 2000;54 Suppl 3:S33-9.

18. Shock NW. The role of nutrition in aging. J Am Coll Nutr 1982;1:3-9.

19. Berenson GS, Srinivasan SR, Bao W, Newman WP, 3rd, Tracy RE, Wattigney WA. Association between multiple cardiovascular risk factors and atherosclerosis in children and young adults. The Bogalusa Heart Study. N Engl J Med 1998;338:1650-6.

20. Ogden $\mathrm{CL}$, Carroll MD, Flegal KM. Epidemiologic trends in overweight and obesity. Endocrinol Metab Clin North Am 2003;32:741-60, vii.

21. Power C, Lake JK, Cole TJ. Body mass index and height from childhood to adulthood in the 1958 British born cohort. Am J Clin Nutr 1997;66:1094-101.

22. Lobstein T, Baur L, Uauy R. Obesity in children and young people: a crisis in public health. Obes Rev 2004;5 Suppl 1:4-104. 
23. Hedley $A A$, Ogden $C L$, Johnson $C L$, Carroll $M D$, Curtin LR, Flegal KM. Prevalence of overweight and obesity among US children, adolescents, and adults, 1999-2002. Jama 2004;291:2847-50.

24. Hirasing RA, Fredriks AM, van Buuren S, Verloove-Vanhorick SP, Wit JM. [Increased prevalence of overweight and obesity in Dutch children, and the detection of overweight and obesity using international criteria and new reference diagrams]. Ned Tijdschr Geneeskd 2001;145:1303-8.

25. Seidell JC. Obesity: a growing problem. Acta Paediatr Suppl 1999;88:46-50.

26. Cole TJ, Bellizzi MC, Flegal KM, Dietz WH. Establishing a standard definition for child overweight and obesity worldwide: international survey. Bmj 2000;320:1240-3.

27. Shaw DI, Hall WL, Williams CM. Metabolic syndrome: what is it and what are the implications? Proc Nutr Soc 2005;64:349-57.

28. Bjorntorp P. Metabolic abnormalities in visceral obesity. Ann Med 1992;24:3-5.

29. Bosello O, Zamboni M. Visceral obesity and metabolic syndrome. Obes Rev 2000;1:47-56.

30. Kissebah AH, Vydelingum N, Murray R, et al. Relation of body fat distribution to metabolic complications of obesity. J Clin Endocrinol Metab 1982;54:254-60.

31. Bray GA, Champagne CM. Obesity and the Metabolic Syndrome: implications for dietetics practitioners. J Am Diet Assoc 2004;104:86-9.

32. Everson $\mathrm{SA}$, Goldberg $\mathrm{DE}$, Helmrich $\mathrm{SP}$, et al. Weight gain and the risk of developing insulin resistance syndrome. Diabetes Care 1998;21:1637-43.

33. Allison DB, Weber MT. Treatment and prevention of obesity: what works, what doesn't work, and what might work. Lipids 2003;38:147-55.

34. Webster JD, Hesp R, Garrow JS. The composition of excess weight in obese women estimated by body density, total body water and total body potassium. Hum Nutr Clin Nutr 1984;38:299-306.

35. Goldstein DJ. Beneficial health effects of modest weight loss. Int J Obes Relat Metab Disord 1992;16:397-415.

36. Giovannini C, Ciucci E, Clementi R, Cugini P, Facchinetti F, Negri M. Beta-endorphin, insulin, ACTH and cortisol plasma levels during oral glucose tolerance test in obesity after weight loss. Horm Metab Res 1990;22:96-100.

37. Tuck ML, Sowers J, Dornfeld L, Kledzik G, Maxwell M. The effect of weight reduction on blood pressure, plasma renin activity, and plasma aldosterone levels in obese patients. $\mathrm{N}$ Engl J Med 1981;304:930-3.

38. Sopko G, Leon AS, Jacobs DR, Jr., et al. The effects of exercise and weight loss on plasma lipids in young obese men. Metabolism 1985;34:227-36.

39. Stunkard AJ, Messick S. The three-factor eating questionnaire to measure dietary restraint, disinhibition and hunger. J Psychosom Res 1985;29:71-83.

40. Herman CP, Polivy J. Restrained eating. Philadelphia: Saunders, W.B., 1980.

41. Westerterp-Plantenga MS, Rolland V, Wilson SA, Westerterp KR. Satiety related to $24 \mathrm{~h}$ diet-induced thermogenesis during high protein/carbohydrate vs high fat diets measured in a respiration chamber. Eur J Clin Nutr 1999;53:495-502.

42. Laessle RG, Tuschl RJ, Kotthaus BC, Pirke KM. A comparison of the validity of three scales for the assessment of dietary restraint. J Abnorm Psychol 1989;98:504-7.

43. Neale BM, Mazzeo SE, Bulik CM. A twin study of dietary restraint, disinhibition and hunger: an examination of the eating inventory (three factor eating questionnaire). Twin Res 2003;6:471-8.

44. Laessle RG, Tuschl RJ, Kotthaus BC, Pirke KM. Behavioral and biological correlates of dietary restraint in normal life. Appetite 1989;12:83-94.

45. Tuschl RJ, Platte P, Laessle RG, Stichler W, Pirke KM. Energy expenditure and everyday eating behavior in healthy young women. Am J Clin Nutr 1990;52:81-6. 
46. Fogelholm M, Kukkonen-Harjula K, Oja P. Eating control and physical activity as determinants of short-term weight maintenance after a very-low-calorie diet among obese women. Int J Obes Relat Metab Disord 1999;23:203-10.

47. Lejeune MP, Van Aggel-Leijssen DP, Van Baak MA, Westerterp-Plantenga MS. Effects of dietary restraint vs exercise during weight maintenance in obese men. Eur J Clin Nutr 2003; 57:1338-44.

48. Pasman WJ, Saris WH, Westerterp-Plantenga MS. Predictors of weight maintenance. Obes Res 1999;7:43-50.

49. Pekkarinen T, Takala I, Mustajoki P. Two year maintenance of weight loss after a VLCD and behavioural therapy for obesity: correlation to the scores of questionnaires measuring eating behaviour. Int J Obes Relat Metab Disord 1996;20:332-7.

50. Westerterp-Plantenga MS, Kempen KP, Saris WH. Determinants of weight maintenance in women after diet-induced weight reduction. Int J Obes Relat Metab Disord 1998;22:1-6.

51. Haus G, Hoerr SL, Mavis B, Robison J. Key modifiable factors in weight maintenance: fat intake, exercise, and weight cycling. J Am Diet Assoc 1994;94:409-13.

52. Kajioka T, Tsuzuku S, Shimokata H, Sato Y. Effects of intentional weight cycling on nonobese young women. Metabolism 2002;51:149-54.

53. McGuire MT, Wing RR, Klem ML, Lang W, Hill JO. What predicts weight regain in a group of successful weight losers? J Consult Clin Psychol 1999;67:177-85.

54. Buscemi S, Verga S, Caimi G, Cerasola G. Low relative resting metabolic rate and body weight gain in adult Caucasian Italians. Int J Obes Relat Metab Disord 2005;29:287-91.

55. Ravussin E, Lillioja S, Knowler WC, et al. Reduced rate of energy expenditure as a risk factor for body-weight gain. N Engl J Med 1988;318:467-72.

56. Astrup A, Gotzsche PC, van de Werken K, et al. Meta-analysis of resting metabolic rate in formerly obese subjects. Am J Clin Nutr 1999;69:1117-22.

57. Golay A. Blunted glucose-induced thermogenesis: a factor contributing to relapse of obesity. Int J Obes Relat Metab Disord 1993;17 Suppl 1:S23-7.

58. Weinsier RL, Nelson KM, Hensrud DD, Darnell BE, Hunter GR, Schutz Y. Metabolic predictors of obesity. Contribution of resting energy expenditure, thermic effect of food, and fuel utilization to four-year weight gain of post-obese and never-obese women. J Clin Invest 1995;95:980-5.

59. Westerterp KR, Plasqui G. Physical activity and human energy expenditure. Curr Opin Clin Nutr Metab Care 2004;7:607-13.

60. Philippaerts RM, Westerterp KR, Lefevre J. Doubly labelled water validation of three physical activity questionnaires. Int J Sports Med 1999;20:284-9.

61. Plasqui $G$, Joosen $A M$, Kester $A D$, Goris $A H$, Westerterp KR. Measuring free-living energy expenditure and physical activity with triaxial accelerometry. Obes Res 2005;13:1363-9.

62. Westerterp-Plantenga MS, Steffens A, Tremblay A. Regulation of food intake and energy expenditure. Milano: EDRA, 1999.

63. Garrow JS, Summerbell CD. Meta-analysis: effect of exercise, with or without dieting, on the body composition of overweight subjects. Eur J Clin Nutr 1995;49:1-10.

64. Dulloo AG, Jacquet J. The control of partitioning between protein and fat during human starvation: its internal determinants and biological significance. $\mathrm{Br}$ J Nutr 1999;82:339-56.

65. van der Kooy K, Leenen R, Seidell JC, Deurenberg P, Hautvast JG. Effect of a weight cycle on visceral fat accumulation. Am J Clin Nutr 1993;58:853-7.

66. Wadden TA, Foster GD, Stunkard AJ, Conill AM. Effects of weight cycling on the resting energy expenditure and body composition of obese women. Int J Eat Disord 1996;19:512.

67. van Aggel-Leijssen DP, van Baak MA, Tenenbaum R, Campfield LA, Saris WH. Regulation of average 24h human plasma leptin level; the influence of exercise and physiological changes in energy balance. Int J Obes Relat Metab Disord 1999;23:151-8. 
68. Friedman JM. The function of leptin in nutrition, weight, and physiology. Nutr Rev 2002;60:S1-14; discussion S68-84, 85-7.

69. Considine RV, Sinha MK, Heiman ML, et al. Serum immunoreactive-leptin concentrations in normal-weight and obese humans. N Engl J Med 1996;334:292-5.

70. Frederich RC, Hamann A, Anderson S, Lollmann B, Lowell BB, Flier JS. Leptin levels reflect body lipid content in mice: evidence for diet-induced resistance to leptin action. Nat Med 1995;1:1311-4.

71. Maffei M, Halaas J, Ravussin E, et al. Leptin levels in human and rodent: measurement of plasma leptin and ob RNA in obese and weight-reduced subjects. Nat Med 1995;1:115561.

72. Havel PJ. Role of adipose tissue in body-weight regulation: mechanisms regulating leptin production and energy balance. Proc Nutr Soc 2000;59:359-71.

73. Caro JF, Sinha MK, Kolaczynski JW, Zhang PL, Considine RV. Leptin: the tale of an obesity gene. Diabetes 1996;45:1455-62.

74. Filozof $\mathrm{CM}$, Murua $\mathrm{C}$, Sanchez MP, et al. Low plasma leptin concentration and low rates of fat oxidation in weight-stable post-obese subjects. Obes Res 2000;8:205-10.

75. Rosenbaum M, Nicolson M, Hirsch J, Murphy E, Chu F, Leibel RL. Effects of weight change on plasma leptin concentrations and energy expenditure. J Clin Endocrinol Metab 1997;82:3647-54.

76. Wing RR, Hill JO. Successful weight loss maintenance. Annu Rev Nutr 2001;21:323-41.

77. Bouchard C, Tremblay A, Despres JP, et al. The response to long-term overfeeding in identical twins. N Engl J Med 1990;322:1477-82.

78. Maffeis C. Aetiology of overweight and obesity in children and adolescents. Eur J Pediatr 2000;159 Suppl 1:S35-44.

79. Poehlman ET, Despres JP, Marcotte M, Tremblay A, Theriault G, Bouchard C. Genotype dependency of adaptation in adipose tissue metabolism after short-term overfeeding. Am J Physiol 1986;250:E480-5.

80. Perusse L, Rankinen T, Zuberi A, et al. The human obesity gene map: the 2004 update. Obes Res 2005;13:381-490.

81. Buemann B, Vohl MC, Chagnon M, et al. Abdominal visceral fat is associated with a BclI restriction fragment length polymorphism at the glucocorticoid receptor gene locus. Obes Res 1997;5:186-92.

82. Nicklas BJ, van Rossum EF, Berman DM, Ryan AS, Dennis KE, Shuldiner AR. Genetic variation in the peroxisome proliferator-activated receptor-gamma2 gene (Pro12Ala) affects metabolic responses to weight loss and subsequent weight regain. Diabetes 2001;50:2172-6.

83. O'Dell SD, Syddall HE, Sayer AA, et al. Null mutation in human ciliary neurotrophic factor gene confers higher body mass index in males. Eur J Hum Genet 2002;10:749-52.

84. Rosmond $R$, Chagnon $M$, Bouchard C. The Pro12Ala PPARgamma2 gene missense mutation is associated with obesity and insulin resistance in Swedish middle-aged men. Diabetes Metab Res Rev 2003;19:159-63.

85. Rosmond R, Chagnon YC, Holm G, et al. A glucocorticoid receptor gene marker is associated with abdominal obesity, leptin, and dysregulation of the hypothalamicpituitary-adrenal axis. Obes Res 2000;8:211-8.

86. Livingstone B. Epidemiology of childhood obesity in Europe. Eur J Pediatr 2000;159 Suppl $1:$ S14-34.

87. Birch LL, Fisher JO. Mothers' child-feeding practices influence daughters' eating and weight. Am J Clin Nutr 2000;71:1054-61.

88. Wang Y, Ge K, Popkin BM. Tracking of body mass index from childhood to adolescence: a 6-y follow-up study in China. Am J Clin Nutr 2000;72:1018-24. 
20 | Chapter 1

89. Fuentes RM, Notkola IL, Shemeikka S, Tuomilehto J, Nissinen A. Tracking of body mass index during childhood: a 15-year prospective population-based family study in eastern Finland. Int J Obes Relat Metab Disord 2003;27:716-21.

90. Twisk JW, Kemper HC, Mellenbergh GJ. Mathematical and analytical aspects of tracking. Epidemiol Rev 1994;16:165-83.

91. Guo SS, Chumlea WC. Tracking of body mass index in children in relation to overweight in adulthood. Am J Clin Nutr 1999;70:145S-8S.

92. Magarey AM, Daniels LA, Boulton TJ, Cockington RA. Predicting obesity in early adulthood from childhood and parental obesity. Int J Obes Relat Metab Disord 2003;27:505-13.

93. Williams S. Overweight at age 21: the association with body mass index in childhood and adolescence and parents' body mass index. A cohort study of New Zealanders born in 1972-1973. Int J Obes Relat Metab Disord 2001;25:158-63.

94. Curhan GC, Willett WC, Rimm EB, Spiegelman D, Ascherio AL, Stampfer MJ. Birth weight and adult hypertension, diabetes mellitus, and obesity in US men. Circulation 1996;94:3246-50.

95. Ong KK, Ahmed ML, Emmett PM, Preece MA, Dunger DB. Association between postnatal catch-up growth and obesity in childhood: prospective cohort study. Bmj 2000;320:96771.

96. Parsons TJ, Power C, Logan S, Summerbell CD. Childhood predictors of adult obesity: a systematic review. Int J Obes Relat Metab Disord 1999;23 Suppl 8:S1-107.

97. Power C, Parsons T. Nutritional and other influences in childhood as predictors of adult obesity. Proc Nutr Soc 2000;59:267-72. 


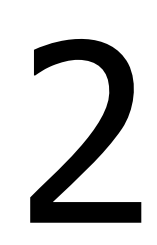

Determinants of overweight in a Dutch children cohort

Neeltje Vogels, Danielle Posthumus, Edwin CM Mariman, Freek Bouwman, Arnold DM Kester, Patrick Rump, Gerard Hornstra and Margriet S WesterterpPlantenga

American Journal of Clinical Nutrition (in press) 


\section{ABSTRACT}

Introduction: To improve effective prevention and treatment of obesity, it is important to focus on body weight (BW) development and its determinants during childhood. The aim of the present study is to investigate the effect of early development, parental and genetic variables on overweight at $12 y$, as well as the effect of behavioral determinants.

Methods: In a Dutch cohort of 105 children, anthropometric measurements were determined from birth until $7 y$. At $12 y$, anthropometric measurements were executed again, as well as body composition, leptin concentration, 3 polymorphisms, the three factor eating questionnaire (TFEQ), and physical activity. In addition, parental BMI and TFEQ scores were determined.

Results: Children's mean BMI at $12 y$ was $19.0 \pm 2.6 \mathrm{~kg} / \mathrm{m}^{2}$ and $15.2 \%$ were classified as overweight. From the first year of life, BMI tracked significantly with BMI-12y ( $r=0.24$, $\mathrm{p}<0.05)$. Linear regression analyses showed that a rapid increase in BW during the first year of life, a high BMI of the father and high dietary restraint scores of the mother were significantly associated with overweight at $12 y(p<0.05)$. No genetic relationship was observed. In addition, overweight was positively associated with dietary restraint (TFEQ) of the child and percent of body fat was negatively associated with the child's activity score $(p<0.05)$.

Conclusion: Even in this homogeneous cohort of normal weight to moderately overweight children, tracking of BMI during childhood took place from the first year of life. Overweight at $12 y$ was predicted by an early rapid increase in BW and parental influences. Overweight during childhood may be maintained or even promoted by a high dietary restraint score and low physical activity. 


\section{INTRODUCTION}

Childhood obesity is emerging as a major health problem $(1,2)$. It is associated with several risk factors for later heart disease and other chronic diseases (3). The majority of obese children remain obese as adults $(4,5)$, which is also referred to as "tracking" of overweight. Tracking is defined as the maintenance of a relative position in the population over time (6). The development of body weight (BW) during childhood may be determined by early development, parental and genetic influences, but also behavioral factors, such as attitude towards eating and physical activity may play an important role. With respect to early development and parental influences, catch-up growth, birth weight, breastfeeding and parental obesity may affect carryover of obesity from childhood into adulthood (4, 5, 7-10). With respect to genetic determinants, three possible polymorphisms may be involved. The nuclear fatty acid receptor, peroxisome proliferator-activated receptor $\gamma($ PPAR $\gamma)$, represents a direct link between adiposity, food response and control of appetite. The glucocorticoid receptor gene (GRL) has an important role in the metabolism of adipose tissue and in the regulation of abdominal fat distribution (11). Both genes have been found to be associated with obesity (12-15). The neurocytokine ciliary neurotrophic factor (CNTF) exerts its multiple effects through a receptor complex that shares remarkable similarities with the receptor for leptin (16), yet no clear associations with obesity have been found $(12,16,17)$.

BW during childhood may also be affected by dietary restrained eating behavior. Overweight may develop as dietary restraint leads overeating, and as a result may cause a further increase in dietary restraint. Parents' restrained eating behavior may also affect this phenomenon. Dietary restraint refers to conscious restriction of food intake to achieve or maintain a preferred BW (18-20) and is reflected in a relatively high score on the cognitive restraint factor of the Three Factor Eating Questionnaire (TFEQ) (18). Birch et al. (2000) found that dietary restraint of mothers, and their perceptions about their daughters' risk of overweight, predicted maternal child feeding practices. This in turn predicted the daughters' eating and relative weight (21). Finally, development of overweight during childhood may be associated with physical activity, inducing reduction in energy expenditure $(22,23)$.

A multiple linear regression model was used to predict the (combined) effect of the different early development, parental and genetic parameters. The behavioral factors were tested in a second model. We hypothesize that a low birth weight, lack of breastfeeding, a high catch-up growth, various parental characteristics and certain genotypes are related with later overweight. Also, behavioral characteristics of the child, e.g. the activity or dietary restraint score, can affect or may be the result of the overweight status. In addition, tracking of BMI during a 12y period in a cohort of Dutch children was investigated, of which a rather small percentage of $15 \%$ were overweight.

\section{SUBJECTS AND METHODS}

\section{Subjects}

Subjects were recruited from a Dutch Caucasian cohort of children born between 1990 and 1993 (24). As infants, these children and their mothers participated in i) a study of essential fatty acids during pregnancy and pregnancy outcome (24), and ii) a study, performed between 1997 and 2000, about the long-term effects of fetal essential fatty acid availability (25). Anthropometric data were available from these children, as well as information about breastfeeding. No interventions were provided. To evaluate the 
development of obesity and related parameters, a follow-up study was performed in 2004. All children who participated in the previous two studies $(n=259)$ received an information letter about a new study on childhood obesity. When no response was obtained, phone-calls were made in an attempt to contact the parents. We were able to contact the parents of 169 children. Of these, 60 refused and 4 retracted their initial consent. In total, 105 children participated $(60 \mathrm{~m} / 45 \mathrm{f})$ (Table 1$)$. The BW and the BMI of the 105 children that participated in the study did not differ from the 154 children that did not participate, at birth, at 1 year and at 7 years of age. Each child and one of his or her parents gave written informed consent to participate in the study, which was approved by the CCMO (Central Committee Human Research in The Hague) and by the Medical Ethical Committee of the Maastricht University Hospital.

Table 1: Neonatal and childhood characteristics of the subjects by status of overweight ${ }^{1}$ at the mean age of 12 years.

\begin{tabular}{|c|c|c|c|c|}
\hline & $\begin{array}{c}\text { Total } \\
(n=105)\end{array}$ & $\begin{array}{c}\text { Lean } \\
(n=89)\end{array}$ & $\begin{array}{c}\text { Overweight } \\
(n=16)\end{array}$ & P-value ${ }^{2}$ \\
\hline \multicolumn{5}{|l|}{ Neonatal } \\
\hline BW $(\mathrm{kg})^{3}$ & $3.4 \pm 0.5$ & $3.4 \pm 0.5$ & $3.3 \pm 0.5$ & 0.479 \\
\hline Height $(\mathrm{cm})$ & $50.2 \pm 2.6$ & $50.2 \pm 2.6$ & $49.9 \pm 2.5$ & 0.631 \\
\hline BMI $\left(\mathrm{kg} / \mathrm{m}^{2}\right)^{3}$ & $13.4 \pm 1.1$ & $13.4 \pm 1.1$ & $13.2 \pm 1.2$ & 0.467 \\
\hline \multicolumn{5}{|l|}{1 year } \\
\hline $\mathrm{BW}(\mathrm{kg})^{3}$ & $9.9 \pm 1.0$ & $9.8 \pm 1.0$ & $10.2 \pm 1.0$ & 0.200 \\
\hline Height $(\mathrm{cm})$ & $76.2 \pm 3.1$ & $76.1 \pm 3.2$ & $76.7 \pm 2.1$ & 0.514 \\
\hline BMI $\left(\mathrm{kg} / \mathrm{m}^{2}\right)^{3}$ & $17.0 \pm 1.4$ & $17.0 \pm 1.4$ & $17.3 \pm 1.5$ & 0.344 \\
\hline $\begin{array}{l}\text { Breast/bottle-feeding } \\
7 \text { year }\end{array}$ & $51 / 49 \%$ & $55 / 45 \%$ & $31 / 69 \%$ & 0.079 \\
\hline $\mathrm{BW}(\mathrm{kg})^{3}$ & $25.3 \pm 3.8$ & $24.6 \pm 3.3$ & $29.2 \pm 4.0$ & 0.001 \\
\hline Height (cm) & $127.4 \pm 5.4$ & $127.1 \pm 5.4$ & $129.1 \pm 4.9$ & 0.184 \\
\hline BMI $\left(\mathrm{kg} / \mathrm{m}^{2}\right)^{3}$ & $15.5 \pm 1.6$ & $15.2 \pm 1.2$ & $17.5 \pm 1.8$ & 0.001 \\
\hline \multicolumn{5}{|l|}{12 year } \\
\hline Age (y) & $12.4 \pm 1.2$ & $12.4 \pm 1.2$ & $12.2 \pm 1.2$ & 0.431 \\
\hline BW $(\mathrm{kg})^{3}$ & $48.1 \pm 10.3$ & $45.8 \pm 8.6$ & $61.3 \pm 9.0$ & 0.001 \\
\hline Height (cm) & $158.6 \pm 10.0$ & $158.3 \pm 10.2$ & $160.2 \pm 9.3$ & 0.485 \\
\hline BMI $\left(\mathrm{kg} / \mathrm{m}^{2}\right)^{3}$ & $19.0 \pm 2.6$ & $18.1 \pm 1.7$ & $23.8 \pm 1.6$ & 0.001 \\
\hline Waist (cm) & $66.3 \pm 6.3$ & $64.6 \pm 4.8$ & $76.1 \pm 4.2$ & 0.001 \\
\hline Body fat (\%) & $19.8 \pm 7.6$ & $17.9 \pm 6.2$ & $30.6 \pm 5.3$ & 0.001 \\
\hline Fat mass $(\mathrm{kg})$ & $9.8 \pm 5.0$ & $8.3 \pm 3.5$ & $18.5 \pm 3.1$ & 0.001 \\
\hline Fat free mass $(\mathrm{kg})$ & $38.0 \pm 7.5$ & $37.2 \pm 7.1$ & $42.7 \pm 8.7$ & 0.008 \\
\hline $\operatorname{Leptin}^{4}(\mu \mathrm{g} / \mathrm{L})$ & $7.6 \pm 6.6$ & $5.7 \pm 3.9$ & $17.7 \pm 8.7$ & 0.001 \\
\hline PPAR $\gamma 2^{3,4}$ (PP/PA/AA) & $76 / 23 / 1 \%$ & $77 / 22 / 1 \%$ & $75 / 25 / 0 \%$ & 0.886 \\
\hline $\mathrm{GRL}^{3,4}(\mathrm{CC} / \mathrm{CG} / \mathrm{GG})$ & $49 / 37 / 14 \%$ & $47 / 40 / 14 \%$ & $62 / 25 / 13 \%$ & 0.475 \\
\hline $\mathrm{CNTF}^{3,4}(\mathrm{GG} / \mathrm{GA} / \mathrm{AA})$ & $77 / 21 / 2 \%$ & $78 / 20 / 2 \%$ & $75 / 25 / 0 \%$ & 0.753 \\
\hline Factor 1 (TFEQ) ${ }^{3}$ & $5.2 \pm 3.4$ & $4.8 \pm 3.2$ & $7.1 \pm 3.8$ & 0.011 \\
\hline Factor 2 (TFEQ) ${ }^{3}$ & $2.7 \pm 1.3$ & $2.6 \pm 1.3$ & $3.6 \pm 1.3$ & 0.004 \\
\hline Factor 3 (TFEQ) $^{3}$ & $3.1 \pm 2.4$ & $3.0 \pm 2.2$ & $3.9 \pm 3.1$ & 0.146 \\
\hline Physical activity (Baecke) & $8.3 \pm 1.0$ & $8.3 \pm 0.9$ & $7.9 \pm 1.4$ & 0.085 \\
\hline
\end{tabular}

${ }_{1}^{1}$ Overweight as defined by age and sex specific cut off points described by Cole et al. (3)

${ }^{2}$ Differences between lean vs. overweight children (t-test for the continuous variables, and chi-square test for the nominal variables)

${ }^{3}$ BW, body weight; BMI, body mass index; TFEQ, three-factor eating questionnaire; PPAR $\gamma 2$, peroxisome proliferators-activated receptor $\gamma 2$; GRL, glucocorticoid receptor; CNTF, ciliary neurotrophic factor; Factor 1, dietary restraint eating behavior; Factor 2, inhibition of restraint; Factor 3, general feelings of hunger ${ }^{4} n=102$ 


\section{Study design}

Children's BW, height, BMI, body composition, leptin concentration, three relevant polymorphisms, TFEQ scores and physical activity were measured by the end of 2004, when the mean age was 12.4 years (range $11-14$ years). BW, height, BMI and TFEQ scores of both parents were determined at this time. These data and the results from the studies of Rump et al. $(2001,2002)(24,25)$ were used to find predictors of and associations with overweight at the mean age of 12 years.

\section{Measurements}

\section{Anthropometry}

At the mean age of $12 y$, the children's height was measured using a wall-mounted stadiometer (Seca, model 220, Hamburg, Germany) and BW was measured using a digital balance accurate to $0.1 \mathrm{~kg}$ (Sauter D7470, Ebingen, Germany). Measurements were executed in underwear, after an overnight fast and after voiding the bladder. BMI was calculated by BW/height ${ }^{2}\left(\mathrm{~kg} / \mathrm{m}^{2}\right)$. BMI in childhood changes substantially with age. To define normal, overweight and obesity in children, we used the specific cut off points described by Cole et al. (2000) (3). They recently developed age and sex specific cut off points for BMI for overweight and obesity in children, using dataset specific centiles linked to adult cut off points. The waist circumference was measured at the site of the smallest circumference between the rib cage and the ileac crest, with the subjects in standing position.

\section{Body composition}

Body composition was measured using the deuterium dilution technique. ${ }^{2} \mathrm{H}_{2} \mathrm{O}$ dilution was used to measure total body water (TBW). Right before they would go to bed, subjects were asked to collect a urine sample, just before drinking the deuteriumenriched water solution. After ingestion of this solution, no further consumption was allowed and the subjects went to sleep. Ten hours after drinking the water solution, another urine sample was collected. The dilution of the deuterium isotope is a measure of the TBW of the subject. Deuterium was measured in the urine samples with an isotope ratio mass spectrometer (VG-Isogas Aqua Sira, VG Isogas, Middlewich, Cheshire, England). TBW was obtained by dividing the measured deuterium dilution space by 1.04. Fat free mass (FFM) was calculated by dividing TBW by the hydration factor 0.73 (26-28). Fat mass (FM) was determined as BW-FFM.

\section{Leptin}

Serum leptin concentrations were measured with a double-antibody, sandwich-type enzyme-linked immunosorbent assay that used a monoclonal antibody specific for human leptin. The lower limit of detection is $0.5 \mu \mathrm{g} / \mathrm{L}$ and the upper limit is $50 \mu \mathrm{g} / \mathrm{L}$. The intra- and inter assay CVs were $9 \%$ and $12 \%$, respectively. The leptin concentrations of normal-weight subjects range from 2 to $12 \mu \mathrm{g} / \mathrm{L}$.

\section{Early development determinants}

At birth, 0.5y, 1y, 2y, 3y, 4y and 7y of age BW, height and BMI were measured. In addition, duration of breast-feeding and bottle-feeding was determined $(24,25)$ (Table 1). BW increase during the first year of life was calculated by subtracting BW at birth from BW at $1 \mathrm{y}$. 
Table 2: Parental characteristics.

\begin{tabular}{|c|c|c|c|c|c|c|}
\hline & \multicolumn{2}{|c|}{ All children } & \multicolumn{2}{|c|}{ Lean children } & \multicolumn{2}{|c|}{ Overweight children } \\
\hline & Father & Mother & Father & Mother & Father & Mother \\
\hline $\mathrm{BW}(\mathrm{kg})^{1}$ & $84.7 \pm 15.0$ & $68.7 \pm 13.3$ & $83.7 \pm 13.0$ & $67.2 \pm 10.0$ & $89.7 \pm 23.3$ & $70.8 \pm 11.5$ \\
\hline Height (cm) & $179.9 \pm 6.5$ & $166.5 \pm 5.9$ & $180.0 \pm 6.8$ & $166.4 \pm 6.1$ & $179.1 \pm 5.2$ & $167.5 \pm 4.7$ \\
\hline BMI $\left(\mathrm{kg} / \mathrm{m}^{2}\right)^{1}$ & $26.0 \pm 4.2$ & $24.4 \pm 3.8$ & $25.7 \pm 3.4$ & $24.3 \pm 3.7$ & $27.9 \pm 7.0^{2}$ & $25.3 \pm 4.5$ \\
\hline Factor 1 (TFEQ) ${ }^{1}$ & $4.6 \pm 3.2$ & $7.1 \pm 3.9$ & $4.7 \pm 3.1$ & $6.9 \pm 3.7$ & $4.5 \pm 3.6$ & $8.1 \pm 4.7$ \\
\hline Factor 2 (TFEQ) ${ }^{1}$ & $2.8 \pm 1.5$ & $3.4 \pm 2.2$ & $2.7 \pm 1.4$ & $3.2 \pm 2.1$ & $3.0 \pm 1.9$ & $4.7 \pm 2.2^{2}$ \\
\hline Factor 3 (TFEQ) ${ }^{1}$ & $2.6 \pm 2.3$ & $2.6 \pm 2.2$ & $2.6 \pm 2.1$ & $2.7 \pm 2.2$ & $2.5 \pm 3.0$ & $2.5 \pm 2.4$ \\
\hline
\end{tabular}

\section{Parental characteristics}

Both the parents reported actual BW measured at home according to our standard instructions (as described in the anthropometry section). Height was copied from their passports, originally measured using a wall-mounted stadiometer. BMI was calculated by BW/height ${ }^{2}\left(\mathrm{~kg} / \mathrm{m}^{2}\right)$. In addition, attitude towards eating was measured with the TFEQ (Table 2).

\section{Determination of the genotypes}

The genomic DNAs of 119 subjects were isolated from peripheral blood leukocytes using a QIAamp kit (Qiagen, Hilden, Germany).

Peroxisome Proliferator-Activated Receptor $\gamma 2$ (PPAR $\gamma 2$ ) genotyping

A 270 bp fragment of the PPAR 2 gene was generated from genomic DNA by PCR using forward primer 5'-GCCAATTCAAGCCCAGTC-3' and mutagenic reverse primer 5'GATATGTITGCAGACAGTGTATCAGTGAAGGAATCGCTTTCCGG-3' which introduces a BstU-I restriction site only when the $\mathrm{C}->\mathrm{G}$ substitution at nucleotide 34 is present related to the Pro12Ala polymorphism (30). The PCR products were digested with BstU-I at $60^{\circ} \mathrm{C}$ for 60 minutes, electrophoresed on a $2.5 \%$ agarose gel and stained with ethidium bromide. The expected products after digestion with BstU-I are $270 \mathrm{bp}$ for $\mathrm{P} / \mathrm{P}$ homozygotes, 227 and 43 bp for A/A homozygotes and 270, 227 and 43 bp for P/A heterozygotes.

\section{Glucocorticoid receptor (GRL) genotyping}

A 87 bp fragment of the GRL gene was generated from genomic DNA by PCR using forward primer 5'-GCTCACAGGGTTCTTGCCATA-3' and reverse primer 5'TTGCACCATGTTGACACCAAT-3', which includes a C/G polymorphism in intron 2, 646 nucleotides downstream from exon 2 (12). The PCR products were digested with BcII at $50^{\circ} \mathrm{C}$ for 60 minutes, electrophoresed on a $3 \%$ agarose gel and stained with ethidium bromide. The expected products after digestion with BclI are 87 bp for G/G homozygotes, 47 and 40 bp for C/C homozygotes and 87,47 and 40 bp for G/C heterozygotes. 


\section{Ciliary Neurotrophic Factor (CNTF) genotyping}

A 134 bp fragment encompassing the null mutation at position -6 before the second exon of the CNTF gene was generated from genomic DNA by PCR using forward primer 5'-CCAGAGAGATGAGTGAGATTTTGT-3' and reverse primer 5'CAGGTTGATGTTCTTGTTCATGCC-3' (16). The PCR products were digested with HaeIII at $37^{\circ} \mathrm{C}$ for 60 minutes, electrophoresed on a $2.5 \%$ agarose gel and stained with ethidium bromide. The expected products after digestion with HaeIII are 94 and $40 \mathrm{bp}$ for normal homozygotes (G/G), 134 bp for null mutation homozygotes (A/A) and 134, 94 and $40 \mathrm{bp}$ for heterozygotes $(\mathrm{G} / \mathrm{A})$.

\section{Attitude towards eating}

Eating behavior was analyzed using a validated Dutch translation of the TFEQ $(18,32)$, which was translated at some questions into an easier, understandable Dutch language for children. The TFEQ consists of 3 factors measuring a person's attitude towards eating. Dietary restraint (Factor 1 ) reflects the extent to which individuals attempt to cognitively control their food intake (18). Inhibition of restraint (Factor 2 or disinhibition) reflects individual differences in the extent to which release from the cognitive suppression of eating occurs in response to the presence of palatable food or other disinhibiting stimuli, such as emotional distress (18). Factor 3 refers to the subjective feeling of hunger (18).

\section{Physical activity}

Physical activity was estimated with the Baecke Questionnaire. This questionnaire consists of three components: work activity, sports activity and leisure activity (33) and has been validated using doubly labelled water (34). For the children the work index was replaced by a school index with exactly the same questions.

\section{Statistical analysis}

Student t-tests (for the continuous variables) and chi-square tests (for the nominal variables) were executed to determine differences in single variables between groups (i.e. lean vs. overweight). The relation of the dependent variable BMI or percent of body fat (\%BF) at the mean age of $12 y$ was analyzed with correction for possible confounder variables by using stepwise (backward) multiple linear regression analyses (SPSS for WINDOWS, version 11.5; SPSS, Chicago, IL). First, the independent variables that are not changeable by willpower (i.e. age, gender, birth weight, increase in BW during the first year of life, breast-feeding vs. formula-feeding, BMI and TFEQ outcomes of the parents and genetic background of the child) were tested, and secondly, the contribution of the changeable variables (i.e. activity scores and TFEQ outcomes) was determined. To test the significance of the contribution of the changeable variables an F-test was used. Correlations between BMI from birth until the age of 12 years were evaluated as Pearson correlation coefficients. All tests were two-sided and differences were considered significant at $\mathrm{P}<0.05$. Values are expressed as mean \pm standard deviation (s.d.). 


\section{RESULTS}

\section{Anthropometry}

Data on BW, BMI, body composition, and leptin concentrations were collected from 60 boys and 45 girls, of whom, at the mean age of $12 y, 15.2 \%$ were overweight and $0 \%$ were obese. Overweight status was determined using two measures, BMI and \%BF (35). Overweight status measured with BMI, was defined on the basis of age- and sexappropriate international standards (3). All overweight childeren were overweight based on both measures. BMI was strongly positively correlated with \%BF $(r=0.67, p<0.001)$, and also leptin concentrations were strongly correlated with \%BF $(r=0.76, p<0.0001)$ (data not shown), which has been frequently shown before $(36,37)$.

The characteristics of the subjects $(n=105)$, including the differences between children's lean and overweight status at $12 y$, are shown in Table 1 . Student t-test analyses showed that the 16 children who were characterized as overweight at $12 y(3)$, already had significantly higher BWs and BMIs at the age of 7 years than did the 89 lean children. At the mean age of $12 \mathrm{y}$, their BW, BMI, waist circumference, \%BF, kg FM, kg FFM and leptin concentration were significantly higher. Their dietary restraint and inhibition of restraint scores were also significantly higher as compared to the lean children.

The effects of differential early development, parental and genetic parameters, corrected for age and gender, on the children's overweight status at the age of $12 y$, were tested in two linear regression models with BMI and \%BF as the dependent variables. For the simple reason that there were only 16 overweight children in this Dutch cohort, logistic regression analysis with lean vs. overweight as the dependent variable was not appropriate. Since the main limitation of BMI is that it does not distinguish FM from lean mass (38), and since it is the excessive body fat that causes the most health consequences $(35,38)$, we used \%BF as well as BMI as an indicator for the children's overweight status.

Table 3: Multiple linear regression analysis with $\mathrm{BMI}^{1}$ as the dependent variable $(n=105)$.

\begin{tabular}{llccc}
\hline Model & Partial $\beta$ & Std. Error & P-value \\
\hline 1 & (Constant) & 6.416 & 2.853 & \\
& Gender $(\mathrm{m} / \mathrm{f})$ & 1.231 & 0.520 & 0.020 \\
& BMI father $\left(\mathrm{kg} / \mathrm{m}^{2}\right)^{1}$ & 0.133 & 0.058 & 0.025 \\
& Factor 1 mother & & 0.002 \\
& $\Delta$ BW 0-1y $(\mathrm{kg})^{1}$ & 0.200 & 0.062 & 0.003 \\
\hline 2 & (Constant) & 0.920 & 0.300 & \\
& Gender $(\mathrm{m} / \mathrm{f})$ & 9.554 & 2.251 & 0.025 \\
& Factor 1 mother & 1 & 0.489 & 0.003 \\
& $\Delta$ BW 0-1y $(\mathrm{kg})^{1}$ & 0.185 & 0.061 & 0.010 \\
& Factor 1 child & 0.748 & 0.285 & 0.030 \\
& Factor 2 child & 0.165 & 0.075 & 0.055 \\
\hline
\end{tabular}

Model $1, \mathrm{R}^{2}=0.239 ;$ Model 2, $\mathrm{R}^{2}=0.365 ; \mathrm{R}^{2}$ Difference $=0.126$

\footnotetext{
${ }^{1}$ BMI, body mass index; BW, body weight; TFEQ, three factor eating questionnaire; Factor 1, dietary restraint eating behavior; Factor 2, inhibition of restraint; Factor 3, general feelings of hunger.
} 


\section{Early development, parental and genetic parameters}

Model 1 (table 3 and 4) shows the final linear regression model, with BMI or \%BF as the dependent variables and the available possible early development, parental and genetic determinants as initial independent variables. From the model with BMI as the dependent variable (table 3 ), we conclude that there were four variables that together predicted $23.9 \%$ of the variance in BMI at the age of $12 y$, namely gender $(p<0.05)$, BMI of the father $(p<0.05)$, dietary restraint score of the mother $(p<0.01)$, and rapid increase in BW during the first year of life $(p<0.01)$. From the model with \%BF as the dependent variable (table 4$)$ we conclude that gender $(p<0.01)$, BMI of the father $(p<0.01)$, inhibition of restraint score of the mother $(p<0.01)$, general feeling of hunger of the mother $(p<0.05)$ and rapid increase in BW during the first year of life $(p<0.05)$ were the variables that together predicted for $29.7 \%$ the variance in $\% \mathrm{BF}$ at the age of 12. In both models, except for the general feelings of hunger of the mother, all the variables were positively associated with the dependent variable. The female gender was associated with both a higher BMI and \%BF. The difference between the two models is that the three different TFEQ scores of the mother are differently associated with the BMI and with the \%BF of the child. Neither of the two models showed a significant association of childhood overweight with the three genotypes of the PPAR 2 , GRL and CNTF genes.

Table 4: Multiple linear regression analysis with $\% \mathrm{BF}^{1}$ as the dependent variable $(n=105)$.

\begin{tabular}{llccc}
\hline Model & Partial $\beta$ & Std. Error & P-value \\
\hline 1 & (Constant) & -14.185 & 7.871 & \\
& Gender $(\mathrm{m} / \mathrm{f})$ & 5.683 & 1.452 & 0.001 \\
& BMI father $\left(\mathrm{kg} / \mathrm{m}^{2}\right)^{1}$ & 0.427 & 0.161 & 0.009 \\
& Factor 2 mother $^{1}$ & 1.026 & 0.352 & 0.005 \\
& Factor 3 mother & & 0.038 \\
& $\Delta$ BW 0-1y $(\mathrm{kg})^{1}$ & -0.733 & 0.348 & \\
\hline 2 & (Constant) & 2.053 & 0.833 & 0.016 \\
\hline Gender (m/f) & 3.177 & 9.413 & 0.001 \\
& BMI father $\left(\mathrm{kg} / \mathrm{m}^{2}\right)^{1}$ & 5.224 & 1.390 & 0.027 \\
& Factor 2 mother & 0.376 & 0.167 & 0.003 \\
& $\Delta$ BW 0-1y $(\mathrm{kg})^{1}$ & 1.034 & 0.341 & 0.044 \\
& Activity (Baecke score) & 1.641 & 0.801 & 0.005 \\
& Factor 1 child & & 0.021 \\
\hline
\end{tabular}

Model $1, \mathrm{R}^{2}=0.297 ;$ Model $2, \mathrm{R}^{2}=0.394 ; \mathrm{R}^{2}$ Difference $=0.098$

\footnotetext{
$1 \% \mathrm{BF}$, percent of body fat; BMI, body mass index; BW, body weight; TFEQ, three factor eating questionnaire; Factor 1, dietary restraint eating behavior; Factor 2, inhibition of restraint; Factor 3, general feelings of hunger.
}

\section{Behavioral parameters}

It was not clear whether behavior were predictors or effects of the weight status of the child. Model 2 (table 3 and 4) shows the additional contribution of the behavioral parameters (parameters that are changeable by willpower) above that of the different early development, parental and genetic parameters (parameters that are not changeable by willpower), again with BMI or \%BF as the dependent variables. Only the final models are presented. The model with BMI as the dependent variable showed that 
gender $(p<0.05)$, dietary restraint score of the mother $(p<0.01)$, rapid increase in BW during the first year of life $(p<0.05)$, dietary restraint score of the child $(p<0.05)$ and inhibition of restraint score of the child $(p=0.05)$ were the variables that were significantly associated with BMI of the child. These variables explained for $36.5 \%$ the variance in BMI. The increase of $R$ Square is 0.126 , which implicates that when the behavioral parameters were added to the model, there was an increase of the explained variance of $12.6 \%$. The model with $\% \mathrm{BF}$ as the dependent variable (table 4 ) showed that gender $(p<0.01)$, BMI of the father $(p<0.05)$, inhibition of restraint of the mother $(p<0.01)$, rapid increase in BW during the first year of life $(p<0.05)$, physical activity score of the child $(p<0.01)$ and dietary restraint score of the child $(p<0.05)$ were significantly associated with \%BF at the age of $12 \mathrm{y}$, with an explained variance of $39.4 \%$. This $\mathrm{R}$ Square is 0.098 higher than in the first model for $\% \mathrm{BF}$, thus, when the behavioral variables were added to the model, the explained variance increased with $9.8 \%$. All the variables mentioned above were positively correlated, except for the activity score, which was negatively correlated with \%BF. The main difference between the two models is the influence of BMI of the father and the activity score of the child, which both appeared to be only associated with \%BF.

Table 5: Pearson correlation coefficients of the BMI for children from birth till the mean age of $12^{1}$.

\begin{tabular}{lcc}
\hline & Age & $12 y$ \\
\hline Birth & $0.05[99]$ \\
$0.5 y$ & $0.18[87]$ \\
$1 y$ & $0.24[93]^{3}$ \\
$2 y$ & $0.38[92]^{2}$ \\
& $3 y$ & $0.38[86]^{2}$ \\
& $4 y$ & $0.45[89]^{2}$ \\
& $7 y$ & $0.76[105]^{2}$ \\
\hline${ }^{1} n$ in brackets & \\
${ }^{3} p<0.001$ & & \\
$p<0.05$ & &
\end{tabular}

\section{BMI tracking}

BMI at $12 y$ was significantly associated with BMI at $1 y(r=0.24, p<0.05)$, as well as with all further years. The Pearson correlation coefficients for childhood BMI's by age are shown in Table 5 . The table shows for instance that the Pearson correlation coefficient for BMI tracking from 7 to 12 years was 0.76 , which indicates that the BMI at 7 years explains for $58 \%$ the variance in BMI at 12 years of age. In figure 1 the development of the BMI is presented, where the mean BMI's of the lean and overweight children at different time points are shown retrospectively. The division of the children into the lean or overweight group was based on their weight status at the age of $12 \mathrm{y}$, as previously described (3). 


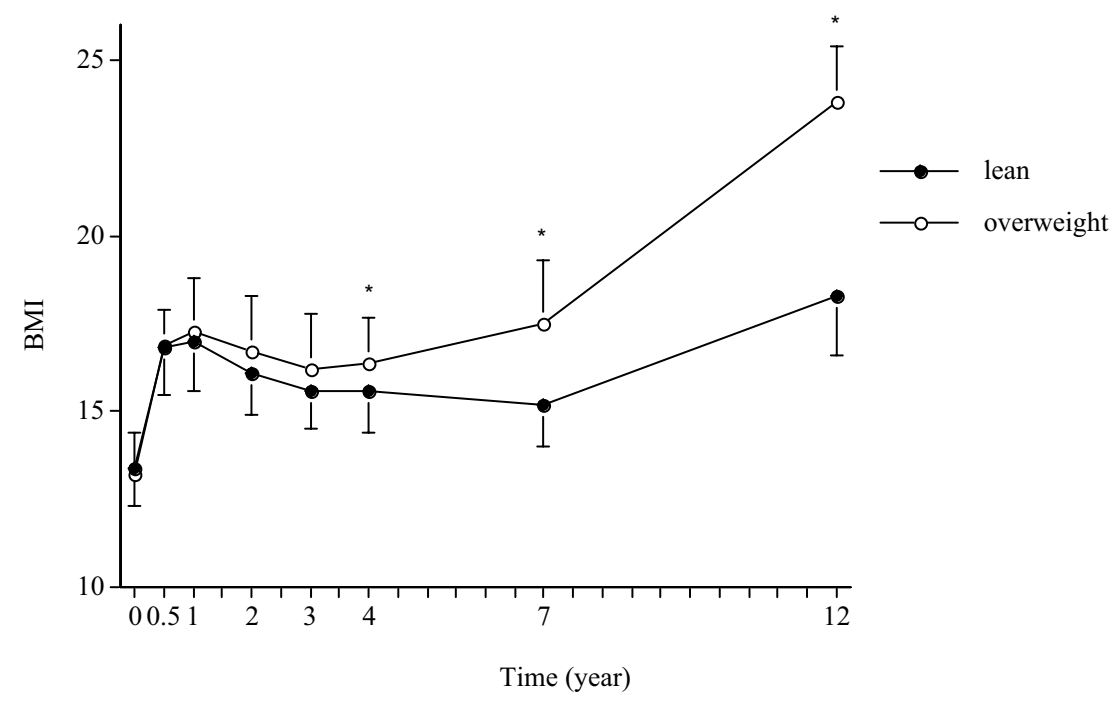

Figure 1: Development of BMI of the lean $(n=89)$ and the overweight $(n=16)$ children (* lean vs. overweight, $p<0.05$, t-test).

\section{DISCUSSION}

The study describes the effects of differential early development, parental and genetic influences as well as behavioral influences on overweight at the mean age of $12 \mathrm{y}$ in a Dutch cohort of children born between 1990 and 1993. In addition, BMI tracking from birth until $12 y$ was assessed.

In this cohort, $15.2 \%$ of the children were overweight (BMI $23.8 \mathrm{~kg} / \mathrm{m}^{2}, \% B F 30.6 \%$ ) and $84.8 \%$ were lean (BMI $18.1 \mathrm{~kg} / \mathrm{m}^{2}, \% B F 17.9 \%$ ). In 2003, the prevalence of childhood obesity in the Netherlands was $12 \%$, which was the lowest in Europe (39). In the US and the United Kingdom, for example, the prevalence is nearly double that figure (40). In the present study, girls had a significantly higher \%BF at $12 y$ than boys. At this age, most girls had already reached puberty and therefore their body composition had changed.

With respect to the early development variables, a rapid increase in BW during the first year of life (from birth until 1y of age) appeared to be a significant predictor of a high $\mathrm{BMI}$ and a high \%BF at $12 \mathrm{y}$. A simple linear regression analysis showed that a rapid increase in BW during the first year of life was not associated with birth weight (data not shown). This indicates that in this cohort of Dutch children, there was no "catch-up growth". Catch-up growth was earlier described by Ong et al. (2000), who found that children that showed catch-up growth between 0 and $2 y$ (i.e. a low birth weight in combination with a rapid increase in BW thereafter) were heavier, taller, and fatter at $5 y$ than the other children (7). From the present study, we conclude that only a rapid increase in BW during the first year of life predicted overweight at the age of $12 y$, independent of whether "catch-up growth" occurred. 
Birth weight was not significantly associated with BMI or \%BF. In the literature, results are conflicting; some studies report a J shaped or $U$ shaped relation, with a higher prevalence of obesity seen for the lowest and highest birth weights, suggesting a more complex association (41). Furthermore, we found no significant association between overweight and breastfeeding. Recently, other researchers reported that breastfeeding for at least 2 months was protective against childhood obesity $(10,42,43)$. A reason why we found no association in this cohort may be a sample size that is too low to pick up the effect, or that there was only a relatively small percentage of overweight in this cohort. Both of these are limitations of the present study, especially the sample size, which is very low in comparison with epidemiological studies.

With respect to parental influences, children of overweight parents are more likely to be overweight themselves $(9,44)$. In this study, BMI of the father was positively correlated with both BMI and \%BF of the child; having an overweight father in this cohort of Dutch children is therefore an important predictor of children becoming overweight. The overall high restraint score of the mothers (data not shown) and the significant correlation between the mother's dietary restraint score and the BMI of the child may be a possible explanation for the that fact that we found no association between BMI of the mother and weight status of the child. Overweight mothers pass on their genetic background to their children. When these mothers are "successfully dietary restraint" $(45,46)$ - when their high restraint scores help them to control there weight successfully - they will have a normal weight despite their heredity. This may hide the possible relationship between BMI of the mother and the weight status of the child. The dietary restraint score of the mother was a significant predictor of the BMI of the child and the disinhibition score of the mother was a significant predictor of the \%BF of the child. Cutting et al. (1999) found that both dietary restraint and inhibition of restraint scores of the mother predicted overweight of the daughter (47). They speculated that mother's dietary restraint and disinhibition may serve as a source of information for daughters regarding what cues should trigger eating and how much to eat (47). There is no doubt that children learn a lot about food and eating from the family environment. Especially mothers, as the primary caretaker, provide children with meals consisting of foods that they prefer or foods they believe are healthy. They also learn the child what and how much to eat (47). These maternal control attempts are influenced partly by mother's own dieting and weight control beliefs and attitudes (21).

No associations with children's overweight and the different genotypes of the PPAR 2 , GRL, and CNTF genes were observed. In adults, we recently found that the GRL gene had a direct influence on weight maintenance after weight loss (12). For the PPAR $\gamma 2$ gene there was an indirect relation (12). Both genes play an important biological role in fat cell differentiation. A possible reason why we did not observe such relations for these particular genotypes in children could be that there was no stimulated experimental situation, like exposure to a diet (and being a successful or unsuccessful dieter). Another possibility is the rather small sample size of the cohort or the small percentage of overweight in this Dutch cohort.

With respect to the child's eating behavior, a high dietary restraint score in children significantly predicted overweight (both BMI and \%BF). Also, inhibition of restraint was positively associated with BMI. This confirms previous observations $(48,49)$. Rather than a preventive method for becoming overweight $(50)$, a high dietary restraint score in children may be interpreted as a consequence of being overweight. Lean children showed no dietary restrained eating behavior. In children, a high score on dietary restraint and inhibition of restraint, and consequently a high focus on diet, may therefore be a risk factor to become even more overweight (48). 
$\% \mathrm{BF}$ was negatively associated with physical activity scored on the Baecke questionnaire. The higher the physical activity score, and thus energy expenditure, the lower the \%BF. The finding of no correlation with BMI may be explained by the fact that BMI does not distinguish FM from lean mass (38), so does not take body composition into account. Moreover, the accumulation of FM may also be a cause to become less active; it is very hard to define a cause or an effect here. A vicious circle may be a better explanation. Future research should combine the use of Baecke questionnaires with triaxial accelerometers to provide more detailed information about physical activity (51).

From the first year of life BMI tracked significantly with BMI at $12 y$. This implies that the BMI at a very young age may already be an important predictor of the BMI in later life, thus stressing the importance of overweight prevention in these young age categories. BMI tracking during childhood and from childhood into adulthood has been reported before $(5,8,52,53)$. The present study confirms BMI tracking, even with the low prevalence of overweight in the Netherlands. This and the fact that we found important associations with childhood overweight in this relatively small cohort is a strength of the present study. Another strength is the accurate measurement method used to determine body composition.

To conclude, the BMI from the first year of life was a predictor of the BMI at $12 y$. Predictors of overweight at $12 y$ were an early rapid increase in BW, a high BMI of the father and restrained eating behavior of the mother. No genetic relationship was observed. Moreover, overweight children appeared to be more diet concerned and they had a lower activity score; factors that may maintain or even promote childhood overweight.

\section{ACKNOWLEDGEMENTS}

We thank our subjects for their thoughtful participation in this study. We gratefully thank Loek Wouters and Wendy Sluijsmans for their assistance and we acknowledge Dr. Kathleen Melanson (University of Rhode Island) for editing the English text. NV carried out the study, collected and analyzed the data, and wrote the largest part of the manuscript. DP and FB (supervised by EM) contributed to the practical work. PR (supervised by $\mathrm{GH}$ ) collected the variables of the children at birth till 7y. AK supervised the statistical analyses. Planning, processing the results and writing the manuscript were done under general supervision by MW. The authors had no conflict of interest. 


\section{REFERENCES}

1. WHO. Obesity: preventing and managing the global epidemic. Report of a WHO consultation. World Health Organ Tech Rep Ser 2000;894:i-xii, 1-253.

2. Livingstone B. Epidemiology of childhood obesity in Europe. Eur J Pediatr 2000;159 Suppl $1:$ S14-34.

3. Cole TJ, Bellizzi MC, Flegal KM, Dietz WH. Establishing a standard definition for child overweight and obesity worldwide: international survey. BMJ 2000;320:1240-3.

4. Mossberg HO. 40-year follow-up of overweight children. Lancet 1989;2:491-3.

5. Magarey AM, Daniels LA, Boulton TJ, Cockington RA. Predicting obesity in early adulthood from childhood and parental obesity. Int J Obes Relat Metab Disord 2003;27:505-13.

6. Twisk JW, Kemper HC, Mellenbergh GJ. Mathematical and analytical aspects of tracking. Epidemiol Rev 1994;16:165-83.

7. Ong KK, Ahmed ML, Emmett PM, Preece MA, Dunger DB. Association between postnatal catch-up growth and obesity in childhood: prospective cohort study. BMJ 2000;320:96771.

8. Wang Y, Ge K, Popkin BM. Tracking of body mass index from childhood to adolescence: a 6-y follow-up study in China. Am J Clin Nutr 2000;72:1018-24.

9. Maffeis C. Aetiology of overweight and obesity in children and adolescents. Eur J Pediatr 2000;159 Suppl 1:S35-44.

10. Arenz S, Ruckerl R, Koletzko B, von Kries R. Breast-feeding and childhood obesity--a systematic review. Int J Obes Relat Metab Disord 2004;28:1247-56.

11. Ukkola O, Rosmond R, Tremblay A, Bouchard C. Glucocorticoid receptor Bcl I variant is associated with an increased atherogenic profile in response to long-term overfeeding. Atherosclerosis 2001;157:221-4.

12. Vogels N, Mariman EC, Bouwman FG, Kester AD, Diepvens K, Westerterp-Plantenga MS. Relation of weight maintenance and dietary restraint to peroxisome proliferator-activated receptor gamma2, glucocorticoid receptor, and ciliary neurotrophic factor polymorphisms. Am J Clin Nutr 2005;82:740-6.

13. Cecil JE, Fischer B, Doney AS, et al. The Pro12Ala and C-681G variants of the PPARG locus are associated with opposing growth phenotypes in young schoolchildren. Diabetologia 2005;48:1496-502.

14. Nicklas BJ, van Rossum EF, Berman DM, Ryan AS, Dennis KE, Shuldiner AR. Genetic variation in the peroxisome proliferator-activated receptor-gamma2 gene (Pro12Ala) affects metabolic responses to weight loss and subsequent weight regain. Diabetes 2001;50:2172-6.

15. Rosmond $R$, Chagnon $M$, Bouchard $C$. The Pro12Ala PPARgamma2 gene missense mutation is associated with obesity and insulin resistance in Swedish middle-aged men. Diabetes Metab Res Rev 2003;19:159-63.

16. Munzberg $\mathrm{H}$, Tafel J, Busing B, et al. Screening for variability in the ciliary neurotrophic factor (CNTF) gene: no evidence for association with human obesity. Exp Clin Endocrinol Diabetes 1998;106:108-12.

17. O'Dell SD, Syddall HE, Sayer AA, et al. Null mutation in human ciliary neurotrophic factor gene confers higher body mass index in males. Eur J Hum Genet 2002;10:749-52.

18. Stunkard AJ, Messick S. The three-factor eating questionnaire to measure dietary restraint, disinhibition and hunger. J Psychosom Res 1985;29:71-83.

19. Lindroos $A K$, Lissner $L$, Mathiassen $M E$, et al. Dietary intake in relation to restrained eating, disinhibition, and hunger in obese and nonobese Swedish women. Obes Res 1997;5:175-82.

20. Bellisle F, Dalix A. Cognitive restraint can be offset by distraction, leading to increased meal intake in women. Am J Clin Nutr 2001;74:197-200. 
21. Birch LL, Fisher JO. Mothers' child-feeding practices influence daughters' eating and weight. Am J Clin Nutr 2000;71:1054-61.

22. Westerterp KR. Obesity and physical activity. Int J Obes Relat Metab Disord 1999;23 Suppl 1:59-64.

23. Ekelund U, Aman J, Yngve A, Renman C, Westerterp K, Sjostrom M. Physical activity but not energy expenditure is reduced in obese adolescents: a case-control study. Am J Clin Nutr 2002;76:935-41.

24. Rump P, Mensink RP, Kester AD, Hornstra G. Essential fatty acid composition of plasma phospholipids and birth weight: a study in term neonates. Am J Clin Nutr 2001;73:797806.

25. Rump P, Popp-Snijders C, Heine RJ, Hornstra G. Components of the insulin resistance syndrome in seven-year-old children: relations with birth weight and the polyunsaturated fatty acid content of umbilical cord plasma phospholipids. Diabetologia 2002;45:349-55.

26. van Marken Lichtenbelt WD, Westerterp KR, Wouters L. Deuterium dilution as a method for determining total body water: effect of test protocol and sampling time. Br J Nutr 1994;72:491-7.

27. Schoeller DA, van Santen E, Peterson DW, Dietz W, Jaspan J, Klein PD. Total body water measurement in humans with 180 and 2H labeled water. Am J Clin Nutr 1980;33:268693.

28. Westerterp KR, Wouters L, van Marken Lichtenbelt WD. The Maastricht protocol for the measurement of body composition and energy expenditure with labeled water. Obes Res 1995;3 Suppl 1:49-57.

29. Yen $\mathrm{CJ}$, Beamer BA, Negri C, et al. Molecular scanning of the human peroxisome proliferator activated receptor gamma (hPPAR gamma) gene in diabetic Caucasians: identification of a Pro12Ala PPAR gamma 2 missense mutation. Biochem Biophys Res Commun 1997;241:270-4.

30. van Rossum EF, Koper JW, van den Beld AW, et al. Identification of the BclI polymorphism in the glucocorticoid receptor gene: association with sensitivity to glucocorticoids in vivo and body mass index. Clin Endocrinol (Oxf) 2003;59:585-92.

31. Takahashi R, Yokoji $\mathrm{H}$, Misawa $\mathrm{H}$, Hayashi M, Hu J, Deguchi T. A null mutation in the human CNTF gene is not causally related to neurological diseases. Nat Genet 1994;7:7984.

32. Westerterp-Plantenga MS, Rolland V, Wilson SA, Westerterp KR. Satiety related to $24 \mathrm{~h}$ diet-induced thermogenesis during high protein/carbohydrate vs high fat diets measured in a respiration chamber. Eur J Clin Nutr 1999;53:495-502.

33. Baecke JA, Burema J, Frijters JE. A short questionnaire for the measurement of habitual physical activity in epidemiological studies. Am J Clin Nutr 1982;36:936-42.

34. Philippaerts RM, Westerterp KR, Lefevre J. Doubly labelled water validation of three physical activity questionnaires. Int J Sports Med 1999;20:284-9.

35. Allison DB, Weber MT. Treatment and prevention of obesity: what works, what doesn't work, and what might work. Lipids 2003;38:147-55.

36. Filozof CM, Murua C, Sanchez MP, et al. Low plasma leptin concentration and low rates of fat oxidation in weight-stable post-obese subjects. Obes Res 2000;8:205-10.

37. Vogels $\mathrm{N}$, Westerterp-Plantenga MS. Categorical strategies based on subject characteristics of dietary restraint and physical activity, for weight maintenance. Int J Obes Relat Metab Disord 2005;29:849-57.

38. Kopelman PG. Obesity as a medical problem. Nature 2000;404:635-43.

39. Lobstein T, Frelut ML. Prevalence of overweight among children in Europe. Obes Rev 2003;4:195-200.

40. Hedley $A A$, Ogden $C L$, Johnson $C L$, Carroll MD, Curtin LR, Flegal KM. Prevalence of overweight and obesity among US children, adolescents, and adults, 1999-2002. JAMA 2004;291:2847-50. 
41. Parsons TJ, Power C, Logan S, Summerbell CD. Childhood predictors of adult obesity: a systematic review. Int J Obes Relat Metab Disord 1999;23 Suppl 8:S1-107.

42. Bergmann $\mathrm{KE}$, Bergmann RL, Von Kries R, et al. Early determinants of childhood overweight and adiposity in a birth cohort study: role of breast-feeding. Int J Obes Relat Metab Disord 2003;27:162-72.

43. von Kries R, Koletzko B, Sauerwald $T$, et al. Breast feeding and obesity: cross sectional study. BMJ 1999;319:147-50.

44. Guillaume M, Lapidus L, Beckers F, Lambert A, Bjorntorp P. Familial trends of obesity through three generations: the Belgian-Luxembourg child study. Int J Obes Relat Metab Disord 1995;19 Suppl 3:S5-9.

45. Westerterp-Plantenga MS, Van den Heuvel E, Wouters L, ten Hoor F. Accuracy of estimates of forthcoming ingestion as a function of menu familiarity and dietary restraint. Appetite 1992;18:101-9.

46. Yeomans MR, Tovey HM, Tinley EM, Haynes CJ. Effects of manipulated palatability on appetite depend on restraint and disinhibition scores from the Three-Factor Eating Questionnaire. Int J Obes Relat Metab Disord 2004;28:144-51.

47. Cutting TM, Fisher JO, Grimm-Thomas K, Birch LL. Like mother, like daughter: familial patterns of overweight are mediated by mothers' dietary disinhibition. Am J Clin Nutr 1999;69:608-13.

48. Shunk JA, Birch LL. Girls at risk for overweight at age 5 are at risk for dietary restraint, disinhibited overeating, weight concerns, and greater weight gain from 5 to 9 years. J Am Diet Assoc 2004;104:1120-6.

49. Edmunds $\mathrm{H}$, Hill AJ. Dieting and the family context of eating in young adolescent children. Int J Eat Disord 1999;25:435-40.

50. Foster GD, Wadden TA, Swain RM, Stunkard AJ, Platte P, Vogt RA. The Eating Inventory in obese women: clinical correlates and relationship to weight loss. Int J Obes Relat Metab Disord 1998;22:778-85.

51. Hoos MB, Gerver WJ, Kester AD, Westerterp KR. Physical activity levels in children and adolescents. Int J Obes Relat Metab Disord 2003;27:605-9.

52. Guo SS, Chumlea WC. Tracking of body mass index in children in relation to overweight in adulthood. Am J Clin Nutr 1999;70:145S-8S.

53. Fuentes RM, Notkola IL, Shemeikka S, Tuomilehto J, Nissinen A. Tracking of body mass index during childhood: a 15-year prospective population-based family study in eastern Finland. Int J Obes Relat Metab Disord 2003;27:716-21. 


\section{Daily physical activity and activity-counts in lean and overweight Dutch children}

Neeltje Vogels, Klaas R Westerterp, Danielle LA Posthumus, Femke Rutters, and Margriet S Westerterp-Plantenga

Submitted for publication 


\section{ABSTRACT}

The objectives of this study were to compare daily physical activities, and activities performed according to a structured protocol, measured with tri-axial accelerometers (Tracmor-4), between lean and overweight children. Fourteen overweight children $(59.8 \pm 9.5 \mathrm{~kg})$ and fifteen lean matched controls $(47.2 \pm 8.7 \mathrm{~kg})$ wore the Tracmor-4 daily, during $24 \mathrm{~h}-2 \mathrm{~h}$-sleeping time, for one week in their home environment. Of these, 24 children participated in a sports afternoon, where they performed activities according to the same structured protocol. In addition, physical activity was estimated using a modified Baecke questionnaire and body composition was determined. Total mean Tracmor counts/day were significantly lower for the overweight children than for the lean children ( $46.1 \pm 6.9$ vs. $54.4 \pm 11.2$ kCounts/day, $\mathrm{p}=0.02$ ), while reported activities (Baecke score) were similar. When performing activities according to the structured protocol, there was no difference in mean Tracmor counts between the two groups $(36.3 \pm 6.9$ vs. $34.7 \pm 6.6$ kCounts, $p=0.6)$. As compared to lean children, overweight children moved less without being aware of it; yet exerted the same movements per activity. 


\section{INTRODUCTION}

The prevalence of childhood obesity is emerging as a major health problem $(1,2)$. It is associated with several risk factors for later heart disease and other chronic diseases (3, 4). Energy expenditure, like energy intake, is an important factor in the development of, or protection against, obesity $(5,6)$. Compared to adolescents (7) or adults, children move relatively much, however, physical activity in this young group seems to decrease over the past several decades (8). Different studies estimating the effect of physical activity in childhood, usually by questionnaire, can be divided between finding no effect, or a protective effect of activity in relation to overweight or obesity (9). One reason for this uncertainty is discrepancy in the accuracy of physical activity measurement techniques used. In recent years, the measurement of physical activity with accelerometers has become more widely used. These instruments provide minute-byminute quantification of body movement over periods of several days or even weeks, enabling patterns of movement or inactivity to be assessed. The Tracmor-4, a tri-axial accelerometer, has been validated against DLW and proven to be a reliable tool for assessment of physical activity (10). To our knowledge there is little direct evidence suggesting a protective effect of physical activity, as measured by accelerometry, against childhood obesity (11-15). In the present study we measured physical activity with a Tracmor-4 and a, for adults, validated questionnaire (Baecke) in a group of lean children and a group of overweight children, in a free-living situation. We hypothesized that overweight children would move less than their lean counterparts. Additionally, we questioned whether there would still be a difference in physical activity when the children performed the activities according to a same structured protocol. Overweight children may for example move less intensively or take more small breaks when performing similar activities. The main research question was "Do overweight children move less compared to a matched group of lean children, even when instructed to perform the activities similarly?"

\section{METHODS}

\section{Study design}

Subjects were recruited from a Dutch Caucasian cohort of children born between 1990 and $1993(16,17)$. As infants, these children and their mothers participated in i) a study of essential fatty acids during pregnancy and pregnancy outcome (16), and ii) a study, performed between 1997 and 2000, about the long-term effects of fetal essential fatty acid availability (17). Anthropometric data were available from these children. No interventions were carried out. To evaluate the development of overweight and related parameters, a follow-up study was performed in 2004 (18). In this whole group of 105 children, 16 children were overweight (4). These 16 overweight children and 16 matched (for age, height and gender) controls from the same cohort were asked to wear a triaxial accelerometer (Tracmor-4) for one week. Two overweight children and one lean child refused. In total, 29 children (14 overweight/15 lean) wore the Tracmor for 7 consecutive days (Table 1). Also, their activity counts were measured during an organized sports afternoon (Table 1$)$, where the children $(n=24)$ performed activities according to exactly the same activity protocol. In addition, measurements of children's reported activity score (Baecke questionnaire) and body composition were executed. 
Each child and one of his or her parents gave written informed consent to participate in the study, which was approved by the CCMO (Central Committee Human Research in The Hague) and by the Medical Ethical Committee of the Maastricht University Hospital.

Table 1: Subject characteristics of 15 lean and 14 overweight children.

\begin{tabular}{|c|c|c|}
\hline & Lean & Overweight \\
\hline Gender $(\mathrm{m} / \mathrm{f})$ & $8 / 7$ & $7 / 7$ \\
\hline Age $(y)$ & $12.1 \pm 1.1$ & $12.0 \pm 1.2$ \\
\hline Height $(\mathrm{cm})$ & $160.7 \pm 10.2$ & $159.5 \pm 9.4$ \\
\hline Body weight $(\mathrm{kg})^{*}$ & $47.2 \pm 8.7$ & $59.8 \pm 9.5$ \\
\hline Waist circumference $(\mathrm{cm})^{*}$ & $64.3 \pm 5.2$ & $75.4 \pm 3.9$ \\
\hline BMI $\left(\mathrm{kg} / \mathrm{m}^{2}\right)^{*}$ & $18.1 \pm 1.5$ & $23.3 \pm 2.1$ \\
\hline Body fat $(\%)^{*}$ & $17.2 \pm 5.4$ & $31.4 \pm 5.1$ \\
\hline Fat mass $(\mathrm{kg})^{*}$ & $8.0 \pm 2.6$ & $18.7 \pm 3.3$ \\
\hline Fat free mass $(\mathrm{kg})$ & $39.2 \pm 8.3$ & $41.5 \pm 8.5$ \\
\hline Physical activity (Baecke total) & $8.4 \pm 0.6$ & $8.1 \pm 1.4$ \\
\hline Baecke school & $2.5 \pm 0.3$ & $2.5 \pm 0.3$ \\
\hline Baecke sports & $3.1 \pm 0.4$ & $2.8 \pm 0.9$ \\
\hline Baecke leisure & $2.8 \pm 0.3$ & $2.8 \pm 0.5$ \\
\hline Physical activity (kCounts/day) ${ }^{*,+}$ & $54.4 \pm 11.2$ & $46.1 \pm 6.9$ \\
\hline Physical activity (kCounts on sports afternoon) (,$\neq^{\prime}$ & $34.7 \pm 6.6$ & $36.3 \pm 6.9$ \\
\hline
\end{tabular}

\title{
Measurements
}

\begin{abstract}
Physical activity
Physical activity can be easily estimated with the Baecke Questionnaire. The Baecke questionnaire consists of three components: work activity, sports activity and leisure activity $(19,20)$ and has been validated using doubly labelled water (21). For the children, the work index was replaced by a school index with similar questions (e.g. "When I am in school, I walk .. never/seldom/sometimes/often/all the time?").

To measure physical activity more accurately, daily movements were assessed with a triaxial accelerometer for movement registration (Tracmor, Philips Research, Eindhoven, The Netherlands). In children, the Tracmor has been validated against doubly labelled water by Hoos et al. $(22,23)$. The Tracmor-4 contains three uni-axial piezo-electric accelerometers, measures $7.2 \times 2.6 \times 0.7 \mathrm{~cm}$, and weighs $22 \mathrm{~g}$ (battery included) (10). It is attached to the lower back by means of an elastic belt, measuring accelerations in the antero-posterior, medio-lateral and longitudinal axis of the trunk. The Tracmor provides minute-by-minute data for all three axes separately. For this study, Tracmor output was defined as activity counts per day (for the sum of all three axes), which is the sum of all counts over 7 days divided by 7. Subjects were instructed to wear the Tracmor for 7 consecutive days, during waking hours, except while showering or swimming. The parents of the children recorded times in a log when the children woke up, when the Tracmor was put on and taken off, and when the children went to bed. According to the protocol, the difference between sleeping time $(9.9 \pm 0.9 \mathrm{~h})$ and hours of wearing the Tracmor (12 $\pm 1.3 \mathrm{~h})$ was two hours per child.
\end{abstract}


A sports afternoon was organized, where 24 children (13 lean and 11 overweight) participated, and again wore the Tracmor. At the gym, they were instructed to perform activities according to a same structured protocol. Activities included walking, running, stretching, street dance, and different ball games. All activities were guided by two sports instructors.

\section{Anthropometry}

The children's height was measured using a wall-mounted stadiometer accurate to 0.1 $\mathrm{cm}$ (Seca, model 220, Hamburg, Germany) and body weight (BW) was measured using a digital balance accurate to $0.1 \mathrm{~kg}$ (Sauter D7470, Ebingen, Germany). Measurements were executed in underwear, after an overnight fast and after voiding. BMI was calculated as BW/height ${ }^{2}\left(\mathrm{~kg} / \mathrm{m}^{2}\right)$. BMI in childhood changes substantially with age. To define normal, overweight and obesity in children, we used the age and sex specific cut off points described by Cole et al. (4). The waist circumference was measured at the site of the smallest circumference between the rib cage and the ileac crest, with the subjects in standing position.

\section{Body composition}

Body composition was measured using the deuterium dilution technique. ${ }^{2} \mathrm{H}_{2} \mathrm{O}$ dilution was used to measure total body water (TBW). Subjects were asked to collect a urine sample in the evening just before drinking the deuterium-enriched water solution. After ingestion of this solution, no further consumption was allowed. Ten hours after drinking the water solution, another urine sample was collected. The dilution of the deuterium isotope is a measure of the TBW of the subject. Deuterium was measured in the urine samples with an isotope ratio mass spectrometer (Optima, VG Isogas, Middlewich, Cheshire, England). TBW was obtained by dividing the measured deuterium dilution space by 1.04 . Fat free mass (FFM) was calculated by dividing TBW by the hydration factor 0.73 (24-26). Fat mass (FM) was determined as BW-FFM.

\section{Data analysis}

Tracmor output was defined as activity counts per day (for the sum of all three axes), which is the sum of all counts over 7 days divided by 7 . This was done individually for wearing hours/day (24h-2h-sleeping time). For the sport afternoon, Tracmor output was defined as total activity counts, which is the sum of all counts registered on that afternoon. First of all, the relationship between the Baecke scores and Tracmor output in children was compared to the validation for adults by Philippaerts et al. (27). Similar to the observed relationship in adults $(0.37(p<0.001))$, we found a correlation of the total mean Tracmor counts and the Baecke sports index of $0.37(p<0.05)$. Daily physical activity in counts per day as well as in Baecke scores were compared between lean and overweight children using an independent $t$-test. An independent $t$-test was also used to compare the Tracmor total counts on the sports afternoon between the lean and overweight children (Statview SE Graphics ${ }^{\mathrm{TM}}$ for Macintosh). All statistical tests were two-sided and differences were considered significant at $P<0.05$. Values are expressed as mean \pm standard deviation (sd). 


\section{RESULTS}

Obviously, overweight children had a significantly higher BW, BMI, waist circumference, $\%$ body fat and fat mass than the lean children. The children showed good compliance with wearing the Tracmor. All of them kept the protocol of wearing the Tracmor from $1 \mathrm{~h}$ after getting up until $1 \mathrm{~h}$ before being in bed again. Mean duration of wearing was $12.1 \pm 1.2$ hours per day in lean children and $11.9 \pm 1.4$ hours per day in overweight children. This did not differ significantly between the lean and overweight children $(p=0.84)$.

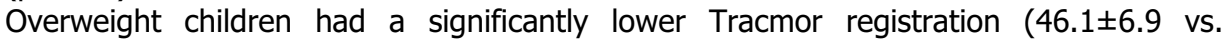
$54.4 \pm 11.2$ kCounts/day, $\mathrm{p}=0.02$ ), while the reported physical activities (score on Baecke questionnaire) were not statistically different (Table 1). During the organized sports afternoon, when all activities were performed according to the same structured protocol, during exactly the same period of time, there was no difference in Tracmor registration between the overweight and the lean children (overweight: $36.3 \pm 6.9$ vs. lean: $34.7 \pm 6.6$ kCounts, $p=0.6)$.

\section{DISCUSSION}

This study clearly shows that overweight children had lower free-living activity counts than lean children. On the other hand, their reported activities were not statistically different. When performing activities according to the same structured protocol, there was also no difference in accelerometer output (kCounts), which shows that the movements of overweight children during specific activities were similar to lean children. When the children were in their typical living environment, where they were free to move as much or as little as they liked, and were free to choose their own types of activities, overweight children moved significantly less than their lean counterparts. This cannot be due to differences in sleeping hours or in hours of wearing the Tracmor, since there were no statistically significant differences in sleeping time or wearing hours.

The present study is limited by its cross-sectional design, so conclusions as to whether an inactive lifestyle causes obesity or whether obesity leads to an inactive lifestyle cannot be drawn. However, it clearly shows differences in physical activity between overweight and lean children. These findings are consistent with other data in children and adolescents (11-15). Furthermore, this study shows that there was no difference in reported physical activity (as measured with the Baecke questionnaire) between both groups, which indicates that the overweight children in fact overestimated their activities. Similar to underreporting food intake (28-30), physical activity is generally overreported, especially in the overweight (31), which offers an explanation of the overestimated physical activity in the overweight children.

Guided by two sports instructors during an organized sports afternoon, the overweight and lean children performed activities according to the same structured protocol. Here, the results showed that the Tracmor movement registration (kCounts) of the overweight and lean children was not statistically different. This implicates that only in free-living daily circumstances, when children are free to choose and perform their own preferred activities, there was a significant difference in physical activity counts between overweight and lean children. The fact that overweight children moved less in these circumstances, in terms of activity counts as measured by accelerometers, does not necessarily mean that their energy expenditure is also lower. Basal metabolic rate (BMR), total energy expenditure (TEE), activity-related energy expenditure (AEE=TEE- 
BMR) or physical activity level (PAL=TEE/BMR) have frequently been reported to be the same between overweight and lean children (14,32-34). This can be explained by the increased energy cost of moving a larger body mass, by a difference in body acceleration (i.e. activity counts), by a difference in movement economy, or by a combination of these factors (14). Also, the calculation of activity induced energy expenditure (AEE) from Tracmor counts consists of a formula that takes anthropometry

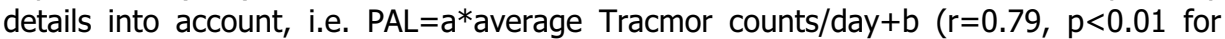
regression PAL and Tracmor counts) (22). Since PAL is defined as TEE/BMR, and $T E E=B M R+A E E+D I T$ (diet induced thermogenesis), and since BMR is determined by body mass, the equation shows that for the same PAL, overweight children need more AEE than lean children (22).

Recently, Page et al (2005) performed a comprehensive study in which they looked at physical activity patterns in children (11). They found that 25 obese children were significantly less physically active than their 108 non-obese counterparts. Physical activity was measured with CSA accelerometers during waking hours when carrying out their normal daily activities for seven days. Comparing our results to the results of Page et al, both reported that overweight children indeed move less than lean children. In addition, from our study we can conclude that it is truly the initiative to move instead of the intensity of moving, that is lower in the overweight children. Page et al (2005) measured a large sample of children. The present study measured a relatively small group of children, but with the use of the tri-axial Tracmor-4, which measures daily physical activity more accurately than the uni-axial CSA's (10), we were able to show significant differences even with a small number of subjects.

We conclude that, in their typical living environment, overweight children moved significantly less than lean children, while at the same time they overestimated their activities. When performing activities in accordance with exactly the same activity protocol, there was no difference in Tracmor output between overweight and lean children, which shows that the movements during specific activities were similar. This implicates that once children are overweight, reduced physical activities may contribute or even promote their overweight status.

\section{ACKNOWLEDGEMENTS}

We thank our subjects for their participation in this study. We gratefully thank Loek Wouters, Jeroen Wijckmans, Marcel den Hoed and Dr. Annemiek Joosen for their assistance, and we acknowledge Dr. Kathleen Melanson for editing the English text. The study was supported by Maastricht University. The authors had no conflict of interest. 


\section{REFERENCES}

1. WHO. Obesity: preventing and managing the global epidemic. Report of a WHO consultation. World Health Organ Tech Rep Ser 2000;894:i-xii, 1-253.

2. Livingstone B. Epidemiology of childhood obesity in Europe. Eur J Pediatr 2000;159 Suppl 1:S14-34.

3. Berenson GS, Srinivasan SR, Bao W, Newman WP, 3rd, Tracy RE, Wattigney WA. Association between multiple cardiovascular risk factors and atherosclerosis in children and young adults. The Bogalusa Heart Study. N Engl J Med 1998;338:1650-6.

4. Cole TJ, Bellizzi MC, Flegal KM, Dietz WH. Establishing a standard definition for child overweight and obesity worldwide: international survey. BMJ 2000;320:1240-3.

5. Brownson RC, Boehmer TK, Luke DA. Declining rates of physical activity in the United States: what are the contributors? Annu Rev Public Health 2005;26:421-43.

6. Williamson DF, Madans J, Anda RF, Kleinman JC, Kahn HS, Byers T. Recreational physical activity and ten-year weight change in a US national cohort. Int J Obes Relat Metab Disord 1993; 17:279-86.

7. Ekelund U, Yngve A, Brage S, Westerterp K, Sjostrom M. Body movement and physical activity energy expenditure in children and adolescents: how to adjust for differences in body size and age. Am J Clin Nutr 2004;79:851-6.

8. Luepker RV. How physically active are American children and what can we do about it? Int J Obes Relat Metab Disord 1999;23 Suppl 2:S12-7.

9. Parsons TJ, Power C, Logan S, Summerbell CD. Childhood predictors of adult obesity: a systematic review. Int J Obes Relat Metab Disord 1999;23 Suppl 8:S1-107.

10. Plasqui $G$, Joosen $A M$, Kester $A D$, Goris $A H$, Westerterp KR. Measuring free-living energy expenditure and physical activity with triaxial accelerometry. Obes Res 2005;13:1363-9.

11. Page A, Cooper AR, Stamatakis E, et al. Physical activity patterns in nonobese and obese children assessed using minute-by-minute accelerometry. Int J Obes Relat Metab Disord 2005;29:1070-6.

12. Abbott RA, Davies PS. Habitual physical activity and physical activity intensity: their relation to body composition in 5.0-10.5-y-old children. Eur J Clin Nutr 2004;58:285-91.

13. Trost SG, Sirard JR, Dowda M, Pfeiffer KA, Pate RR. Physical activity in overweight and nonoverweight preschool children. Int J Obes Relat Metab Disord 2003;27:834-9.

14. Ekelund U, Aman J, Yngve A, Renman C, Westerterp K, Sjostrom M. Physical activity but not energy expenditure is reduced in obese adolescents: a case-control study. Am J Clin Nutr 2002;76:935-41.

15. Trost SG, Kerr LM, Ward DS, Pate RR. Physical activity and determinants of physical activity in obese and non-obese children. Int J Obes Relat Metab Disord 2001;25:822-9.

16. Rump P, Mensink RP, Kester AD, Hornstra G. Essential fatty acid composition of plasma phospholipids and birth weight: a study in term neonates. Am J Clin Nutr 2001;73:797-806.

17. Rump P, Popp-Snijders C, Heine RJ, Hornstra G. Components of the insulin resistance syndrome in seven-year-old children: relations with birth weight and the polyunsaturated fatty acid content of umbilical cord plasma phospholipids. Diabetologia 2002;45:349-55.

18. Vogels N, Posthumus DLA, Mariman ECM, et al. Determinants of overweight in a Dutch children cohort. AJCN in press 2006.

19. Baecke JA, Burema J, Frijters JE. A short questionnaire for the measurement of habitual physical activity in epidemiological studies. Am J Clin Nutr 1982;36:936-42.

20. Jacobs DR, Jr., Ainsworth BE, Hartman TJ, Leon AS. A simultaneous evaluation of 10 commonly used physical activity questionnaires. Med Sci Sports Exerc 1993;25:81-91.

21. Philippaerts RM, Westerterp KR, Lefevre J. Doubly labelled water validation of three physical activity questionnaires. Int J Sports Med 1999;20:284-9.

22. Hoos MB, Plasqui G, Gerver WJ, Westerterp KR. Physical activity level measured by doubly labeled water and accelerometry in children. Eur J Appl Physiol 2003;89:624-6.

23. Hoos MB, Kuipers H, Gerver WJ, Westerterp KR. Physical activity pattern of children assessed by triaxial accelerometry. Eur J Clin Nutr 2004;58:1425-8.

24. van Marken Lichtenbelt WD, Westerterp KR, Wouters L. Deuterium dilution as a method for determining total body water: effect of test protocol and sampling time. $\mathrm{Br} \mathrm{J}$ Nutr 1994;72:491-7. 
25. Schoeller DA, van Santen E, Peterson DW, Dietz W, Jaspan J, Klein PD. Total body water measurement in humans with 180 and 2H labeled water. Am J Clin Nutr 1980;33:2686-93.

26. Westerterp KR, Wouters L, van Marken Lichtenbelt WD. The Maastricht protocol for the measurement of body composition and energy expenditure with labeled water. Obes Res 1995;3 Suppl 1:49-57.

27. Philippaerts RM, Westerterp KR, Lefevre J. Comparison of two questionnaires with a tri-axial accelerometer to assess physical activity patterns. Int J Sports Med 2001;22:34-9.

28. Goris AH, Westerterp-Plantenga MS, Westerterp KR. Undereating and underrecording of habitual food intake in obese men: selective underreporting of fat intake. Am J Clin Nutr 2000;71:130-4.

29. Schoeller DA, Seidell JC. How accurate is self-reported dietary energy intake? Nutr Rev 1990;48:373-9.

30. Lissner $\mathrm{L}$, Heitmann BL, Lindroos AK. Measuring intake in free-living human subjects: a question of bias. Proc Nutr Soc 1998; 57:333-9.

31. Rzewnicki R, Vanden Auweele Y, De Bourdeaudhuij I. Addressing overreporting on the International Physical Activity Questionnaire (IPAQ) telephone survey with a population sample. Public Health Nutr 2003;6:299-305.

32. Bandini LG, Schoeller DA, Dietz WH. Energy expenditure in obese and nonobese adolescents. Pediatr Res 1990;27:198-203.

33. DeLany JP, Harsha DW, Kime JC, Kumler J, Melancon L, Bray GA. Energy expenditure in lean and obese prepubertal children. Obes Res 1995;3 Suppl 1:67-72.

34. Treuth MS, Figueroa-Colon R, Hunter GR, Weinsier RL, Butte NF, Goran MI. Energy expenditure and physical fitness in overweight vs non-overweight prepubertal girls. Int J Obes Relat Metab Disord 1998;22:440-7. 
46 | Chapter 3 


\section{4}

\section{Predictors of long-term weight maintenance}

Neeltje Vogels, Kristel Diepvens, Margriet S. Westerterp-Plantenga

Obesity Research 2005;13:2162-2168 


\section{ABSTRACT}

Objective: The purpose of the present study was to evaluate available variables of a long-term weight maintenance study, to investigate possible factors predisposing to weight regain after a period of weight loss.

Research methods and procedures: The Maastricht Weight Maintenance Study is an ongoing longitudinal study of healthy men and women $(29 \mathrm{~m} / 62 \mathrm{f} ; 18-65$ yrs; BMI $30.2 \pm 3.1 \mathrm{~kg} / \mathrm{m}^{2}$ ). A variety of parameters were measured before and after a very low calorie diet and after a follow-up of at least 2 years.

Results: Mean weight loss was $7.9 \pm 3.6 \mathrm{~kg}$ and \%weight regain was $113.8 \pm 98.1 \%$. $\% B M I$ regain was negatively associated with an increase in dietary restraint $(r=-0.47$, $\mathrm{p}<0.05)$. \%weight regain was negatively correlated with baseline resting metabolic rate (RMR) $(r=-0.38, p=0.01)$ and baseline fat mass (FM) $(r=0.24, p=0.05)$ and positively correlated with the magnitude of change in BW expressed as maximum amplitude of body weight $(r=0.21, p<0.05)$. In addition, amplitude of body weight was positively correlated with the frequency of dieting $(r=0.57, p<0.01)$.

Discussion: The best predictors for weight maintenance after weight loss were an increase in dietary restraint during weight loss, a high baseline RMR, a relatively high baseline FM favoring a fat free mass sparing effect during weight loss, a rather stable BW, and a low frequency of dieting. Therefore, BW maintenance after BW loss appears to be a multi-factorial issue, including mechanisms that regulate an individuals' energy expenditure, body composition and eating behavior in such a way that energy homeostasis is maintained. 


\section{INTRODUCTION}

Obesity results from a chronic imbalance between energy intake and expenditure. It increases the risk of numerous conditions including type 2 diabetes, hypertension and coronary heart disease, which themselves are associated with an increased morbidity and mortality $(1,2)$. Modest weight loss reduces the risks associated with obesity related disorders and diseases $(3,4)$. Although typically prescribed weight loss strategies produce short-term success, sustained weight maintenance is rarely achieved (5-7). Determining and understanding the possible parameters that predispose individuals to body weight (BW) regain after a period of weight reduction is therefore necessary to improve current weight maintenance strategies.

A large number of studies have previously addressed this issue. Weight (re)gain has been associated with a low resting metabolic rate (RMR), (8-12), a high respiratory quotient (RQ) (13-17), and higher scores on cognitive dietary restraint measured with the three factor eating questionnaire $(6,18-21)$. RMR is the component of energy expenditure that explains the largest proportion of an individual's total daily energy expenditure. A low RMR therefore may explain why some individuals regain weight more easily than others. An elevated post-absorptive RQ after discontinuation of a low energy diet showed that the endogenous fat oxidation is reduced (13). Therefore, a high fasting RQ should be considered predictive of body weight regain (14). The Three Factor Eating Questionnaire (TFEQ) is a self-report measure of eating behaviors that are believed to be particularly relevant to the development and maintenance of obesity. The TFEQ has been widely used in obesity treatment and includes three subscales: cognitive dietary restraint (Factor 1), disinhibition of dietary restraint and emotional eating (Factor 2) and hunger (Factor 3) (22). Restrained eating has been studied extensively. In general, lower overall intake of food energy, especially fat and carbohydrate intake, has been associated with higher cognitive restraint scores, especially in the obese (23-26). Weight cycling has also been put forward as an important predictor for weight gain. Different studies showed that repeated weight losses and regains did not improve the success of future weight loss attempts (27-29), they may even be related to net weight gain $(7,18$, $30-32)$ and may therefore have truly negative health consequences $(27,29)$. Weight cycling may induce an unfavorable change in body composition, elevated blood pressure and decreased resting energy expenditure (29). Moreover, weight regain is associated with life stress, negative coping style, and use of eating to cope with negative emotions (33).

The purpose of the present study was to evaluate relevant variables of different longterm weight maintenance studies, to determine possible factors predisposing to weight regain after a period of weight loss. In addition to taking the frequency of dieting into account, the magnitude of dieting will be addressed.

\section{RESEARCH METHODS AND PROCEDURES}

\section{Subjects}

The MWMS (Maastricht Weight Maintenance Study) is an ongoing longitudinal study of healthy men and women (aged 18-65 yrs, BMI $>25 \mathrm{~kg} / \mathrm{m}^{2}$ ) living in the south of the Netherlands. They were recruited by advertisement in local newspapers. All subjects evaluated in this study $(n=91,29 m / 62 f)$ have participated in a Very Low Calorie Diet (VLCD) in order to lose weight. After a follow-up of at least 2 years all subjects were remeasured; most had regained weight. The follow-up period varied from 2-8 years 
between the different weight loss studies. There was however, no effect of the duration of follow-up period on percentage of BW regain.

\section{Study design}

The experimental design (Figure 1) shows that BW, BMI, body composition, attitude towards eating, resting metabolic rate and respiratory quotient were measured before (M1) and after (M2) a VLCD. The diet was followed by a period where the subjects followed a free-living eating pattern for 2 years or more. Measurements were repeated once: 2 years or more had lapsed since the end of the VLCD (M3). The protocol was approved by the Ethics Committee of Maastricht University.

\begin{tabular}{|l|l|}
\hline \multicolumn{2}{|c|}{ Measurements (M1, M2 and M3) } \\
\hline Weight loss & Weight regain (free-living for at least 2 years) \\
\hline M1 & M2
\end{tabular}

Figure 1: Study design. Measurements including BW, BMI, body composition, attitude towards eating, BW amplitude, RMR and RQ, were taken 3 times over at least 2 years.

\section{Measurements}

\section{Anthropometry}

Height was measured using a wall-mounted stadiometer (Seca, model 220, Hamburg, Germany) and body weight (BW) was measured to the nearest $0.02 \mathrm{~kg}$ using a digital balance (model 707; Seca, Hamburg, Germany). Measurements were executed in underwear, after an overnight fast and after voiding the bladder. Body mass index (BMI) was calculated by BW/height ${ }^{2}\left(\mathrm{~kg} / \mathrm{m}^{2}\right)$. Waist circumference was measured at the site of the smallest circumference between the rib cage and the ileac crest, with the subjects in standing position.

\section{Body composition}

Body composition was measured using the deuterium dilution technique (34). ${ }^{2} \mathrm{H}_{2} \mathrm{O}$ dilution was used to measure total body water (TBW). Subjects were asked to collect a urine sample in the evening just before drinking the deuterium-enriched water solution. After ingestion of this solution, no further fluid or food consumption was allowed. Ten hours after drinking the water solution, another urine sample was collected. The dilution of the deuterium isotope is a measure of the TBW of the subject. Deuterium was measured in the urine samples with an isotope ratio mass spectrometer (VG-Isogas Aqua Sira, VG Isogas, Middlewich, Cheshire, England). TBW was obtained by dividing the measured deuterium dilution space by 1.04 (34). Fat free mass (FFM) was calculated by dividing TBW by the hydration factor 0.73 . By substracting FFM from BW, fat mass (FM) was obtained. FM expressed as a percentage of BW revealed body fat percentage. 
Attitude towards eating, frequency of dieting and BW amplitude

Eating behavior was assessed before and after losing weight, and at the last measurement section, using a validated Dutch translation of the Three Factor Eating Questionnaire (TFEQ) $(22,35)$. Cognitive restrained and unrestrained eating behavior (factor 1), emotional eating and disinhibition (factor 2) and the subjective feeling of hunger (factor 3) were scored. BW concern and chronic dieting behavior were investigated once, using the Herman-Polivy questionnaire (HP), which addresses weight consciousness (36).

BW amplitude is the sum of person's maximum weight loss (over a period of one month) and person's maximum life time weight gain in kilogram BW above desired BW (measured by 2 questions of the HP questionnaire).

\section{Resting metabolic rate and Respiratory Quotient}

Resting metabolic rate (RMR) and respiratory quotient (RQ) was measured after an overnight fast. $\mathrm{O}_{2}$ consumption and $\mathrm{CO}_{2}$ production were determined using a computerized, open-circuit, ventilated hood system. Gas analyses were performed using a paramagnetic $\mathrm{O}_{2}$ analyzer (Servomex, Type 500A, Crowborough Sussex, UK) and an infrared $\mathrm{CO}_{2}$ analyzer (Servomex, Type 12-X1), similar to the analysis system described by Schoffelen et al. (1997) (37). Calculation of RMR was based upon Weir's formula (38). RQ was calculated as $\mathrm{CO}_{2}$ produced $/ \mathrm{O}_{2}$ consumed.

\section{Statistical analysis}

Data are presented as mean \pm standard deviation (sd). Statistical analyses were performed with Statview SE Graphics ${ }^{\mathrm{TM}}$ for Macintosh. Pearson correlation coefficients, $r$, were calculated to determine the relationship between selected variables. Subsequently, multiple regression analyses were performed to obtain the combined independent predictors of weight regain. Differences were considered significant at $p<0.05$.

Table 1: Subject characteristics at baseline (M1), after weight loss (M2), and after follow-up (M3).

\begin{tabular}{|c|c|c|c|}
\hline & M1 & M2 & M3 \\
\hline Age $(y)$ & $44.6 \pm 9.6$ & $44.8 \pm 9.6$ & $48.8 \pm 9.6$ \\
\hline Height (m) & $1.7 \pm 0.1$ & $1.7 \pm 0.1$ & $1.7 \pm 0.1$ \\
\hline Body weight $(\mathrm{kg})$ & $87.3 \pm 12.3$ & $79.4 \pm 12.3$ & $88.0 \pm 14.3$ \\
\hline BMI $\left(\mathrm{kg} / \mathrm{m}^{2}\right)$ & $30.2 \pm 3.1$ & $27.9 \pm 3.3$ & $30.6 \pm 3.9$ \\
\hline Fat mass $(\mathrm{kg})$ & $31.3 \pm 7.2$ & $25.3 \pm 8.8$ & $30.6 \pm 9.2$ \\
\hline Fat free mass $(\mathrm{kg})$ & $66.5 \pm 9.9$ & $65.3 \pm 10.0$ & $71.0 \pm 8.5$ \\
\hline Body fat (\%) & $31.9 \pm 5.8$ & $27.9 \pm 8.0$ & $29.7 \pm 5.9$ \\
\hline Resting metabolic rate $\left(\mathrm{MJ} /\right.$ day) ${ }^{*}$ & $6.7 \pm 1.1$ & $6.1 \pm 1.1$ & - \\
\hline Respiratory quotient ${ }^{*}$ & $0.84 \pm .05$ & $0.80 \pm .05$ & - \\
\hline F1 (of the TFEQ) & $7.4 \pm 4.2$ & $12.6 \pm 4.6$ & $9.2 \pm 4.6$ \\
\hline F2 (of the TFEQ) & $6.9 \pm 2.6$ & $5.2 \pm 3.2$ & $5.5 \pm 3.0$ \\
\hline F3 (of the TFEQ) & $5.9 \pm 2.7$ & $3.5 \pm 3.0$ & $6.8 \pm 4.6$ \\
\hline Herman Polivy questionnaire ${ }^{\dagger}$ & - & - & $17.9 \pm 3.4$ \\
\hline Body weight amplitude $^{+}$ & - & - & $17.5 \pm 6.5$ \\
\hline
\end{tabular}

\footnotetext{
${ }^{*}$ Measured twice: before and after weight loss
}

${ }^{\dagger}$ Measured only once: after follow-up 


\section{RESULTS}

Total body weight loss was $7.9 \pm 3.6 \mathrm{~kg}$ (BMI: $2.3 \pm 1.3 \mathrm{~kg} / \mathrm{m}^{2}$ ). Mean BMI regain was $2.6 \pm 2.5$, i.e. percent BMI regain was $114 \%$. Percent weight regain was 113.8 .

Percent BMI regain was negatively associated with the increase in dietary restraint during weight loss $(r=-0.47, p<0.05)$, which means that an early increase in dietary restraint was associated with less regain.

Baseline characteristics of the subjects, as well as the characteristics after weight loss and after follow-up, are shown in Table 1. Flexibility in body weight loss was expressed as percent weight regained from the weight lost. With respect to this flexibility, multiple regression analysis showed that baseline RMR appeared to be the explanatory variable for percent weight regain $(r=-0.38, p=0.01)$ (Figure 2$)$, without FFM adding to the explained variation (Table 2). Furthermore, simple regression analyses showed that percent weight regain was positively correlated with the magnitude of change in body weight (maximum amplitude of BW) $(r=0.21, p<0.05)$ (Figure 3$)$, and negatively correlated with baseline FM $(r=-0.24, p=0.05)$ and baseline fat percentage $(r=-0.25$, $\mathrm{p}<0.05)$.

Moreover, amplitude of BW was positively correlated with the frequency of dieting $(r=0.57, p<0.01)$.

The other variables at baseline (age, waist circumference, and RQ) did not contribute to the variation in percent BMI or weight regain.
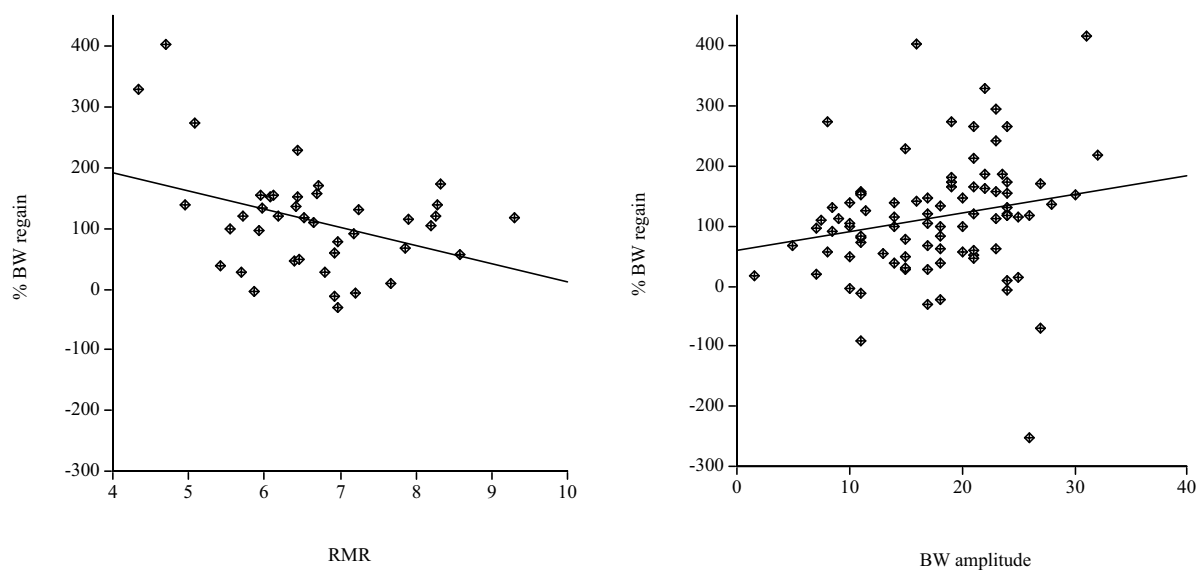

Figure 2 (left): \% BW regain as a function of RMR in a subset of 41 subjects $(r=-0.38, p=0.01)$.

Figure 3 (right): \% BW regain as a function of BW amplitude (the sum of person's maximum weight loss over a period of one month and maximum weight gain in kilogram BW above desired BW) $(r=0.21, p<0.05)$. 
Table 2: Multiple regression analysis of predictors for weight regain.

\begin{tabular}{lcccc}
\hline & B-coefficient & Std Error & Probability & Partial F \\
\hline Intercept & 327.04 & & & \\
Baseline FFM & 0.73 & 1.26 & 0.57 & 0.33 \\
Baseline RMR & -38.59 & 13.74 & 0.01 & 7.89 \\
\hline
\end{tabular}

\section{DISCUSSION}

We evaluated data collected during the Maastricht Weight Maintenance Study which itself was a compilation of long-term weight maintenance studies that included a variety of measurements made 2-8 years after initial weight loss.

An inverse relationship between an increase in dietary restraint during energy restriction and subsequent percent BMI regain (corrected for height) was found; the explained variance was $22 \%$. This is in line with many previous observations that have been made over the short- as well as over the long-term $(6,19,21,39,40)$. Due to an improved, successful restrained eating behavior energy intake is decreased, which will result in less weight regain. We speculate that with the present affluent society, with its abundant choice of food and decreased energy expenditure level, successful dietary restraint is necessary to prevent subsequent weight gain.

Flexibility in body weight loss was expressed as percent weight regained from the weight lost. For weight maintenance, being in energy balance is crucial. Here we approached energy balance by measuring RMR (the largest part of energy expenditure (EE)) and dietary restraint (the degree to which subjects restrain their energy intake (EI)), since we were not able to measure total EE (because the doubly labeled water method was too expensive), or total EI (due to the frequent problem of underreporting of food intake $(41,42))$. We found that the best predictor for weight maintenance over a follow up period of at least 2 years was RMR at baseline; which predicted $14 \%$ of the variability in the ability to maintain weight. Baseline RMR was found to be inversely related to percent weight regain and the correlation did not disappear when RMR was expressed as a function of FFM. This corresponds with the results from Astrup et al. who previously concluded that a low RMR may contribute to weight regain in some formerly obese subjects (8), and with the results from Ravussin et al. who showed that in Pima Indians the RMR for a given body composition was a predictor for subsequent weight gain (1012). Recently, Buscemi et al. concluded that in adult Caucasians, a low relative RMR at baseline was associated with body weight gain in the long run (9). On the contrary, no association between RMR and weight gain has also been reported (14, 15, 43-46). It was mainly concluded that RMR values returned to baseline values when obese individuals regained their lost weight (44), even within 10 days of energy balance, which was reflected by a return to the euthyroid state (43). Thus, similar to previous studies we conclude that in the present study a low RMR explained why some individuals regained weight more easily than others. Whether a low RMR is acquired or genetic (47, 48 ) is still unclear.

With respect to energy expenditure, data about the subject's physical activity level would also be valuable. Physical activity level had been measured before and after previous weight loss and after 3 months weight maintenance in $~ 50 \%$ of the subjects in this study. The level was $1.6 \pm 0.15$ at every time it was measured (49). Therefore the changes in total EE were dependent mainly on the changes in RMR. 
To a minor extent, the new concept amplitude of body weight (BW), which explained $5 \%$ of the variance in weight regain, was correlated positively with percent weight regain. BW amplitude is measured as the sum of an individual's maximum weight loss (over a period of one month) and their maximum lifetime weight gain (in kilogram BW above desired BW). Thus, it describes the magnitude of change in body weight over an individual's lifetime. It seems that people who have previously experienced large weight losses, followed by large weight regains, are at a higher risk to regain weight after a period of energy restriction.

Frequency of dieting was correlated positively with the amplitude of BW. This suggests that individuals who frequently follow diets have a greater predisposition to regain a large amount of weight. In the past, this phenomenon has been described as weight cycling, or the yo-yo effect, and has been put forward as an important predictor for weight regain $(7,18,27-32)$. In addition to the yo-yo frequency, also the yo-yo amplitude appears to be of importance. Kajioka et al. concluded that weight cycling induced a decrease in RMR (29), which can be one possible explanation for this phenomenon. Lejeune et al. suggested an additional mechanism for weight cycling, namely a limit in the possibility to increase cognitive restrained eating behavior. When the restraint score approaches the limit (an F1 score of 21), the success of subsequent dieting will decrease (21).

In the present study, we found that (absolute and relative) FM was an unexpected predictor of weight regain, which explained $5 \%$ of the variance in weight regain. Subjects with a high FM regained less weight. The explanation for this phenomenon is speculative. Obese people have a lot of body fat, which results in a body composition that is out of proportion (50). In this study, the highest FM was $42 \%$. For obese people, it is easier to lose a lot of weight in a small period of time than it is for non obese or very lean people $(21,51-55)$. After losing weight, which is mostly fat (56), subsequent FM and FFM are going towards a more "common" ratio (1/3 FM and 2/3 FFM) of body composition. This new, more favorable body composition, may explain why less weight regain is followed. The initial high FM, that changes by weight loss and regain in a relatively lower FM may be the result of a fat free mass sparing effect. Previously Dulloo and colleagues (1999) described this sparing effect in which the body composition of a given individual changes continuously towards a leaner composition during the course of starvation (56). In our study, we found this sparing effect in the weight loss phase as well as in the weight maintenance phase.

In summary, we found that the maintenance of BMI was predicted by an increase in cognitive dietary restraint during weight loss. The best predictors for weight maintenance after weight loss were a high baseline RMR; a rather stable body weight (referring to a low BW amplitude); a low frequency of dieting; and a relatively high baseline fat mass that favored a fat free mass sparing effect during weight loss. The explained variance is $5-22 \%$, i.e. dietary restraint or limiting the food intake, physiological variables such as body composition and RMR, as well as previous dieting periods contribute to a small proportion of the explanation of BMI or weight regain. Therefore, other factors such as social support of the environment $(57,58)$, and habitual physical activity $(30,57,59,60)$, still are of importance.

To conclude, preventing weight gain is obviously the best way of curbing the obesity epidemic. However, for individuals who are already overweight, weight loss, but more importantly the maintenance of this weight loss at once, is vital for optimal health. Ingredients that increase RMR (e.g. green tea (61)) may be helpful in maintaining the newly reduced body weight. 


\section{ACKNOWLEDGEMENTS}

We thank Dr. Natalie Luscombe-Marsh for editing the English text and we gratefully thank Manuela Lejeune, Chris Hukshorn, Wilrike Pasman and Kitty Kempen for providing their early data in the Maastricht Weight Maintenance Study. There was no funding/outside support for this study. 


\section{REFERENCES}

1. Burton BT, Foster WR. Health implications of obesity: an NIH Consensus Development Conference. J Am Diet Assoc 1985;85:1117-21.

2. Pi-Sunyer FX, Becker DM, Bouchard C, al. e. NHLBI Obesity education initiative expert panel on the identification, evaluation, and treatment of overweight and obesity in adults. Obes Res 1998;6:51S-209S.

3. Lean ME, Powrie JK, Anderson AS, Garthwaite PH. Obesity, weight loss and prognosis in type 2 diabetes. Diabet Med 1990;7:228-33.

4. Goldstein DJ. Beneficial health effects of modest weight loss. Int J Obes Relat Metab Disord 1992;16:397-415.

5. Pasman WJ, Rossner S, Westerterp-Plantenga MS, Saris WH. Body weight changes after treatment of obesity or pregnancy. Milan, Italy: Edra, 1999.

6. Westerterp-Plantenga MS, Kempen KP, Saris WH. Determinants of weight maintenance in women after diet-induced weight reduction. Int J Obes Relat Metab Disord 1998;22:1-6.

7. Pasman WJ, Saris WH, Westerterp-Plantenga MS. Predictors of weight maintenance. Obes Res 1999;7:43-50.

8. Astrup A, Gotzsche PC, van de Werken K, et al. Meta-analysis of resting metabolic rate in formerly obese subjects. Am J Clin Nutr 1999;69:1117-22.

9. Buscemi S, Verga S, Caimi G, Cerasola G. Low relative resting metabolic rate and body weight gain in adult Caucasian Italians. Int J Obes Relat Metab Disord 2005;29:287-91.

10. Ravussin E, Lillioja S, Knowler WC, et al. Reduced rate of energy expenditure as a risk factor for body-weight gain. N Engl J Med 1988;318:467-72.

11. Ravussin E. Low resting metabolic rate as a risk factor for weight gain: role of the sympathetic nervous system. Int J Obes Relat Metab Disord 1995;19 Suppl 7:S8-S9.

12. Tataranni PA, Harper IT, Snitker S, et al. Body weight gain in free-living Pima Indians: effect of energy intake vs expenditure. Int J Obes Relat Metab Disord 2003;27:1578-83.

13. Froidevaux F, Schutz $Y$, Christin L, Jequier E. Energy expenditure in obese women before and during weight loss, after refeeding, and in the weight-relapse period. Am J Clin Nutr 1993;57:35-42.

14. Hainer V, Kunesova M, Parizkova J, Stich V, Mikulova R, Slaba S. Respiratory quotient in obesity: its association with an ability to retain weight loss and with parental obesity. Sb Lek 2000;101:99-104.

15. Larson DE, Ferraro RT, Robertson DS, Ravussin E. Energy metabolism in weight-stable postobese individuals. Am J Clin Nutr 1995;62:735-9.

16. Valtuena S, Salas-Salvado J, Lorda PG. The respiratory quotient as a prognostic factor in weight-loss rebound. Int J Obes Relat Metab Disord 1997;21:811-7.

17. Zurlo F, Lillioja S, Esposito-Del Puente A, et al. Low ratio of fat to carbohydrate oxidation as predictor of weight gain: study of 24-h RQ. Am J Physiol 1990;259:E650-7.

18. McGuire MT, Wing RR, Klem ML, Lang W, Hill JO. What predicts weight regain in a group of successful weight losers? J Consult Clin Psychol 1999;67:177-85.

19. Pekkarinen T, Takala I, Mustajoki P. Two year maintenance of weight loss after a VLCD and behavioural therapy for obesity: correlation to the scores of questionnaires measuring eating behaviour. Int J Obes Relat Metab Disord 1996;20:332-7.

20. Hays NP, al. e. Eating behavior correlates of adult weight gain and obesity in healthy women aged 55-65 y. Am J Clin Nutr 2002;75:476-83.

21. Lejeune MP, Van Aggel-Leijssen DP, Van Baak MA, Westerterp-Plantenga MS. Effects of dietary restraint vs exercise during weight maintenance in obese men. Eur J Clin Nutr 2003;57:1338-44.

22. Stunkard AJ, Messick S. The three-factor eating questionnaire to measure dietary restraint, disinhibition and hunger. J Psychosom Res 1985;29:71-83.

23. Laessle RG, Tuschl RJ, Kotthaus BC, Pirke KM. Behavioral and biological correlates of dietary restraint in normal life. Appetite 1989;12:83-94.

24. Tuschl RJ, Platte P, Laessle RG, Stichler W, Pirke KM. Energy expenditure and everyday eating behavior in healthy young women. Am J Clin Nutr 1990;52:81-6. 
25. Wardle J, Beales S. Restraint and food intake: an experimental study of eating patterns in the laboratory and in normal life. Behav Res Ther 1987;25:179-85.

26. Lindroos AK, Lissner $\mathrm{L}$, Mathiassen ME, et al. Dietary intake in relation to restrained eating, disinhibition, and hunger in obese and nonobese Swedish women. Obes Res 1997; 5:175-82.

27. Weight cycling. National Task Force on the Prevention and Treatment of Obesity. JAMA 1994;272:1196-202.

28. Korkeila M, Rissanen A, Kaprio J, Sorensen TI, Koskenvuo M. Weight-loss attempts and risk of major weight gain: a prospective study in Finnish adults. Am J Clin Nutr 1999;70:965-75.

29. Kajioka T, Tsuzuku S, Shimokata H, Sato Y. Effects of intentional weight cycling on nonobese young women. Metabolism 2002;51:149-54.

30. Bild DE, Sholinsky P, Smith DE, Lewis CE, Hardin JM, Burke GL. Correlates and predictors of weight loss in young adults: the CARDIA study. Int J Obes Relat Metab Disord 1996;20:47-55.

31. Field $A E$, Austin $\mathrm{SB}$, Taylor $\mathrm{CB}$, et al. Relation between dieting and weight change among preadolescents and adolescents. Pediatrics 2003;112:900-6.

32. Haus G, Hoerr SL, Mavis B, Robison J. Key modifiable factors in weight maintenance: fat intake, exercise, and weight cycling. J Am Diet Assoc 1994;94:409-13.

33. Foreyt JP, Brunner RL, Goodrick GK, Cutter G, Brownell KD, St Jeor ST. Psychological correlates of weight fluctuation. Int J Eat Disord 1995;17:263-75.

34. Schoeller DA, van Santen E, Peterson DW, Dietz W, Jaspan J, Klein PD. Total body water measurement in humans with 180 and 2H labeled water. Am J Clin Nutr 1980;33:268693.

35. Westerterp-Plantenga MS, Rolland V, Wilson SA, Westerterp KR. Satiety related to $24 \mathrm{~h}$ diet-induced thermogenesis during high protein/carbohydrate vs high fat diets measured in a respiration chamber. Eur J Clin Nutr 1999;53:495-502.

36. Herman CP, Polivy J. Restrained eating. Philadelphia: Saunders, W.B., 1980.

37. Schoffelen PF, Westerterp KR, Saris WH, Ten Hoor F. A dual-respiration chamber system with automated calibration. J Appl Physiol 1997;83:2064-72.

38. Weir JB. New methods for calculating metabolic rate with special reference to protein metabolism. 1949. Nutrition 1990;6:213-21.

39. Provencher V, Drapeau V, Tremblay A, Despres JP, Lemieux S. Eating behaviors and indexes of body composition in men and women from the Quebec family study. Obes Res 2003;11:783-92.

40. Bjorvell $\mathrm{H}$, Aly A, Langius A, Nordstrom G. Indicators of changes in weight and eating behaviour in severely obese patients treated in a nursing behavioural program. Int J Obes Relat Metab Disord 1994;18:521-5.

41. Goris AH, Westerterp-Plantenga MS, Westerterp KR. Undereating and underrecording of habitual food intake in obese men: selective underreporting of fat intake. Am J Clin Nutr 2000;71:130-4.

42. Goris AH, Meijer EP, Westerterp KR. Repeated measurement of habitual food intake increases under-reporting and induces selective under-reporting. Br J Nutr 2001;85:62934.

43. Weinsier RL, Nagy TR, Hunter GR, Darnell BE, Hensrud DD, Weiss HL. Do adaptive changes in metabolic rate favor weight regain in weight-reduced individuals? An examination of the set-point theory. Am J Clin Nutr 2000;72:1088-94.

44. Wadden TA, Foster GD, Stunkard AJ, Conill AM. Effects of weight cycling on the resting energy expenditure and body composition of obese women. Int J Eat Disord 1996;19:512.

45. Wadden TA, Bartlett S, Letizia KA, Foster GD, Stunkard AJ, Conill A. Relationship of dieting history to resting metabolic rate, body composition, eating behavior, and subsequent weight loss. Am J Clin Nutr 1992;56:203S-208S.

46. Jebb SA, Goldberg GR, Coward WA, Murgatroyd PR, Prentice AM. Effects of weight cycling caused by intermittent dieting on metabolic rate and body composition in obese women. Int J Obes 1991;15:367-74. 
47. Bouchard C, Tremblay A, Nadeau A, et al. Genetic effect in resting and exercise metabolic rates. Metabolism 1989;38:364-70.

48. Bogardus $\mathrm{C}$, Lillioja $\mathrm{S}$, Ravussin $\mathrm{E}$, et al. Familial dependence of the resting metabolic rate. N Engl J Med 1986;315:96-100.

49. Westerterp-Plantenga MS, Lejeune MP, Nijs I, van Ooijen M, Kovacs EM. High protein intake sustains weight maintenance after body weight loss in humans. Int J Obes Relat Metab Disord 2004;28:57-64.

50. Webster JD, Hesp R, Garrow JS. The composition of excess weight in obese women estimated by body density, total body water and total body potassium. Hum Nutr Clin Nutr 1984;38:299-306.

51. Wadden TA, Foster GD, Wang J, et al. Clinical correlates of short- and long-term weight loss. Am J Clin Nutr 1992;56:271S-274S.

52. Womble LG, Williamson DA, Greenway FL, Redmann SM. Psychological and behavioral predictors of weight loss during drug treatment for obesity. Int J Obes Relat Metab Disord 2001;25:340-5.

53. Stein PM, Hassanein RS, Lukert BP. Predicting weight loss success among obese clients in a hospital nutrition clinic. Am J Clin Nutr 1981;34:2039-44.

54. Krotkiewski M, Sjostrom L, Bjorntorp P, Carlgren G, Garellick G, Smith U. Adipose tissue cellularity in relation to prognosis for weight reduction. Int J Obes 1977;1:395-416.

55. Hansen D, Astrup A, Toubro S, et al. Predictors of weight loss and maintenance during 2 years of treatment by sibutramine in obesity. Results from the European multi-centre STORM trial. Sibutramine Trial of Obesity Reduction and Maintenance. Int J Obes Relat Metab Disord 2001;25:496-501.

56. Dulloo AG, Jacquet $\mathrm{J}$. The control of partitioning between protein and fat during human starvation: its internal determinants and biological significance. Br J Nutr 1999;82:339-56.

57. Williamson DA, Stewart TM. Behavior and lifestyle: approaches to treatment of obesity. J La State Med Soc 2005;157 Spec No 1:S50-5.

58. Elfhag $K$, Rossner $S$. Who succeeds in maintaining weight loss? A conceptual review of factors associated with weight loss maintenance and weight regain. Obes Rev 2005;6:6785.

59. van Baak MA, van Mil E, Astrup AV, et al. Leisure-time activity is an important determinant of long-term weight maintenance after weight loss in the Sibutramine Trial on Obesity Reduction and Maintenance (STORM trial). Am J Clin Nutr 2003;78:209-14.

60. Klem ML, Wing RR, McGuire MT, Seagle HM, Hill JO. A descriptive study of individuals successful at long-term maintenance of substantial weight loss. Am J Clin Nutr 1997;66:239-46.

61. Dulloo AG, Duret C, Rohrer D, et al. Efficacy of a green tea extract rich in catechin polyphenols and caffeine in increasing 24-h energy expenditure and fat oxidation in humans. Am J Clin Nutr 1999;70:1040-5. 
Categorical strategies based on subject characteristics of dietary restraint and physical activity, for weight maintenance

Neeltje Vogels, Margriet S. Westerterp-Plantenga

International Journal of Obesity 2005;29:849-857 


\section{ABSTRACT}

Objective: Investigate the effect of categorical strategies based on subject specific characteristics of dietary restraint and physical activity, on weight maintenance (WM) in overweight and obese subjects, after a very low calorie diet (VLCD). Furthermore find predictors of WM that can be important in the context of obesity treatment.

Methods: 120 subjects (age: $49.0 \pm 9.8 \mathrm{yr}$, BMI $\left.31.0 \pm 3.8 \mathrm{~kg} / \mathrm{m}^{2}\right)$ followed a VLCD $(2.1$ $\mathrm{MJ} / \mathrm{d}$ ) for six weeks in a free-living situation, followed by a period of 1 year WM. Body weight (BW), body composition, leptin concentration, dietary restraint and physical activity were determined right before (to) and after (t1) the VLCD, after 3 months (t2) and after 1 year (t3). During WM, subjects were divided into four categories of WM guidelines (dietary, activity, diet+activity, placebo), taking their capability measured during weight loss and their preference for particular guidelines into account.

Results: BW loss during VLCD was $7.0 \pm 3.1 \mathrm{~kg}$. After 1y follow-up BW regain was $56.3 \pm 55.0 \%$, without significant differences between the 4 groups. With respect to measured capability during weight loss, subjects with an increased dietary restraint (F1 of the Three Factor Eating Questionnaire) had less BW regain than subjects with an increased physical activity (Baecke questionnaire) $(35.5 \pm 53.2 \%$ vs. $68.5 \pm 46.4 \%$, $\mathrm{p}<0.05)$. Moreover, activity guidelines promoted WM in dietary disciplined subjects compared to activity related disciplined subjects (\%regain: $25.2 \%$ vs. $74.3 \%, p<0.05$ ). Subjects receiving guidelines which were opposite to their preference showed a better WM than subjects receiving preferred guidelines. After 1y WM, 21 subjects were successful ( $<10 \%$ BW regain) and 99 unsuccessful ( $\geq 10 \%$ BW regain). At baseline, these groups were significantly different in BMI (resp. $32.7 \pm 4.9$ vs. $30.7 \pm 3.5 \mathrm{~kg} / \mathrm{m}^{2}$, $\mathrm{p}<0.05)$, waist circumference $(106.5 \pm 14.0$ vs. $100.6 \pm 11.2 \mathrm{~cm}, \mathrm{p}<0.05)$, and fat mass (FM) $(35.2 \pm 10.6$ vs. $32.1 \pm 6.6 \%, p=0.06)$. Finally, successful subjects appeared to spare fat free mass (FFM) to a greater extent than unsuccessful subjects.

Conclusion: After weight loss, type of guidelines (dietary, activity, placebo) is not related to the magnitude of WM, whereas guidelines opposite to the subject's capability and preference are related. These only reach successful WM ( $<10 \%$ regain) in originally dietary disciplined subjects who are supported by characteristics such as a relatively high baseline BMI, waist circumference and FM, together with the ability to spare FFM. 


\section{INTRODUCTION}

The prevalence of overweight (defined as a BMI between 25 and $30 \mathrm{~kg} / \mathrm{m}^{2}$, and a relatively high fat mass (FM)) and obesity (defined as a BMI $>30 \mathrm{~kg} / \mathrm{m}^{2}$, including a high FM as well) is not only increasing in the US, but also in Western Europe (1-3). Overweight and obesity are emerging as major health problems. Obese individuals and even individuals with mild to moderate overweight have increased risk for multiple conditions, many of which are associated with a relatively high rate of morbidity and mortality, such as type 2 diabetes, hypertension and coronary heart disease (1-6). The risks associated with many of these co morbid conditions may be reduced with modest weight loss. Clinical studies suggest that minimal, sustained weight loss of 5 to $10 \%$ can reduce or eliminate obesity-related disorders (5).

Weight control methods often produce short-term success, but sustained weight maintenance (WM) is difficult to reach $(2,7,8)$. Weight cycling and relapse of body weight (BW) are common features after a weight loss intervention. The maintenance of treatment-induced weight loss thus remains a significant challenge in the management of obesity (9). Strategies to improve the maintenance of weight loss have resulted in behavior modification: changes in diet and increased physical activity (9-11). These interventions show a great promise for improving long-term outcome (9). To maintain weight loss some people may prefer to change their dietary pattern while others prefer to become more physically active. Most importantly, one needs to continuously keep up with these changes as long as one lives (12-14).

Weight loss maintenance strategies need to be further developed (15). It has been observed that placebo-group subjects maintain their body weight after weight loss as well as subjects receiving a certain treatment do. The reason lies in a dietary discipline, which can be characterized as an increase in dietary restraint during the weight loss phase that predicts WM thereafter $(2,16)$. The way subjects increase dietary restraint is invented and applied by themselves. Therefore, this study used a subject specific approach to achieve maintenance of the body weight lost. Strategies of WM may differ between subjects and choosing these strategies according to the subjects' capability may facilitate WM. Dietary restraint and physical activity are examples of these strategies. Dietary restraint refers to conscious restriction of food intake to achieve or maintain a preferred BW (17-21). Stunkard \& Messick reported that high scores on dietary restraint indicate that a subject might be especially responsive to information about caloric balance, nutrition, and behavioural strategies for stimulus control (22). Food consciousness is reflected in a relatively high score on the cognitive restraint factor of the Three Factor Eating Questionnaire (TFEQ) $(22,23)$. Physical activity can be measured using the Baecke Questionnaire. The Baecke questionnaire consists of three components: work activity, sports activity and leisure activity $(24,25)$ and has been validated using doubly labelled water (26).

Preference and/or discipline for certain methods may explain why some individuals can better keep up with a diet program while others prefer an activity program. Thus, subjects were categorized according to their possible increase in dietary restraint, or physical activity, or both, or none of these, during the first six weeks of the study. The purpose of this study was to investigate the effect of categorical strategies based on these subject specific characteristics of dietary restraint and physical activity, on WM in overweight and obese subjects, after a period of weight loss. Furthermore parameters were assessed that may predict possible BW regain, such as body composition and leptin concentrations, and may play an important role in the prevention of obesity for people at risk. 


\section{METHODS}

\section{Subjects}

Subjects were recruited by advertisements in local newspapers. The ads asked for subjects that were willing to participate a long-term weight loss study. At the screening visit, subjects were explained the study started with a $6 \mathrm{w}$ diet after which WM was measured for 2-3 years. They were told to receive different guidelines for WM. 150 subjects complied with the selection criteria: BMI $>25 \mathrm{~kg} / \mathrm{m}^{2}$ and age between 20 and 65 years. The exclusion criteria were: use of other research medication or diet up to 30 days prior to the study, and participation in an other scientific study 30 days prior to the study. 133 subjects started with a Very Low Calorie Diet (VLCD) for six weeks. Before the start 17 subjects had withdrawn for several reasons (e.g. not enough motivation). The 133 subjects (age: $48.1 \pm 9.5 \mathrm{y}$, BMI: $31.1 \pm 3.7 \mathrm{~kg} / \mathrm{m}^{2}$ ) who participated in the 6weeks energy restriction period underwent measurements before and after weight loss, at three months and at one year. At three months WM, another 13 subjects dropped-out

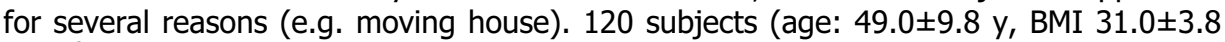
$\mathrm{kg} / \mathrm{m}^{2}$ ) completed the whole study. Subjects gave their written informed consent to participate in the study, which was approved by the Medical Ethical Comittee of the Maastricht University.

Table 1: Division of the subjects over the different category groups.

\begin{tabular}{|c|c|c|c|c|}
\hline & $\begin{array}{c}\text { Score on F1 } \\
(\mathrm{t} 1-\mathrm{t} 0)\end{array}$ & $\begin{array}{c}\text { Score on } \\
\text { Baecke (t1-t0) }\end{array}$ & 'Capability' & Guidelines \\
\hline Group A & increase & decrease or $=$ & Dietary discipline & $\begin{array}{c}\text { Dietary: SS } \\
\text { Activity: SNS }\end{array}$ \\
\hline Group B & decrease or $=$ & Increase & $\begin{array}{l}\text { Activity related } \\
\text { discipline }\end{array}$ & $\begin{array}{l}\text { Dietary: SNS } \\
\text { Activity: SS }\end{array}$ \\
\hline Group C & increase & increase & $\begin{array}{l}\text { Dietary and activity } \\
\text { related discipline }\end{array}$ & $\begin{array}{l}\text { Dietary+activity: SS } \\
\text { Placebo: SNS }\end{array}$ \\
\hline Group D & decrease or $=$ & decrease or $=$ & No discipline & $\begin{array}{c}\text { Dietary+activity: SNS } \\
\text { Placebo: SS }\end{array}$ \\
\hline
\end{tabular}

t0: baseline

t1: after VLCD

SS: subject category specific guidelines

SNS: subject category non-specific guidelines

\section{Experimental design}

The study consisted of a dietary weight loss intervention in free-living circumstances of six weeks and a WM period of 1 year. The subjects $(n=120)$ followed an energy restriction program for six weeks in a free-living situation. The program consisted of a VLCD (Modifast, Novartis Nutrition, Brussels, Belgium) containing $2.1 \mathrm{MJ} / \mathrm{d}$ (500 kcal/d). It provides $50 \mathrm{~g}$ carbohydrates, $52 \mathrm{~g}$ protein, $7 \mathrm{~g}$ fat and a vitamins- and minerals content which meets the Dutch recommended daily allowance, in three sachets per day consumed as prescribed. The VLCD was dissolved in water to make a soup, milkshake or dessert. In addition to the VLCD, subjects were allowed to consume two pieces of fruit and an unrestricted amount of vegetables every day, without sauces or vinaigrettes. 
After the VLCD, subjects received WM guidelines during the whole WM period. The guidelines were presented as information letters applicable and readable for every individual, and contained general information based on scientific research about diet (e.g. portion size, meal frequency, macronutrients, snacks, breakfast, fibers and water etc (27-30)), or about exercise (e.g. physical activity level, low/moderate/high intensity, activity induced decrease in appetite, weight maintenance, activity energy expenditure as compared to total energy expenditure, maintain fat free mass, prevent osteoporosis, importance of walking and cycling, etc. (31-37)), or about diet + exercise $(38,39)$, or about all other cues but diet + exercise (placebo or distraction from obsessive dieting). Frequent dieting is one of the strategies for subjects to maintain their weight, while it has been shown that this can have a contrary effect (8). The placebo guidelines had the objective to divert the attention from all diet and activity cues and give subjects other alternatives to concentrate on instead (e.g. reading, painting, solving puzzles, visiting cinema/theatre or play or listen to music etc.). Guidelines were sent by mail or through a specially developed encrypted web page. The kind of guidelines the subjects received was dependent on their measured capability during the first six weeks (table 1). Dietary discipline is determined by the change of the score on the F1 (of the TFEQ), and physical activity related discipline by a change in the score on the Baecke questionnaire, from before to after the six weeks VLCD. Half of the subjects were assigned to a treatment according to their estimated capability (subject category specific guidelines: SS) and half were assigned to a treatment according to the opposite of their estimated capability (subject category non-specific guidelines: SNS) (table 1). Stratification was applied with respect to BMI (at baseline), age, height, sex, $\Delta \mathrm{F} 1$ and $\Delta$ Baecke. Subjects were also asked for the type of guidelines they would prefer to receive.

Measurements of body weight, body composition, leptin concentration, dietary restraint and physical activity took place before the VLCD (t0), immediately after the VLCD (t1), 3 months after t0 (t2), and one year after to (t3) (figure 1).

\section{Anthropometry}

Measuring height was performed using a wall-mounted stadiometer (Seca, model 220, Hamburg, Germany) and body weight (BW) using a digital balance accurate to $0.1 \mathrm{~kg}$ (Sauter D7470, Ebingen, Germany). Measurements were executed in underwear, after an overnight fast and after voiding the bladder. BMI was calculated by BW/height ${ }^{2}$ $\left(\mathrm{kg} / \mathrm{m}^{2}\right)$. The waist circumference was measured at the site of the smallest circumference between the rib cage and the ileac crest, with the subjects in standing position.

\section{Body composition}

Body composition was measured using the deuterium dilution technique. ${ }^{2} \mathrm{H}_{2} \mathrm{O}$ dilution was used to measure total body water (TBW). Subjects were asked to collect a urine sample in the evening just before drinking the deuterium-enriched water solution. After ingestion of this solution, no further consumption was allowed. Ten hours after drinking the water solution, another urine sample was collected. The dilution of the deuterium isotope is a measure of the TBW of the subject. Deuterium was measured in the urine samples with an isotope ratio mass spectrometer (VG-Isogas Aqua Sira, VG Isogas, Middlewich, Cheshire, England). TBW was obtained by dividing the measured deuterium dilution space by 1.04 . Fat free mass (FFM) was calculated by dividing TBW by the hydration factor 0.73 (40-42). 


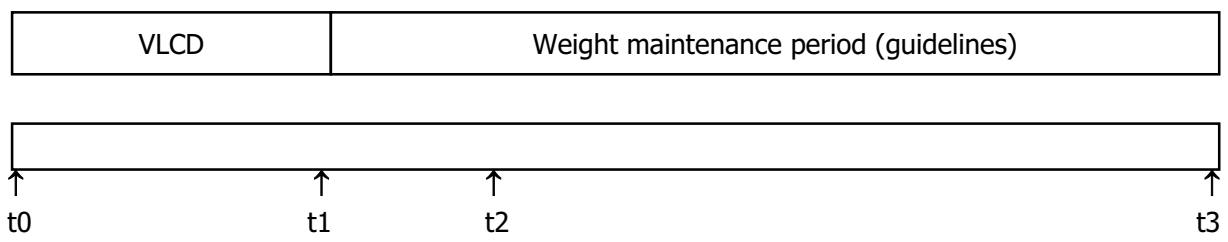

Dietary guidelines $(n=24)$

Activity guidelines $(n=21)$

Dietary + activity guidelines $(n=40)$

Placebo $(n=35)$

Figure 1: Study design. Subjects $(n=120)$ participated an energy restriction program (VLCD) during the first 6 weeks. After the VLCD, subjects were divided over four different strategies. Measurements of body weight, body composition, leptin concentrations, dietary restraint and physical activity were executed at baseline (t0), after VLCD (t1), 3 month after t0 (t2) and 1 year after to (t3) as indicated by the arrows.

\section{Attitude towards eating}

Eating behavior was analyzed using a validated Dutch translation of the TFEQ $(22,28)$. Cognitive restrained and unrestrained eating behavior (factor 1), emotional eating and disinhibition (factor 2) and the subjective feeling of hunger (factor 3) were scored. BW concern and chronic dieting behavior were investigated using the HP-questionnaire, which addresses weight consciousness (43).

\section{Leptin}

Blood samples were obtained, following a 12-h overnight fast. Serum leptin concentrations were measured with a double-antibody, sandwich-type enzyme-linked immunosorbent assay that used a monoclonal antibody specific for human leptin. The lower limit of detection is $0.5 \mu \mathrm{g} / \mathrm{L}$ and the upper limit is $50 \mu \mathrm{g} / \mathrm{L}$. The intra- and interassay CVs were $9 \%$ and $12 \%$, respectively. The leptin concentrations of normalweight subjects range from 2 to $12 \mu \mathrm{g} / \mathrm{L}$.

\section{Physical activity}

An estimation of the physical activity level was determined using the validated Baecke questionnaire (26). The Baecke questionnaire consists of a work index, a sports index, a leisure time index and the total index (24).

\section{Statistical analysis}

Weight loss from to to $\mathrm{t} 1$ was determined and compared between groups with paired $\mathrm{t}$ tests. Differences between groups and changes over time were determined with factorial analysis of variance (ANOVA) and Scheffé- $F$ post-hoc test (Statview SE Graphics ${ }^{\mathrm{TM}}$ for Macintosh). Pearson correlation coefficients, $r$, were calculated to determine the relationship between selected variables.

All statistical tests were two-sided, differences were considered significant at $p<0.05$. Values are expressed as mean \pm standard deviation (sd). 


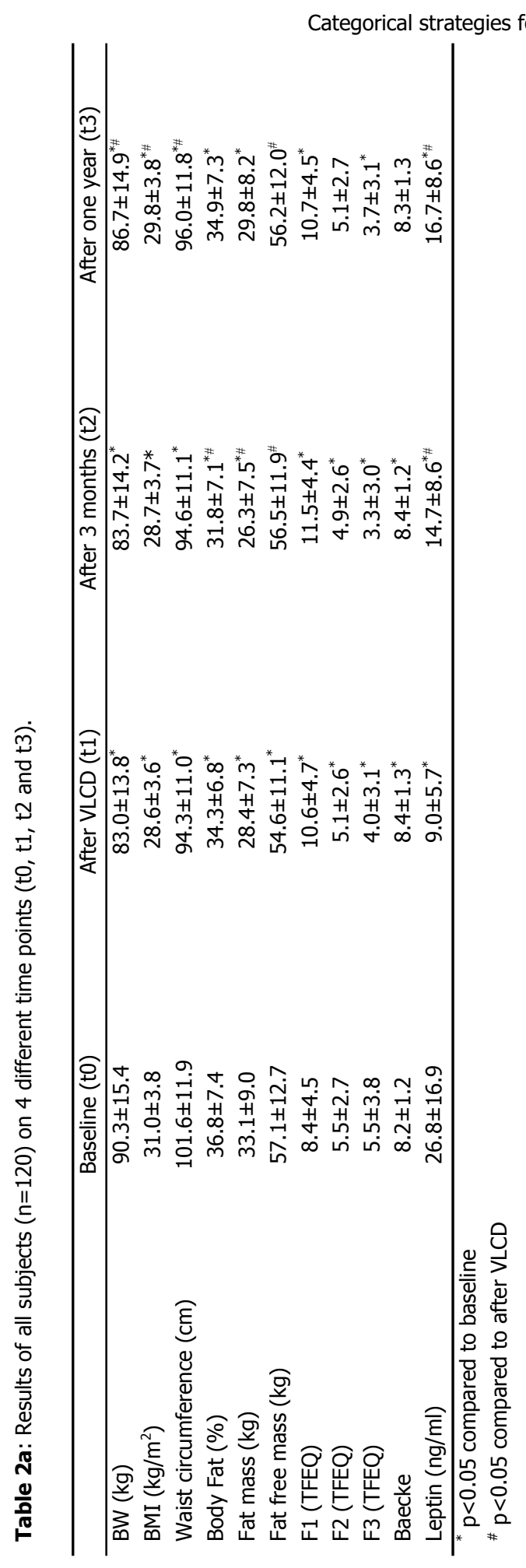


66 | Chapter 5

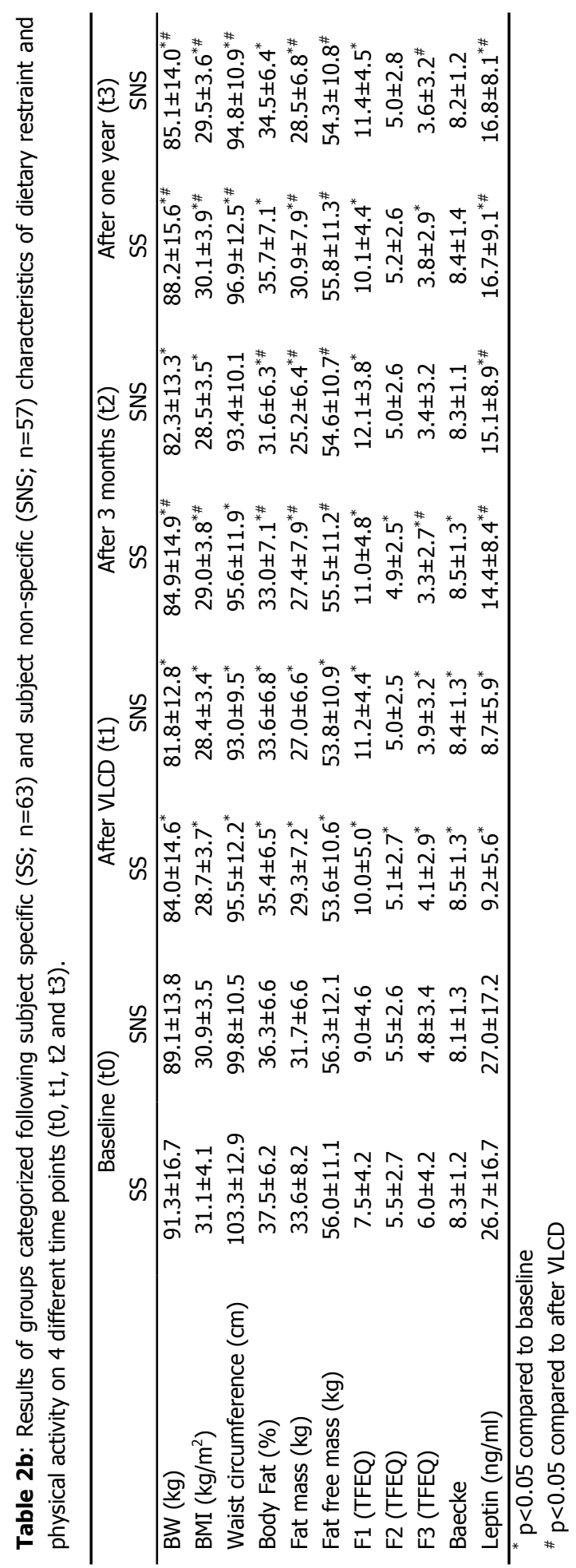




\section{RESULTS}

\section{Subject characteristics at 1 year assessment}

Taking all subjects together, body weight (BW) loss during the VLCD was $7.0 \pm 3.1 \mathrm{~kg}$. Furthermore, BMI, waist circumference, \%body fat (\%BF), FM, FFM, disinhibition (F2 of the TFEQ), hunger feelings (F3 of the TFEQ), and leptin concentrations decreased significantly, whereas dietary restraint (F1 of the TFEQ) and physical activity increased significantly (table 2a). At 3 months (t2) \%BF and FM were significantly decreased as compared to after weight loss ( $\mathrm{t} 1)$, whereas FFM and leptin levels were significantly increased. At 1y (t3) BW, BMI, waist circumference, FFM and leptin concentrations were significantly increased compared to t1 (table 2a). BW regain after 1y WM was $56.3 \pm 55.0 \%$. All subject characteristics are shown in table $2 a$. The characteristics of the subjects that dropped out were not statistically different from the subjects that remained in the study.

\section{Influence of different guidelines during weight maintenance}

During WM 39 subjects received guidelines by mail and 81 through a specially developed encrypted web page. BW regain after one year was not significantly different between these two groups $(53.3 \% \pm 56.3$ vs. $62.3 \% \pm 52.6$ respectively, $p=0.41)$, which shows that BW regain was not influenced by the way subjects received the guidelines. Afterwards subjects were asked whether they really had read the guidelines they received. 100 confirmed that they actually read the guidelines (of which 51 agreed that the guidelines were in one way or the other helpful to control their weight), 20 admitted that they did not read them at all. Again, no correlation was found between BW regain and whether subjects had read the guidelines or not $(56.1 \% \pm 53.7$ vs. $57.0 \% \pm 62.5$, $\mathrm{p}=0.95$ ) nor between BW regain and whether subjects found the guidelines helpful to control their weight or not $(55.1 \% \pm 54.9$ vs. $57.1 \% \pm 55.5, p=0.85)$.

Comparing the results of the groups categorized following subject specific (SS) $(26 \mathrm{~m} / 37 \mathrm{f})$ and subject non-specific (SNS) $(23 \mathrm{~m} / 34 \mathrm{f})$ characteristics, there were no statistically significant differences between the groups at any of the four measured time points (table $2 \mathrm{~b}$ ).

Subjects were also asked what category of guidelines they preferred. Subjects receiving guidelines opposite their preference showed a better WM than subjects receiving preferred guidelines (BW regain: $49.7 \% \pm 53.3$ vs. $72.8 \% \pm 56.5, p<0.05$ ).

With respect to the kind of guidelines received, no difference was observed in BW regain or any other variables.

\section{Compliancy for dietary restraint and physical activity}

Table 3 presents compliance of the 8 different category groups for dietary restraint (F1), physical activity (Baecke questionnaire), and BW, at the four time points. Dietary disciplined subjects showed good compliance since they kept their increased F1 score during weight loss high. Other subjects showed no compliance for dietary restraint, or for the Baecke score (table 3). Surprisingly, "non-disciplined" subjects with placebo guidelines (plac SS) showed a significant increase in F1 score at 3 months WM (t2) as compared to after weight loss (t1) (table 3 ). This increase was not present immediately after weight loss and as a result these subjects were characterized as "non-disciplined". Whereas, when examined at $\mathrm{t} 2$, they would be characterized as being dietary disciplined and according to the placebo guidelines, SNS. In all groups, BW significantly decreased during weight loss (table 3 ). After weight loss, only the dietary disciplined subjects with 
opposite guidelines and the "non-disciplined" subjects with placebo guidelines (who were in fact also dietary disciplined subjects with opposite guidelines) showed greater WM (\%BW regain: $27.3 \pm 56.9 \%$ ) then the other groups (\%BW regain $62.1 \pm 53.0 \%$ ).

\section{Measured capability}

With respect to capability, differences appeared between diet related and activity related capability. During weight loss, subjects with an increased dietary restraint had significantly less BW regain than subjects with an increased physical activity (Baecke questionnaire) $(35.5 \% \pm 53.2$ vs. $68.5 \% \pm 46.4, \mathrm{p}<0.05)$. Within these groups the activity guidelines appeared to stimulate dietary disciplined subjects to control their weight, while activity related disciplined subjects had no benefit of these, for them subject category specific, activity guidelines (BW regain: $25.2 \% \pm 59.5$ vs. $74.3 \% \pm 49.6$ resp., $\mathrm{p}<0.05)$.

\section{Successful vs. unsuccessful weight maintenance}

Subjects were categorized into 2 distinct groups according to either high or low rates of weight change over the follow-up period in order to identify factors that distinguish successful subjects from unsuccessful subjects. Based upon Weinsier's analysis, we assessed relative success in WM using the $10 \%$ weight regain criterion (44). A distinct break below and above a $10 \%$ weight regain appeared. After one year WM, 99 subjects $(41 \mathrm{~m} / 58 \mathrm{f})$ regained more than $10 \%$ of their weight, and 21 subjects $(8 \mathrm{~m} / 13 \mathrm{f})$ regained no, or less than $10 \%$ of their weight. Comparing the successful group with the unsuccessful group, most interestingly the groups appeared to be significantly different in baseline BMI (respectively $32.7 \pm 4.9$ vs. $30.7 \pm 3.5 \mathrm{~kg} / \mathrm{m}^{2}, \mathrm{p}<0.05$ ), and baseline waist circumference $(106.5 \pm 14.0$ vs. $100.6 \pm 11.2 \mathrm{~cm}, \mathrm{p}<0.05)$ and tended to have a higher baseline FM ( $35.2 \pm 10.6$ vs. $32.1 \pm 6.6 \mathrm{~kg}, \mathrm{p}=0.06)$. The groups were similar in baseline BW, age and height (table 4). During the whole study (t3-t0) the successful subjects increased their dietary restraint significantly more as compared to the unsuccessful subjects $(\Delta \mathrm{F} 1: 4.8 \pm 5.0$ vs. $1.8 \pm 3.9, \mathrm{p}<0.01)$, whereas their general hunger feelings were significantly reduced $(\Delta \mathrm{F} 3:-4.0 \pm 4.9$ vs. $-1.2 \pm 2.7, \mathrm{p}<0.05)$ (table 5$)$. During WM (t3-t1) the successful subjects had a significantly smaller change in leptin concentrations as compared to the unsuccessful subjects ( $3.4 \pm 4.6$ vs. $8.8 \pm 5.7, \mathrm{p}<0.001$ ) (table 5 ). Moreover, FM/FFM during WM was found to be negatively correlated with \%BW regain $(r=-0.2, p<0.05)$. Baseline FM was positively correlated with $\Delta F M$ (t0-t1) $(r=0.6$, $\mathrm{p}<0.001)$. During VLCD (t1-t0) $\Delta \mathrm{F} 1$ was inversely correlated with $\Delta \mathrm{F} 2(\mathrm{r}=-0.4, \mathrm{p}<0.001)$. BW regain was negatively correlated with weight loss during VLCD $(r=-0.02, p<0.05)$. Leptin was correlated positively with FM at all measured time points $(r=0.6, p<0.001)$. Finally, $\Delta$ leptin concentrations during $\mathrm{WM}$ were positively correlated with $\triangle \mathrm{FM}$ and with $\% B W$ regain at $1 y(r=0.2, p=0.01)$.

Table 5: Results of successful (S) $(n=21)$ and unsuccessful $(U)(n=99)$ groups.

\begin{tabular}{lcc}
\hline & $\mathrm{S}$ & $\mathrm{U}$ \\
\hline$\Delta$ Body weight (t0-t1) & $7.5 \pm 3.4$ & $7.2 \pm 3.1$ \\
$\Delta$ Fat mass (t0-t1) & $4.9 \pm 4.2$ & $4.7 \pm 2.7$ \\
$\Delta$ Fat free mass (t0-t1) & $2.5 \pm 2.0$ & $2.4 \pm 2.2$ \\
$\Delta$ Fat mass/fat free mass (t0-t1) & $9.1 \pm 25.6$ & $2.9 \pm 7.6^{\#}$ \\
$\Delta$ F1 (t3-t0) & $4.8 \pm 5.0$ & $1.8 \pm 3.9^{*}$ \\
$\Delta$ F2 (t3-t0) & $-0.38 \pm 2.9$ & $-0.41 \pm 2.1$ \\
$\Delta$ F3 (t3-t0) & $-4.0 \pm 4.9$ & $-1.2 \pm 2.7^{*}$ \\
Leptin (t3-t1) & $3.4 \pm 4.6$ & $8.8 \pm 5.7^{*}$ \\
\hline
\end{tabular}

${ }^{*} p<0.05 \mathrm{U}$ versus $\mathrm{S},{ }^{*} p=0.06 \mathrm{U}$ versus $\mathrm{S}$ 


\section{DISCUSSION}

During 1 WM no difference was found between subjects receiving subject category specific (SS) guidelines and subjects receiving subject category non-specific (SNS) guidelines. In contrast to our hypothesis SS, guidelines did not lead to better WM. The way the subjects received the guidelines (by mail or internet), nor the kind of guidelines they received, were related to WM. In this respect, Harvey-Berino and colleagues (45, 46) reported similar results. Comparing dietary disciplined subjects and activity related disciplined subjects, dietary disciplined subjects showed significantly better WM after weight loss compared to activity related disciplined subjects. Moreover, WM was even better when dietary disciplined subjects received additional activity, SNS, guidelines. Opposite to their capability related discipline, the activity guidelines may have contained new useful information, which dietary disciplined subjects could use for BW control. Also "non-disciplined" subjects with placebo, SS, guidelines showed good WM. These subjects showed a later significant increase in dietary restraint (table 3). In all probability, they have been misjudged and therefore misplaced, because they were in fact also dietary disciplined receiving opposite, SNS, guidelines. This confirms the success of dietary disciplined behavior with additional SNS guidelines, while the type of opposite guidelines does not seem to matter. Previously, similar results were reported with respect to dietary discipline shown by an increase in dietary restraint. Less weight regain was predicted by larger early increases in cognitive dietary restraint $(2,16,47)$. Contrarily, an increase in physical activity hardly appeared to promote better WM $(1,16,48)$. In line with the results of other studies, an increase in physical activity without an increase in dietary restraint does not seem to help people to maintain their weight after weight reduction, while an increase in dietary restraint alone does seem to help $(9,16)$. In our study the increase in physical activity was marginal ( $<1$ Baecke Item), this could also be a reason that it did not promote WM. In general, subjects receiving guidelines opposite their preference showed less weight regain than subjects receiving preferred guidelines. As far as we know, very little research, concerning subject specific preference, has been done in this field so far. One study by Renjilian and colleagues (2001) randomly assigned 75 obese subjects to either their preferred or their non-preferred treatment modality. They observed no significant effects of treatment preference or the interaction of treatment preference by type of therapy (49). In our study, we actually found that preferred strategies showed significantly poorer WM results compared to non-preferred strategies. We suggest that new, unknown guidelines may have given subjects "renewed" ideas on how to maintain their lower body weight, while the familiar guidelines that subjects obviously applied already, did not add anymore to WM.

All subjects were categorized into 2 distinct groups according to either high or low rates of weight change over the period of follow-up. A distinct break below and above a $10 \%$ weight regain appeared. Analyzing the results it appeared to be more likely to maintain weight after weight loss, when, in addition to an early increase in dietary restraint, baseline BMI, waist circumference and FM were high. FM loss was positively correlated with baseline FM, which indicates that subjects with a high initial FM also lost most fat during VLCD. Subjects with the highest weight loss during VLCD (both relative and absolute) showed best WM after one year. A meta-analysis done by Anderson et al. showed similar results; after weight loss of more then $20 \mathrm{~kg}$ individuals maintained significantly more weight loss than after weight loss of less than $10 \mathrm{~kg}(50)$. Taking body composition into account, unsuccessful subjects lost and regained weight in the usual ratio (2/3FM and $1 / 3 \mathrm{FFM})$, whereas successful subjects showed changes in body composition during WM. BW remained reduced with FM slowly decreasing and FFM 
slowly increasing. Body composition appeared to change on behalf of the FFM. Previously Dulloo and colleagues (1999) described this sparing effect in which the body composition of a given individual changes continuously towards a leaner body composition during the course of starvation (51). In our study we found this FFM sparing effect during the WM phase. Taking these observations together, subjects with a relative high baseline BMI, waist circumference and FM appeared to lose relatively more weight and body fat, and showed at the same time better WM, related to effective changes in body composition.

As previously has been shown, we observed a strong positive relationship between serum leptin concentrations and FM at any measured time point (52-55). After 1y WM unsuccessful subjects showed an increase in their leptin concentrations compared to after weight loss, as a consequence of their regain in FM. Successful subjects did not regain FM and thus kept their leptin concentrations reduced. All in all, leptin appeared to be dependent on FM in (both successful and unsuccessful) obese subjects.

Subjects that were able to increase their dietary restraint during the whole study period appeared to be better in controlling or maintaining their weight, similar to previously reported observations $(2,16)$. McGuire and colleagues (2001) found that increases in dietary restraint in the WM period were related to decreases in BW (47). An increase in dietary restraint (F1 score) is often related to a decrease in disinhibition (F2 score) (5658). In this study we found this correlation as well. Moreover, weight gainers appear to be low in dietary restraint and high in disinhibition $(14,20,56)$. This implies that dietary restraint only can be sustained with very low chance of inhibition of restraint. Moreover, our results showed that successful subjects appeared to increase dietary restraint and at the same time reduce general hunger feelings. Thus, subjects that do not suffer from hunger feelings may not be vulnerable to inhibit dietary restraint, therefore sustain or even increase dietary restraint, which will be rewarded by WM. Subjects may have a genetic background for their dietary restraint behavior and lower vulnerability for disinhibition. Steinle and colleagues (2002) observed that eating behavior scores were associated with obesity and obesity-related phenotypes (59).

The overall conclusion from this study is that after weight loss, type of guidelines (dietary, activity, placebo) is not related to the magnitude of WM, whereas guidelines opposite to the subject's capability and preference are related. These only reach successful WM ( $<10 \%$ regain) in originally dietary disciplined subjects who are supported by characteristics such as a relatively high baseline BMI, waist circumference and FM, together with the ability to spare FFM. 


\section{REFERENCES}

1. Pasman WJ, Saris WH, Muls E, Vansant G, Westerterp-Plantenga MS. Effect of exercise training on long-term weight maintenance in weight- reduced men. Metabolism 1999;48:15-21.

2. Westerterp-Plantenga MS, Kempen KP, Saris WH. Determinants of weight maintenance in women after diet-induced weight reduction. Int J Obes Relat Metab Disord 1998;22:1-6.

3. WHO. Obesity: preventing and managing the global epidemic. Report of a WHO consultation. World Health Organ Tech Rep Ser 2000;894:i-xii, 1-253.

4. Burton BT, Foster WR. Health implications of obesity: an NIH Consensus Development Conference. J Am Diet Assoc 1985;85:1117-21.

5. Ditschuneit HH, Flechtner-Mors M. Value of structured meals for weight management: risk factors and long- term weight maintenance. Obes Res 2001;9 Suppl 4:284S-289S.

6. Pi-Sunyer FX, Becker DM, Bouchard C, al. e. NHLBI Obesity education initiative expert panel on the identification, evaluation, and treatment of overweight and obesity in adults. Obes Res 1998;6:51S-209S.

7. Pasman WJ, Rossner S, Westerterp-Plantenga MS, Saris WH. Body weight changes after treatment of obesity or pregnancy. Milan, Italy: Edra, 1999.

8. Pasman WJ, Saris WH, Westerterp-Plantenga MS. Predictors of weight maintenance. Obes Res 1999;7:43-50.

9. Leermakers EA, Perri MG, Shigaki CL, Fuller PR. Effects of exercise-focused versus weight-focused maintenance programs on the management of obesity. Addict Behav 1999;24:219-27.

10. Anderson JW, Vichitbandra S, Qian W, Kryscio RJ. Long-term weight maintenance after an intensive weight-loss program. J Am Coll Nutr 1999;18:620-7.

11. Ewbank PP, Darga LL, Lucas CP. Physical activity as a predictor of weight maintenance in previously obese subjects. Obes Res 1995;3:257-63.

12. McGuire MT, Wing RR, Klem ML, Hill JO. Behavioral strategies of individuals who have maintained long-term weight losses. Obes Res 1999;7:334-41.

13. Perri MG, Sears SF, Jr., Clark JE. Strategies for improving maintenance of weight loss. Toward a continuous care model of obesity management. Diabetes Care 1993;16:200-9.

14. McGuire MT, Wing RR, Klem ML, Lang W, Hill JO. What predicts weight regain in a group of successful weight losers? J Consult Clin Psychol 1999;67:177-85.

15. Leslie WS, Lean ME, Baillie HM, Hankey CR. Weight management: a comparison of existing dietary approaches in a work-site setting. Int J Obes Relat Metab Disord 2002;26:1469-75.

16. Lejeune MP, Van Aggel-Leijssen DP, Van Baak MA, Westerterp-Plantenga MS. Effects of dietary restraint vs exercise during weight maintenance in obese men. Eur J Clin Nutr 2003;57:1338-44.

17. Bellisle F, Dalix A. Cognitive restraint can be offset by distraction, leading to increased meal intake in women. Am J Clin Nutr 2001;74:197-200.

18. Karlsson J, Persson LO, Sjostrom L, Sullivan M. Psychometric properties and factor structure of the Three-Factor Eating Questionnaire (TFEQ) in obese men and women. Results from the Swedish Obese Subjects (SOS) study. Int J Obes Relat Metab Disord 2000;24:1715-25.

19. Lindroos $A K$, Lissner $L$, Mathiassen $M E$, et al. Dietary intake in relation to restrained eating, disinhibition, and hunger in obese and nonobese Swedish women. Obes Res 1997; 5:175-82.

20. Lawson OJ, Williamson DA, Champagne CM, et al. The association of body weight, dietary intake, and energy expenditure with dietary restraint and disinhibition. Obes Res 1995;3:153-61.

21. Lowe MR, Kleifield EI. Cognitive restraint, weight suppression, and the regulation of eating. Appetite 1988;10:159-68.

22. Stunkard AJ, Messick S. The three-factor eating questionnaire to measure dietary restraint, disinhibition and hunger. J Psychosom Res 1985;29:71-83. 
23. Westerterp KR, Nicolson NA, Boots JM, Mordant A, Westerterp MS. Obesity, restrained eating and the cumulative intake curve. Appetite 1988;11:119-28.

24. Baecke JA, Burema J, Frijters JE. A short questionnaire for the measurement of habitual physical activity in epidemiological studies. Am J Clin Nutr 1982;36:936-42.

25. Jacobs DR, Jr., Ainsworth BE, Hartman TJ, Leon AS. A simultaneous evaluation of 10 commonly used physical activity questionnaires. Med Sci Sports Exerc 1993;25:81-91.

26. Philippaerts RM, Westerterp KR, Lefevre J. Doubly labelled water validation of three physical activity questionnaires. Int J Sports Med 1999;20:284-9.

27. Westerterp-Plantenga MS, Pasman WJ, Yedema MJ, Wijckmans-Duijsens NE. Energy intake adaptation of food intake to extreme energy densities of food by obese and nonobese women. Eur J Clin Nutr 1996;50:401-7.

28. Westerterp-Plantenga MS, Rolland V, Wilson SA, Westerterp KR. Satiety related to $24 \mathrm{~h}$ diet-induced thermogenesis during high protein/carbohydrate vs high fat diets measured in a respiration chamber. Eur J Clin Nutr 1999;53:495-502.

29. Westerterp-Plantenga MS, Goris AH, Meijer EP, Westerterp KR. Habitual meal frequency in relation to resting and activity-induced energy expenditure in human subjects: the role of fat-free mass. Br J Nutr 2003;90:643-9.

30. Westerterp-Plantenga MS, Kovacs EM, Melanson KJ. Habitual meal frequency and energy intake regulation in partially temporally isolated men. Int J Obes Relat Metab Disord 2002;26:102-10.

31. Foster GD, Wadden TA, Kendrick ZV, Letizia KA, Lander DP, Conill AM. The energy cost of walking before and after significant weight loss. Med Sci Sports Exerc 1995;27:888-94.

32. Morris JN, Hardman AE. Walking to health. Sports Med 1997;23:306-32.

33. Blair SN, Kohl HW, Gordon NF, Paffenbarger RS, Jr. How much physical activity is good for health? Annu Rev Public Health 1992;13:99-126.

34. Votruba SB, Horvitz MA, Schoeller DA. The role of exercise in the treatment of obesity. Nutrition 2000;16:179-88.

35. Westerterp KR. Pattern and intensity of physical activity. Nature 2001;410:539.

36. Westerterp KR. Obesity and physical activity. Int J Obes Relat Metab Disord 1999;23 Suppl 1:59-64.

37. Westerterp-Plantenga MS, Verwegen CR, Ijedema MJ, Wijckmans NE, Saris WH. Acute effects of exercise or sauna on appetite in obese and nonobese men. Physiol Behav 1997; 62:1345-54.

38. Van Aggel-Leijssen DP, Saris WH, Hul GB, Van Baak MA. Long-term effects of lowintensity exercise training on fat metabolism in weight-reduced obese men. Metabolism 2002; 51:1003-10.

39. Fogelholm M, Kukkonen-Harjula K, Oja P. Eating control and physical activity as determinants of short-term weight maintenance after a very-low-calorie diet among obese women. Int J Obes Relat Metab Disord 1999;23:203-10.

40. van Marken Lichtenbelt WD, Westerterp KR, Wouters L. Deuterium dilution as a method for determining total body water: effect of test protocol and sampling time. $\mathrm{Br} \mathrm{J}$ Nutr 1994;72:491-7.

41. Schoeller DA, van Santen E, Peterson DW, Dietz W, Jaspan J, Klein PD. Total body water measurement in humans with 180 and 2H labeled water. Am J Clin Nutr 1980;33:268693.

42. Westerterp KR, Wouters L, van Marken Lichtenbelt WD. The Maastricht protocol for the measurement of body composition and energy expenditure with labeled water. Obes Res 1995;3 Suppl 1:49-57.

43. Herman CP, Polivy J. Restrained eating. Philadelphia: Saunders, W.B., 1980.

44. Weinsier RL, Hunter GR, Desmond RA, Byrne NM, Zuckerman PA, Darnell BE. Free-living activity energy expenditure in women successful and unsuccessful at maintaining a normal body weight. Am J Clin Nutr 2002;75:499-504.

45. Harvey-Berino J, Pintauro S, Buzzell P, Gold EC. Effect of internet support on the longterm maintenance of weight loss. Obes Res 2004;12:320-9.

46. Harvey-Berino J, Pintauro SJ, Gold EC. The feasibility of using Internet support for the maintenance of weight loss. Behav Modif 2002;26:103-16. 
47. McGuire MT, Jeffery RW, French SA, Hannan PJ. The relationship between restraint and weight and weight-related behaviors among individuals in a community weight gain prevention trial. Int J Obes Relat Metab Disord 2001;25:574-80.

48. van Aggel-Leijssen DP, Saris WH, Wagenmakers AJ, Senden JM, van Baak MA. Effect of exercise training at different intensities on fat metabolism of obese men. J Appl Physiol 2002;92:1300-9.

49. Renjilian DA, Perri MG, Nezu AM, McKelvey WF, Shermer RL, Anton SD. Individual versus group therapy for obesity: effects of matching participants to their treatment preferences. J Consult Clin Psychol 2001;69:717-21.

50. Anderson JW, Konz EC, Frederich RC, Wood CL. Long-term weight-loss maintenance: a meta-analysis of US studies. Am J Clin Nutr 2001;74:579-84.

51. Dulloo AG, Jacquet J. The control of partitioning between protein and fat during human starvation: its internal determinants and biological significance. $\mathrm{Br}$ J Nutr 1999;82:339-56.

52. Sartorio A, Agosti F, Resnik M, Lafortuna CL. Effects of a 3-week integrated body weight reduction program on leptin levels and body composition in severe obese subjects. J Endocrinol Invest 2003;26:250-6.

53. Nagy TR, Davies SL, Hunter GR, Darnell B, Weinsier RL. Serum leptin concentrations and weight gain in postobese, postmenopausal women. Obes Res 1998;6:257-61.

54. Neuhauser-Berthold M, Herbert BM, Luhrmann PM, et al. Resting metabolic rate, body composition, and serum leptin concentrations in a free-living elderly population. Eur J Endocrinol 2000;142:486-92.

55. Sudi KM, Gallistl S, Borkenstein MH, et al. Effects of weight loss on leptin, sex hormones, and measures of adiposity in obese children. Endocrine 2001;14:429-35.

56. Dykes J, Brunner EJ, Martikainen PT, Wardle J. Socioeconomic gradient in body size and obesity among women: the role of dietary restraint, disinhibition and hunger in the Whitehall II study. Int J Obes Relat Metab Disord 2004;28:262-8.

57. Hays NP, al. e. Eating behavior correlates of adult weight gain and obesity in healthy women aged 55-65 y. Am J Clin Nutr 2002;75:476-83.

58. Williamson DA, Lawson OJ, Brooks ER, et al. Association of body mass with dietary restraint and disinhibition. Appetite 1995;25:31-41.

59. Steinle NI, Hsueh WC, Snitker S, et al. Eating behavior in the Old Order Amish: heritability analysis and a genome-wide linkage analysis. Am J Clin Nutr 2002;75:1098106. 
74 
Successful long-term weight maintenance, a $\mathbf{2 y}$ follow-up

Neeltje Vogels, Margriet S Westerterp-Plantenga

Submitted for publication 


\section{ABSTRACT}

Objective: Find factors associated with successful weight maintenance (WM) in overweight and obese subjects, after a very low calorie diet (VLCD).

Research Methods and Procedures: 133 subjects followed a VLCD (2.1 MJ/d) for six

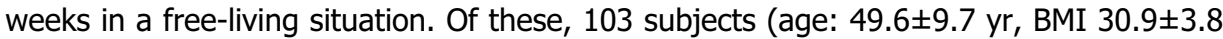
$\mathrm{kg} / \mathrm{m}^{2}$ ) completed the following 2 years WM period. Body weight (BW), body composition, leptin concentration, attitude towards eating, and physical activity were determined right before (t0) and after (t1) the VLCD, after 3 months (t2), after 1y (t3), after 1.5y (t4) and after 2y (t5).

Results: BW loss during VLCD was $7.2 \pm 3.1 \mathrm{~kg}$. After $2 y$ follow-up BW regain was $69.0 \pm 98.4 \%$. After $2 y$ WM, 13 subjects were successful ( $<10 \%$ BW regain) and 90 unsuccessful ( $\geq 10 \% \mathrm{BW}$ regain). At baseline, these groups were significantly different in BMI (resp. $33.7 \pm 4.7$ vs. $\left.30.5 \pm 3.5 \mathrm{~kg} / \mathrm{m}^{2}, \mathrm{p}<0.05\right)$ and fat mass $(38.3 \pm 9.8$ vs. $32.1 \pm 8.3$ $\mathrm{kg}, \mathrm{p}<0.05)$. Successful subjects increased their dietary restraint significantly more during the whole study period (F1: $-4.9 \pm 4.4$ vs. $-2.1 \pm 3.8$ ). Furthermore, \%BW regain was associated with the amount of percent body fat lost during VLCD, which indicates that the more fat lost, the better the WM, suggesting a fat free mass sparing effect.

Conclusion: Characteristics such as the ability to increase dietary restraint and maintain this high level of restraint, fat free mass sparing, and a relatively high baseline BMI and fat mass were associated with successful long-term WM ( $<10 \%$ regain after $2 y$ ). 


\section{INTRODUCTION}

Overweight and obesity are emerging as major health problems. Obese individuals and even individuals with mild to moderate overweight have increased risk for multiple conditions, many of which are associated with a relatively high rate of morbidity and mortality, such as type 2 diabetes, hypertension and coronary heart disease $(1,2)$. The risks associated with many of these co morbid conditions may be reduced with modest weight loss. Clinical studies suggest that minimal, sustained weight loss of 5 to $10 \%$ can reduce or eliminate obesity-related disorders (3).

Weight loss is difficult to achieve and maintaining the weight loss is an even greater challenge (4-6). Weight cycling and relapse of body weight (BW) are common features after a weight loss intervention. Strategies to improve the maintenance of weight loss have resulted in behavior modification: changes in diet and increased physical activity (7-9). These interventions show a great promise for improving long-term outcome (8). To maintain weight loss some people may prefer to change their dietary pattern while others prefer to become more physically active. Most importantly, one needs to continuously keep up with these changes as long as one lives $(10,11)$. In an earlier study we investigated the effect of different guidelines based on subject specific characteristics of dietary restraint and physical activity, on weight maintenance (WM) in overweight and obese subjects, after a period of 6-weeks weight loss. Data were analyzed after 1-year WM and the main outcome was that the type of guidelines (dietary, activity, placebo) received was not related to the magnitude of WM, whereas guidelines opposite to the subject's capability and preference were related. Successful WM $(<10 \%$ BW regain) was reached only in originally dietary disciplined subjects who were supported by characteristics such as a relatively high baseline BMI, waist circumference and fat mass, together with the ability to spare fat free mass.

The subjects were measured again after 1.5 year and after 2 years WM. The purpose of the present study is to find factors associated with successful long-term WM and compare the results with the 1 year data. The overall results are important in the context of obesity prevention and treatment for people at risk.

\section{RESEARCH METHODS AND PROCEDURES}

\section{Subjects}

Subjects were recruited by advertisements in local newspapers. The ads asked for subjects that were willing to participate in a long-term weight loss study. At the screening visit, subjects were explained that the study started with a $6 \mathrm{w}$ diet after which WM was measured for 2-3 years. They were told to receive different guidelines for WM. The guidelines were presented as information letters applicable and readable for every individual, and contained general information based on scientific research about diet (e.g. portion size, meal frequency, macronutrients, snacks, breakfast, fibers and water etc (12-15)), or about exercise (e.g. physical activity level, low/moderate/high intensity, activity induced decrease in appetite, weight maintenance, activity energy expenditure as compared to total energy expenditure, maintain fat free mass, prevent osteoporosis, importance of walking and cycling, etc. (16-22)), or about diet + exercise $(23,24)$, or about all other cues but diet + exercise (placebo or distraction from obsessive dieting). Frequent dieting is one of the strategies for subjects to maintain their weight, while it has been shown that this can have a contrary effect (6). The placebo guidelines had the 
objective to divert the attention from all diet and activity cues and give subjects other alternatives to concentrate on instead (e.g. reading, painting, solving puzzles, visiting cinema/theatre or play or listen to music etc.). Guidelines were sent by mail or through a specially developed encrypted web page.

150 subjects complied with the selection criteria: BMI $>25 \mathrm{~kg} / \mathrm{m}^{2}$ and age between 20 and 65 years. The exclusion criteria were: use of other research medication or diet up to 30 days prior to the study, and participation in an other scientific study 30 days prior to the study. 133 subjects started with a Very Low Calorie Diet (VLCD) for six weeks. Before the start 17 subjects had withdrawn for several reasons (e.g. not enough motivation). The 133 subjects (age: $48.1 \pm 9.5$ y, BMI: $31.1 \pm 3.7 \mathrm{~kg} / \mathrm{m}^{2}$ ) who participated in the 6-weeks energy restriction period underwent measurements before and after weight loss, at three months and at one year. At three months WM, another 13 subjects dropped-out for several reasons. 120 subjects (age: $49.0 \pm 9.8$ y, BMI $31.0 \pm 3.8 \mathrm{~kg} / \mathrm{m}^{2}$ ) completed 1-year of the study (25). Another 17 subjects dropped out during the second

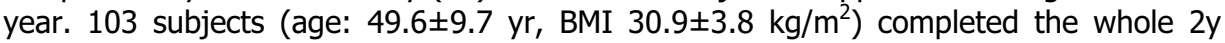
study. Intention-to-treat analysis showed that the baseline characteristics of these 103 subjects were not different from the 120 subjects that completed 1-year of the study, nor was there any difference in baseline characteristics or WM parameters between the characteristics of the subjects that dropped out and the 103 subjects that remained in the study. Subjects gave their written informed consent to participate in the study, which was approved by the Medical Ethical Committee of the Maastricht University.

\section{Design}

The study consisted of a dietary weight loss intervention in free-living circumstances of six weeks and a WM period of 2 years. The subjects $(n=103)$ followed an energy restriction program for six weeks in a free-living situation. The program consisted of a VLCD (Modifast, Novartis Nutrition, Brussels, Belgium) containing $2.1 \mathrm{MJ} / \mathrm{d}$ (500 kcal/d). It provides $50 \mathrm{~g}$ carbohydrates, $52 \mathrm{~g}$ protein, $7 \mathrm{~g}$ fat and a vitamins- and minerals content which meets the Dutch recommended daily allowance, in three sachets per day consumed as prescribed. The VLCD was dissolved in water to make a soup, milkshake or dessert. In addition to the VLCD, subjects were allowed to consume two pieces of fruit and an unrestricted amount of vegetables every day, without sauces or vinaigrettes.

Measurements of body weight, body composition, leptin concentration, dietary restraint and physical activity took place right before (t0) and after (t1) the VLCD, after 3 months $(\mathrm{t} 2)$, after 1 year ( $\mathrm{t} 3)$, after 1.5 year ( $\mathrm{t} 4)$ and after 2 years (t5).

\section{Anthropometry}

Measuring height was performed using a wall-mounted stadiometer (Seca, model 220, Hamburg, Germany) and body weight (BW) using a digital balance accurate to $0.1 \mathrm{~kg}$ (Sauter D7470, Ebingen, Germany). Measurements were executed in underwear, after an overnight fast and after voiding the bladder. BMI was calculated by BW/height ${ }^{2}$ $\left(\mathrm{kg} / \mathrm{m}^{2}\right)$. The waist circumference was measured at the site of the smallest circumference between the rib cage and the ileac crest, with the subjects in standing position.

\section{Body composition}

Body composition was measured using the deuterium dilution technique. ${ }^{2} \mathrm{H}_{2} \mathrm{O}$ dilution was used to measure total body water (TBW). Subjects were asked to collect a urine sample in the evening just before drinking the deuterium-enriched water solution. After 
ingestion of this solution, no further consumption was allowed. Ten hours after drinking the water solution, another urine sample was collected. The dilution of the deuterium isotope is a measure of the TBW of the subject. Deuterium was measured in the urine samples with an isotope ratio mass spectrometer (VG-Isogas Aqua Sira, VG Isogas, Middlewich, Cheshire, England). TBW was obtained by dividing the measured deuterium dilution space by 1.04 . Fat free mass (FFM) was calculated by dividing TBW by the hydration factor 0.73 (26-28).

\section{Attitude towards eating}

Eating behavior was analyzed using a validated Dutch translation of the Three Factor Eating Questionnaire (TFEQ) $(13,29)$. The TFEQ is a self-report measure of eating behaviors that are believed to be particularly relevant to the development and maintenance of overweight or obesity. The TFEQ includes three subscales: cognitive dietary restraint (Factor 1 ), inhibition of dietary restraint and emotional eating (Factor 2) and the general feeling of hunger (Factor 3) $(13,29)$. The factor cognitive dietary restraint is regarded as the best tool available for the psychometric assessment of restrained eating (30). It determines control over food intake to influence BW and body shape (e.g. "I consciously hold back at meals to keep from gaining weight") (31). The factor inhibition of restraint eating (Factor 2) refers to the tendency to lose control over eating when feeling hungry or when exposed to external stimuli (e.g. "Sometimes when I start eating, I just can't seem to stop") and emotional eating (which is also included in this factor) refers to the propensity to overeat in relation to negative mood states, e.g. when feeling lonely, anxious, or depressed (31). Factor 3 refers to the general feelings of hunger.

\section{Leptin}

Blood samples were obtained, following a 12-h overnight fast. Serum leptin concentrations were measured with a double-antibody, sandwich-type enzyme-linked immunosorbent assay that used a monoclonal antibody specific for human leptin. The lower limit of detection is $0.5 \mu \mathrm{g} / \mathrm{L}$ and the upper limit is $50 \mu \mathrm{g} / \mathrm{L}$. The intra- and interassay CVs were $9 \%$ and $12 \%$, respectively. The leptin concentrations of normalweight subjects range from 2 to $12 \mu \mathrm{g} / \mathrm{L}$.

\section{Physical activity}

An estimation of the physical activity level was determined using the validated Baecke questionnaire (32). The Baecke questionnaire consists of a work index, a sports index, a leisure time index and the total index (33).

\section{Statistical analysis}

We used repeated-measures analysis of variance (ANOVA) to test for differences between groups over time and 2-sample t tests to assess differences in single variables between groups (Statview SE GraphicsTM for Macintosh). Pearson correlation coefficients, $r$, were calculated to determine the relationship between selected variables. All statistical tests were two-sided, differences were considered significant at $p<0.05$. Values are expressed as mean \pm standard deviation (sd). 
Table 1: Characteristics (mean $\pm s d)$ of successful $(S)(n=13)$ and unsuccessful $(U)(n=90)$ subjects on baseline, after VLCD, after 3 months, after 1 year, after 1.5 year and after 2 years.

\begin{tabular}{|c|c|c|c|c|c|c|c|}
\hline & & $\begin{array}{c}\text { Baseline } \\
(\mathrm{t} 0)\end{array}$ & $\begin{array}{c}\text { After } \\
\text { VLCD (t1) }\end{array}$ & $\begin{array}{c}\text { After } 3 \mathrm{mo} \\
(\mathrm{t} 2)\end{array}$ & $\begin{array}{l}\text { After } 1 \mathrm{yr} \\
(\mathrm{t} 3)\end{array}$ & $\begin{array}{l}\text { After } 1.5 \\
\text { yr (t4) }\end{array}$ & $\begin{array}{l}\text { After } 2 \mathrm{yr} \\
\text { (t5) }\end{array}$ \\
\hline BW & $\mathrm{S}$ & $93.9 \pm 12.4$ & $87.4 \pm 12.8$ & $86.9 \pm 12.5$ & $87.7 \pm 13.0$ & $87.1 \pm 12.8$ & $84.8 \pm 12.0^{\dagger}$ \\
\hline$(\mathrm{kg})^{*}$ & $U$ & $89.4 \pm 15.1$ & $82.1 \pm 13.3$ & $83.0 \pm 13.5$ & $86.6 \pm 14.7$ & $87.7 \pm 14.5$ & $88.3 \pm 14.8$ \\
\hline BMI & $\mathrm{S}$ & $33.7 \pm 4.7^{\ddagger}$ & $31.4 \pm 5.0$ & $31.2 \pm 5.2$ & $31.4 \pm 4.9$ & $31.5 \pm 5.0$ & $30.4 \pm 4.7^{\dagger}$ \\
\hline$\left(\mathrm{kg} / \mathrm{m}^{2}\right)^{*}$ & U & $30.5 \pm 3.5$ & $28.0 \pm 3.1$ & $28.3 \pm 3.1$ & $29.6 \pm 3.5$ & $30.0 \pm 3.4$ & $30.1 \pm 3.5$ \\
\hline Waist circumfe- & $\mathrm{S}$ & $107.2 \pm 9.3$ & $100.8 \pm 8.7$ & $99.8 \pm 9.6$ & $98.8 \pm 10.1$ & $97.7 \pm 9.2$ & $95.1 \pm 9.6^{\dagger}$ \\
\hline rence $(\mathrm{cm})^{*}$ & U & $100.9 \pm 12.0$ & $93.2 \pm 10.8$ & $93.8 \pm 10.8$ & $95.3 \pm 11.8$ & $95.5 \pm 12.0$ & $95.9 \pm 12.0$ \\
\hline Body Fat & $\mathrm{S}$ & $40.2 \pm 7.2$ & $37.0 \pm 7.2$ & $33.9 \pm 9.0$ & $36.5 \pm 9.8$ & $38.1 \pm 7.5$ & $35.8 \pm 7.9^{\dagger}$ \\
\hline$(\%)^{*}$ & U & $36.2 \pm 7.4$ & $33.8 \pm 6.7$ & $31.3 \pm 6.7$ & $34.6 \pm 6.8$ & $35.3 \pm 7.2$ & $35.8 \pm 6.6$ \\
\hline Fat mass & S & $38.3 \pm 9.8^{\ddagger}$ & $32.8 \pm 9.5$ & $30.4 \pm 11.5$ & $32.8 \pm 11.1$ & $33.7 \pm 9.5$ & $30.6 \pm 9.4^{\dagger}$ \\
\hline$(\mathrm{kg})^{*}$ & U & $32.1 \pm 8.3$ & $27.6 \pm 6.4$ & $25.5 \pm 6.1$ & $29.6 \pm 6.9$ & $30.8 \pm 7.2$ & $31.0 \pm 7.3$ \\
\hline Fat free mass & $\mathrm{S}$ & $56.3 \pm 8.5$ & $54.6 \pm 7.3$ & $56.3 \pm 7.3$ & $55.8 \pm 9.0$ & $53.8 \pm 8.3$ & $54.1 \pm 8.0^{\dagger}$ \\
\hline$(\mathrm{kg})$ & U & $57.2 \pm 13.3$ & $54.6 \pm 11.6$ & $56.8 \pm 12.5$ & $56.5 \pm 12.4$ & $56.8 \pm 12.6$ & $56.2 \pm 11.8$ \\
\hline Dietary restraint & $\mathrm{S}$ & $7.1 \pm 4.7$ & $9.6 \pm 4.6$ & $12.4 \pm 4.4$ & $11.6 \pm 4.4$ & $10.4 \pm 3.7$ & $12.0 \pm 4.0^{\dagger}$ \\
\hline$(\mathrm{F} 1 \text { of TFEQ })^{*}$ & U & $8.6 \pm 4.4$ & $10.6 \pm 4.7$ & $11.4 \pm 4.4$ & $10.7 \pm 4.5$ & $10.9 \pm 4.3$ & $10.5 \pm 4.5$ \\
\hline Disinhibition & $\mathrm{S}$ & $6.3 \pm 2.4$ & $5.5 \pm 2.9$ & $5.5 \pm 2.8$ & $5.9 \pm 2.7$ & $5.6 \pm 3.1$ & $4.8 \pm 3.1$ \\
\hline (F2 of TFEQ) & U & $5.4 \pm 2.7$ & $5.0 \pm 2.6$ & $4.9 \pm 2.6$ & $5.1 \pm 2.7$ & $5.0 \pm 2.5$ & $4.8 \pm 2.8$ \\
\hline Hunger & $\mathrm{S}$ & $6.9 \pm 4.3$ & $5.2 \pm 3.0$ & $4.4 \pm 2.9$ & $4.2 \pm 2.4$ & $4.3 \pm 2.9$ & $3.5 \pm 3.0$ \\
\hline (F3 of TFEQ) & U & $5.5 \pm 3.9$ & $4.0 \pm 3.2$ & $3.3 \pm 3.1$ & $3.7 \pm 3.1$ & $3.6 \pm 3.2$ & $3.2 \pm 3.1$ \\
\hline Physical activity & $\mathrm{S}$ & $7.9 \pm 1.4$ & $8.3 \pm 1.9$ & $8.3 \pm 1.5$ & $8.2 \pm 1.8$ & $8.3 \pm 1.6$ & $8.3 \pm 1.3$ \\
\hline (Baecke) & U & $8.2 \pm 1.2$ & $8.4 \pm 1.2$ & $8.5 \pm 1.2$ & $8.4 \pm 1.2$ & $8.4 \pm 1.2$ & $8.4 \pm 1.1$ \\
\hline Leptin & S & $31.5 \pm 18.9$ & $13.4 \pm 8.6$ & $21.2 \pm 13.8$ & $19.5 \pm 11.2$ & $19.7 \pm 12.6$ & $18.8 \pm 12.9^{\dagger}$ \\
\hline$(\mu \mathrm{g} / \mathrm{L})$ & U & $26.3 \pm 17.0$ & $8.4 \pm 5.0$ & $13.8 \pm 7.5$ & $16.3 \pm 8.0$ & $18.4 \pm 10.6$ & $19.1 \pm 9.2$ \\
\hline
\end{tabular}

${ }^{*}$ Overall group $x$ time interaction was significant, $\mathrm{P}<0.05$ (2-factor repeated measures ANOVA)

${ }^{\dagger} \mathrm{P}<0.05$ (2-factor repeated-measures ANOVA with group $x$ time interaction from t1 to t5)

${ }^{\ddagger}$ Significantly different from unsuccessful subjects at baseline, $\mathrm{P}<0.05$ (t-test)

\section{RESULTS}

Taking all subjects together, body weight (BW) loss during the VLCD was $7.2 \pm 3.1 \mathrm{~kg}$.

Subjects were categorized into two distinct groups according to either high or low rates of weight change over the follow-up period of 2 years in order to identify factors that distinguish successful subjects from unsuccessful subjects. Based upon Weinsier's analysis, we assessed relative success in WM using the $10 \%$ weight regain criterion (34). A distinct break below and above a $10 \%$ weight regain appeared. After 2-y WM, 90 subjects regained more than $10 \%$ of their weight, and 13 subjects regained no, or less than $10 \%$ of their weight. Comparing the successful group with the unsuccessful group, most interestingly the groups appeared to be significantly different in baseline BMI (respectively $33.7 \pm 4.7$ vs. $30.5 \pm 3.5 \mathrm{~kg} / \mathrm{m} 2, \mathrm{p}<0.01$ ), and baseline fat mass (FM) $(38.3 \pm 9.8$ vs. $32.1 \pm 8.3 \mathrm{~kg}, \mathrm{p}<0.05)$. There was a significant overall group $\mathrm{x}$ time interaction $(p<0.05)$ based on a 2 -factor repeated measures ANOVA for BMI, FM and dietary restraint. Treatment over time analysis showed that with respect to BW, BMI, waist circumference, percent of body fat (\%BF), FM, FFM and leptin concentration, after 2 years WM, the successful group maintained their reduced values after weight loss whereas the unsuccessful group showed a regain. For dietary restraint this was the opposite; the successful subjects increased their restraint while the unsuccessful remained the same level compared to after weight loss (Table 1).

The development of \%BMI (BMI expressed as a percentage of BMI at baseline) in time of the two groups is shown in figure 1. 
During the whole study period (t5-t0) the successful subjects increased their dietary restraint ( $\mathrm{F} 1)$ significantly more than the unsuccessful subjects ( $\Delta \mathrm{F} 1: 4.9 \pm 4.4$ vs. $2.1 \pm 3.8, \mathrm{p}<0.05$ ), which was a difference of $58 \%$ (Figure 2). Taking all subjects together, delta BW (t5-t0) after 2 years was a function of delta F1 (t5-t0) ( $r=-0.36$, $\mathrm{p}<0.01$ ) (Figure 3). During VLCD (t1-t0) and during the whole study period (t5-t0), delta F1 was inversely correlated with delta F2 (inhibition of restraint) $(r=-0.4, p<0.001$ (Figure 4) and $r=-0.3, p<0.01$ ). Both delta FM and delta \%BF during VLCD (t0-t1) were a function of baseline FM (both: $r=0.4, p<0.001$ ). \%BW regain was negatively associated with delta \%BF during VLCD (t0-t1) $(r=-0.24, p=0.02)$ (Figure 5). Thus, the more fat lost, the better the 2-y WM, indicating a fat free mass sparing effect. Leptin was positively correlated with $\% B F$ at all measured time points $(r=0.7, p<0.001)$. Delta leptin concentration during WM ( $\mathrm{t} 1-\mathrm{t} 5)$ was positively correlated with delta \%BF $(r=0.3$, $p<0.01)$. Finally, figure 6 shows the leptin/\%BF ratio of the successful and unsuccessful subjects in time. After VLCD, the successful subjects had a significantly higher ratio than the unsuccessful subjects $(0.35 \pm 0.22$ vs. $0.23 \pm 0.11, \mathrm{p}<0.05)$.

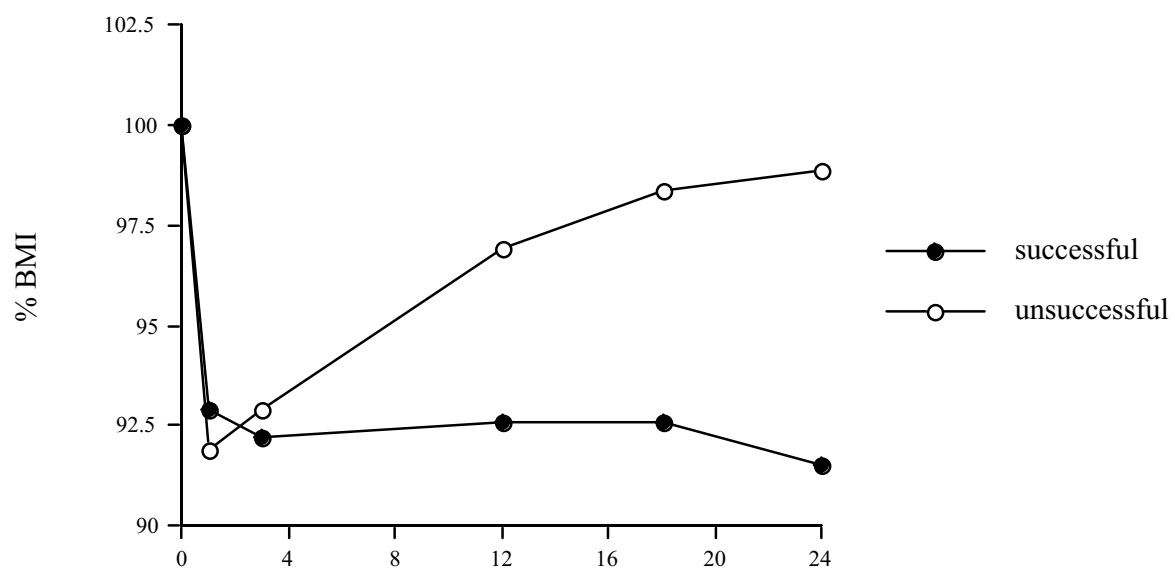

Time (months)

Figure 1: Development of \%BMI of the successful and unsuccessful subjects in time. 


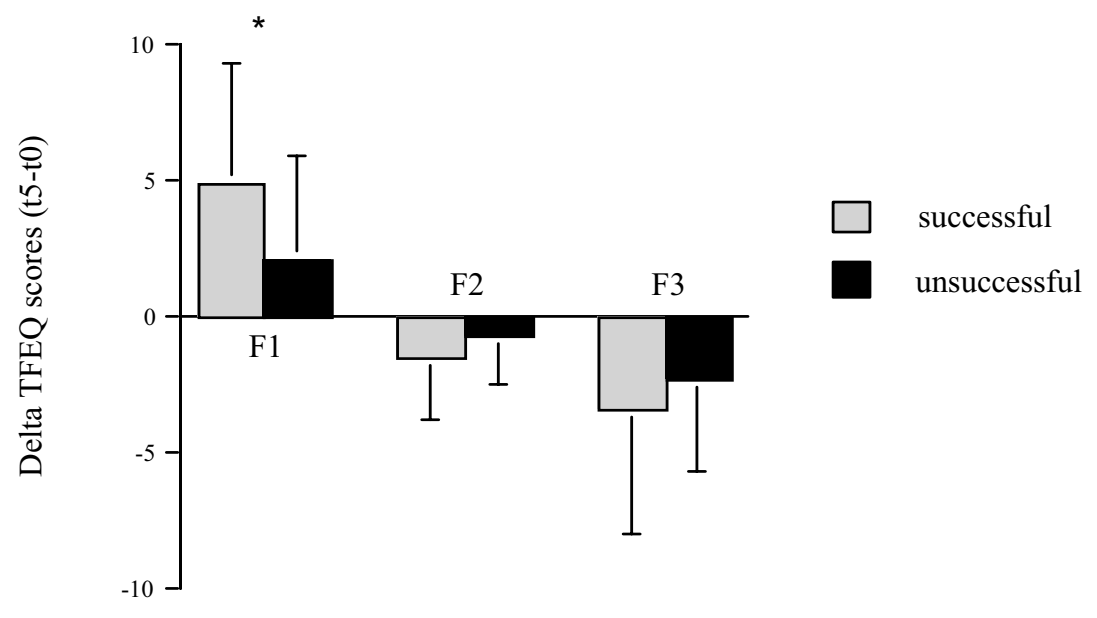

Figure 2: Changes in Three Factor Eating Questionnaire (TFEQ) scores during the whole study period of the successful and unsuccessful subjects.

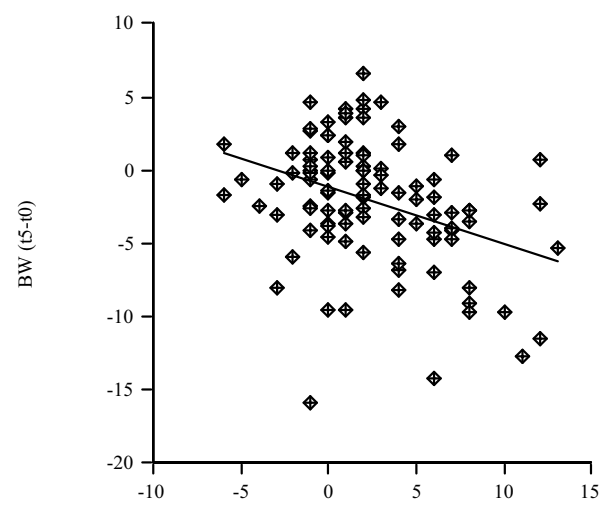

F1 (t5-t0)

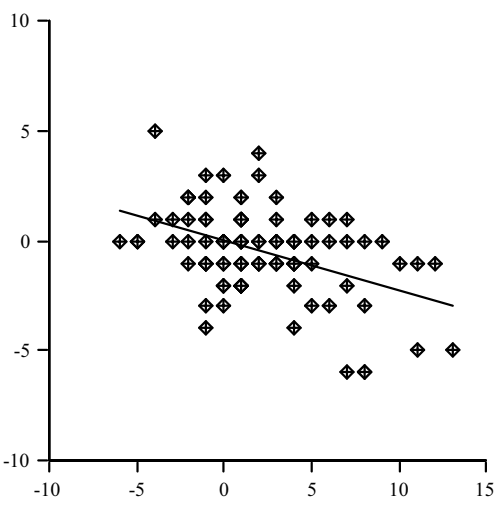

F1 (t1-t0)

Figure 3 (left): Simple regression analysis between change in restraint score (F1) and change in body weight (BW) after 2 years $(r=-0.36, p<0.01)$.

Figure 4 (right): Simple regression analysis between change in restraint score (F1) and change in inhibition score (F2) during weight loss $(r=0.44, p<0.01)$. 


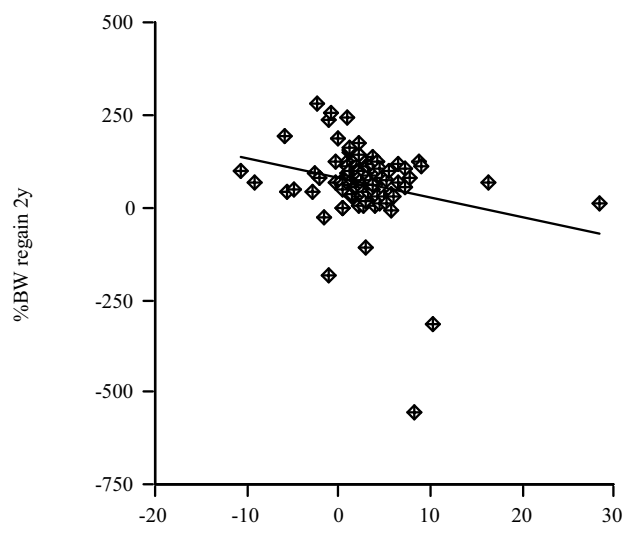

$\% \mathrm{BF}(\mathrm{t} 0-\mathrm{t} 1)$

Figure 5: Simple regression analysis between change in percent of body fat (\%BF) and \%BW regain after 2 years $(r=0.24, p<0.05)$.

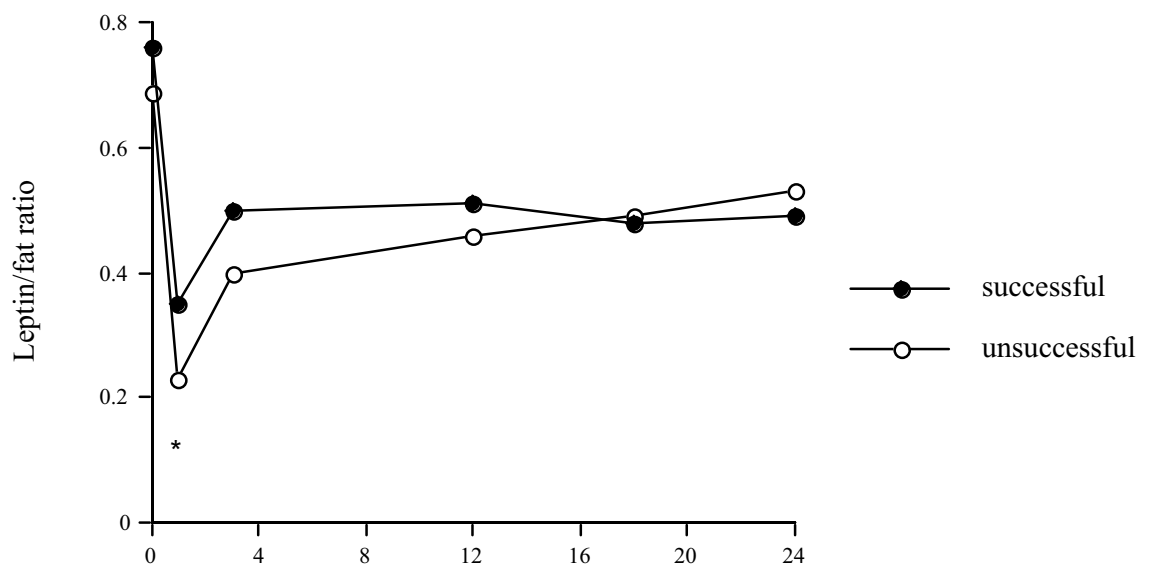

Time (months)

Figure 6: Leptin/\%BF ratio of the successful and unsuccessful subjects in time $(* p<0.05)$.

\section{DISCUSSION}

All subjects were categorized into 2 distinct groups according to either high or low rates of weight change over a 2-y period of follow-up. Analyzing the results, it appeared that 
long-term WM was associated with an increase in dietary restraint and the maintenance of this higher level of restraint. In addition, the higher the increase in restraint, the lower $\% B W$ regain appeared after 2 years. Other factors associated with successful long-term WM were sparing FFM, a high initial BMI and a higher FM. The results described in the present study are very consistent with the 1-y results described previously (25).

Less weight regain was associated with an increase in dietary restraint, which refers to a behavior-change (35). The dietary restraint score reflects a variable behavioral pattern, influenced by, for example, environmental cues (36) or being on a diet or not (35). It shows an individual's description of their own behaviors to control their weight. In accordance with our results, previous studies reported that less weight regain was predicted by larger early increases in cognitive dietary restraint $(5,37,38)$. The present study shows not only this predictive effect of dietary restraint on WM, but also a prolonged effect; subjects that were able to increase their dietary restraint during the whole study period, and more importantly maintained this high level of restraint, appeared to be better in controlling their BW. Furthermore, we found that the bigger the increase in restraint was, the smaller the change in BW (Figure 3). A more flexible attitude towards food consumption or eating behavior, which allows more variation in restraint scores, was previously related with successful WM (5). The TFEQ includes three subscales: cognitive dietary restraint (Factor 1$)$, inhibition of dietary restraint and emotional eating (Factor 2) and the general feeling of hunger (Factor 3) (13, 29). The first factor is regarded as the best tool available for the psychometric assessment of restrained eating (30). It was observed that e.g. restrained eaters consumed less energy, took fewer meals, and showed higher preferences for low-calorie foods than did the complementarily defined unrestrained group $(39,40)$. The present study shows that changes in dietary restraint were inversely correlated with changes (during the same period) in inhibition of restraint. An increase in dietary restraint has previously been related to a decrease in disinhibition (41-43). Moreover, weight gainers appear to be low in dietary restraint and high in disinhibition $(11,41,44)$. To summarize the findings of the present study, subjects that show successful WM after 2 years continue long-term to use behavior-change strategies (e.g. increase their dietary restraint). From the 1-y results we have learned that a bigger increase in dietary restraint was also related to 3 months and 1 year successful WM (25). Moreover, the combination of a high dietary restraint and a low inhibition of restraint seems to give the best chance of successful WM.

Other factors related to better WM were baseline BMI and FM. Compared to the unsuccessful subjects, the successful subjects showed a significantly higher BMI and FM at the start of the study. There are two possible explanations for this. Firstly, when subjects have large amounts of fat, it may be easier to lose fat. This was shown in the present study, since baseline FM was positively correlated with delta FM during VLCD (t0-t1). When all subjects then regain the same amount of weight, subjects that have lost the most, showed less \%BW regain. A meta-analysis done by Anderson et al. showed comparable results; after weight loss of more than $20 \mathrm{~kg}$, individuals maintained significantly more weight loss than after weight loss of less than $10 \mathrm{~kg}$ (45). When subjects lose a large amount of fat, their body composition will change into a more usual ratio. This renewed ratio may be more favorable and therefore preserved by the body. Previously, Dulloo et al. (1999) described this effect, in which the body composition of a given individual changes continuously towards a leaner body composition during the course of starvation (46). In the present study, \%BW regain was associated with the amount of \%BF lost during VLCD. Thus the more fat lost, the better the WM, which indicates a FFM sparing effect. The other explanation may be that when people lose a 
large amount of fat, which they might experience through changes in their body shape, they will be more rewarded and willing to keep this lower fat amount. Taken together, due to metabolic factors of the body and/or behavioral factors e.g. more motivation and therefore an increase in dietary restraint, the lost weight will be better maintained.

As shown previously, we observed a strong positive relationship between serum leptin concentrations and fat mass at all measured time points (25, 47-49). Treatment over time analysis also showed that after weight loss leptin concentrations run parallel to increasing or maintaining FM (table 1). Figure 6 shows that leptin/\%BF ratio after VLCD was significantly lower for the unsuccessful subjects. This significantly lower ratio may initiate weight gain; both animal and human studies indicate that low or reduced (as observed during fasting) leptin concentrations act as a peripheral signal of starvation, which subsequently may be a trigger to increase weight, thereby ensuring survival of the species (50).

The long-term effects of weight loss have frequently been investigated. Different studies reported that even modest reductions in BW (5-10\% of baseline BW) have positive health benefits in subjects with obesity-associated medical complication such as hypertension and cardiovascular disease $(1,51,52)$. Modest weight loss improved glycemic control, reduced blood pressure and reduced cholesterol levels (52). However, a long-term trial of Sjostrom et al. (1998) has shown a rebound effect in risk factors in spite of maintained weight reduction. Also, the study by Diepvens et al. (2006) showed a reversal effect for different at risk blood parameters, even when these subjects were still in the late weight loss phase (53). Maintained weight reduction in both these studies was about $5 \%(53,54)$. Prolonged weight reductions of about $10 \%$ are probably required for long-lasting risk-factor improvements to be detected. In the present study the maintained weight reduction in the successful subjects was about $10 \%$.

We conclude that characteristics such as the ability to increase dietary restraint and maintain this high level of restraint, FFM sparing, and a relatively high baseline BMI and FM were associated with successful long-term WM ( $<10 \%$ regain after 2 years).

\section{ACKNOWLEDGEMENTS}

We gratefully thank Loek Wouters and Wendy Sluijsmans for their assistance and we thank the subjects for their participation in this study. We acknowledge Dr. Kathleen Melanson (University of Rhode Island) for editing the English text. 


\section{REFERENCES}

1. Pi-Sunyer FX, Becker DM, Bouchard C, et al. Clinical Guidelines on the Identification, Evaluation, and Treatment of Overweight and Obesity in Adults--The Evidence Report. National Institutes of Health. Obes Res 1998;6 Suppl 2:51S-209S.

2. Burton BT, Foster WR. Health implications of obesity: an NIH Consensus Development Conference. J Am Diet Assoc 1985;85:1117-21.

3. Ditschuneit $\mathrm{HH}$, Flechtner-Mors M. Value of structured meals for weight management: risk factors and long- term weight maintenance. Obes Res 2001;9 Suppl 4:284S-289S.

4. Pasman WJ, Rossner S, Westerterp-Plantenga MS, Saris WH. Body weight changes after treatment of obesity or pregnancy. Milan, Italy: Edra, 1999.

5. Westerterp-Plantenga MS, Kempen KP, Saris WH. Determinants of weight maintenance in women after diet-induced weight reduction. Int J Obes Relat Metab Disord 1998;22:1-6.

6. Pasman WJ, Saris WH, Westerterp-Plantenga MS. Predictors of weight maintenance. Obes Res 1999;7:43-50.

7. Anderson JW, Vichitbandra S, Qian W, Kryscio RJ. Long-term weight maintenance after an intensive weight-loss program. J Am Coll Nutr 1999;18:620-7.

8. Leermakers EA, Perri MG, Shigaki CL, Fuller PR. Effects of exercise-focused versus weight-focused maintenance programs on the management of obesity. Addict Behav 1999;24:219-27.

9. Ewbank PP, Darga LL, Lucas CP. Physical activity as a predictor of weight maintenance in previously obese subjects. Obes Res 1995;3:257-63.

10. Perri MG, Sears SF, Jr., Clark JE. Strategies for improving maintenance of weight loss. Toward a continuous care model of obesity management. Diabetes Care 1993;16:200-9.

11. McGuire MT, Wing RR, Klem ML, Lang W, Hill JO. What predicts weight regain in a group of successful weight losers? J Consult Clin Psychol 1999;67:177-85.

12. Westerterp-Plantenga MS, Pasman WJ, Yedema MJ, Wijckmans-Duijsens NE. Energy intake adaptation of food intake to extreme energy densities of food by obese and nonobese women. Eur J Clin Nutr 1996;50:401-7.

13. Westerterp-Plantenga MS, Rolland V, Wilson SA, Westerterp KR. Satiety related to $24 \mathrm{~h}$ diet-induced thermogenesis during high protein/carbohydrate vs high fat diets measured in a respiration chamber. Eur J Clin Nutr 1999;53:495-502.

14. Westerterp-Plantenga MS, Goris AH, Meijer EP, Westerterp KR. Habitual meal frequency in relation to resting and activity-induced energy expenditure in human subjects: the role of fat-free mass. Br J Nutr 2003;90:643-9.

15. Westerterp-Plantenga MS, Kovacs EM, Melanson KJ. Habitual meal frequency and energy intake regulation in partially temporally isolated men. Int J Obes Relat Metab Disord 2002;26:102-10.

16. Foster GD, Wadden TA, Kendrick ZV, Letizia KA, Lander DP, Conill AM. The energy cost of walking before and after significant weight loss. Med Sci Sports Exerc 1995;27:888-94.

17. Morris JN, Hardman AE. Walking to health. Sports Med 1997;23:306-32.

18. Blair SN, Kohl HW, Gordon NF, Paffenbarger RS, Jr. How much physical activity is good for health? Annu Rev Public Health 1992;13:99-126.

19. Votruba SB, Horvitz MA, Schoeller DA. The role of exercise in the treatment of obesity. Nutrition 2000;16:179-88.

20. Westerterp KR. Pattern and intensity of physical activity. Nature 2001;410:539.

21. Westerterp KR. Obesity and physical activity. Int J Obes Relat Metab Disord 1999;23 Suppl 1:59-64.

22. Westerterp-Plantenga MS, Verwegen CR, Ijedema MJ, Wijckmans NE, Saris WH. Acute effects of exercise or sauna on appetite in obese and nonobese men. Physiol Behav 1997;62:1345-54.

23. Van Aggel-Leijssen DP, Saris WH, Hul GB, Van Baak MA. Long-term effects of lowintensity exercise training on fat metabolism in weight-reduced obese men. Metabolism 2002;51:1003-10. 
24. Fogelholm M, Kukkonen-Harjula K, Oja P. Eating control and physical activity as determinants of short-term weight maintenance after a very-low-calorie diet among obese women. Int J Obes Relat Metab Disord 1999;23:203-10.

25. Vogels N, Westerterp-Plantenga MS. Categorical strategies based on subject characteristics of dietary restraint and physical activity, for weight maintenance. Int J Obes Relat Metab Disord 2005;29:849-57.

26. van Marken Lichtenbelt WD, Westerterp KR, Wouters L. Deuterium dilution as a method for determining total body water: effect of test protocol and sampling time. $\mathrm{Br}$ J Nutr 1994;72:491-7.

27. Schoeller DA, van Santen E, Peterson DW, Dietz W, Jaspan J, Klein PD. Total body water measurement in humans with 180 and 2H labeled water. Am J Clin Nutr 1980;33:268693.

28. Westerterp KR, Wouters L, van Marken Lichtenbelt WD. The Maastricht protocol for the measurement of body composition and energy expenditure with labeled water. Obes Res 1995;3 Suppl 1:49-57.

29. Stunkard AJ, Messick S. The three-factor eating questionnaire to measure dietary restraint, disinhibition and hunger. J Psychosom Res 1985;29:71-83.

30. Laessle RG, TuschI RJ, Kotthaus BC, Pirke KM. A comparison of the validity of three scales for the assessment of dietary restraint. J Abnorm Psychol 1989;98:504-7.

31. Neale BM, Mazzeo SE, Bulik CM. A twin study of dietary restraint, disinhibition and hunger: an examination of the eating inventory (three factor eating questionnaire). Twin Res 2003;6:471-8.

32. Philippaerts RM, Westerterp KR, Lefevre J. Doubly labelled water validation of three physical activity questionnaires. Int J Sports Med 1999;20:284-9.

33. Baecke JA, Burema J, Frijters JE. A short questionnaire for the measurement of habitual physical activity in epidemiological studies. Am J Clin Nutr 1982;36:936-42.

34. Weinsier RL, Hunter GR, Desmond RA, Byrne NM, Zuckerman PA, Darnell BE. Free-living activity energy expenditure in women successful and unsuccessful at maintaining a normal body weight. Am J Clin Nutr 2002;75:499-504.

35. Wing RR, Hill JO. Successful weight loss maintenance. Annu Rev Nutr 2001;21:323-41.

36. Westerterp-Plantenga MS, Westerterp KR, Rubbens M, Verwegen CR, Richelet JP, Gardette B. Appetite at "high altitude" [Operation Everest III (Comex-'97)]: a simulated ascent of Mount Everest. J Appl Physiol 1999;87:391-9.

37. McGuire MT, Jeffery RW, French SA, Hannan PJ. The relationship between restraint and weight and weight-related behaviors among individuals in a community weight gain prevention trial. Int J Obes Relat Metab Disord 2001;25:574-80.

38. Lejeune MP, Van Aggel-Leijssen DP, Van Baak MA, Westerterp-Plantenga MS. Effects of dietary restraint vs exercise during weight maintenance in obese men. Eur J Clin Nutr 2003;57:1338-44.

39. Laessle RG, Tuschl RJ, Kotthaus BC, Pirke KM. Behavioral and biological correlates of dietary restraint in normal life. Appetite 1989;12:83-94.

40. Tuschl RJ, Platte P, Laessle RG, Stichler W, Pirke KM. Energy expenditure and everyday eating behavior in healthy young women. Am J Clin Nutr 1990;52:81-6.

41. Dykes J, Brunner EJ, Martikainen PT, Wardle J. Socioeconomic gradient in body size and obesity among women: the role of dietary restraint, disinhibition and hunger in the Whitehall II study. Int J Obes Relat Metab Disord 2004;28:262-8.

42. Hays NP, al. e. Eating behavior correlates of adult weight gain and obesity in healthy women aged 55-65 y. Am J Clin Nutr 2002;75:476-83.

43. Williamson DA, Lawson OJ, Brooks ER, et al. Association of body mass with dietary restraint and disinhibition. Appetite 1995;25:31-41.

44. Lawson OJ, Williamson DA, Champagne CM, et al. The association of body weight, dietary intake, and energy expenditure with dietary restraint and disinhibition. Obes Res 1995;3:153-61.

45. Anderson JW, Konz EC, Frederich RC, Wood CL. Long-term weight-loss maintenance: a meta-analysis of US studies. Am J Clin Nutr 2001;74:579-84.

46. Dulloo AG, Jacquet J. The control of partitioning between protein and fat during human starvation: its internal determinants and biological significance. Br J Nutr 1999;82:339-56. 
47. Sartorio A, Agosti F, Resnik M, Lafortuna CL. Effects of a 3-week integrated body weight reduction program on leptin levels and body composition in severe obese subjects. J Endocrinol Invest 2003;26:250-6.

48. Neuhauser-Berthold M, Herbert BM, Luhrmann PM, et al. Resting metabolic rate, body composition, and serum leptin concentrations in a free-living elderly population. Eur J Endocrinol 2000;142:486-92.

49. Sudi KM, Gallistl S, Borkenstein MH, et al. Effects of weight loss on leptin, sex hormones, and measures of adiposity in obese children. Endocrine 2001;14:429-35.

50. Havel PJ. Role of adipose tissue in body-weight regulation: mechanisms regulating leptin production and energy balance. Proc Nutr Soc 2000;59:359-71.

51. Blackburn G. Effect of degree of weight loss on health benefits. Obes Res 1995;3 Suppl 2:211s-216s.

52. Goldstein DJ. Beneficial health effects of modest weight loss. Int J Obes Relat Metab Disord 1992;16:397-415.

53. Diepvens K, Kovacs EM, Vogels N, Westerterp-Plantenga MS. Metabolic effects of green tea and of phases of weight loss. Physiol Behav 2006;87:185-91.

54. Sjostrom L, Rissanen A, Andersen T, et al. Randomised placebo-controlled trial of orlistat for weight loss and prevention of weight regain in obese patients. European Multicentre Orlistat Study Group. Lancet 1998;352:167-72. 


\section{Relationship of weight maintenance and dietary restraint with peroxisome proliferator-activated receptor $\gamma \mathbf{2}$, glucocorticoid receptor and ciliary neurotrophic factor polymorphisms}

Neeltje Vogels, Edwin CM Mariman, Freek G Bouwman, Arnold DM Kester, Kristel Diepvens and Margriet S Westerterp-Plantenga

American Journal of Clinical Nutrition 2005;82:740-746 


\section{ABSTRACT}

Background: Genetic variation in the peroxisome proliferator-activated receptor- $\gamma 2$ (PPAR $\gamma 2)$, glucocorticoid receptor (GRL) and neurocytokine ciliary neurotrophic factor (CNTF) genes may play an important role in the etiology of obesity.

Objective: We examined different biological, psychological and genetic determinants associated with weight maintenance (WM) after weight loss.

Methods: 120 subjects followed a 6 week diet, followed by a period of 1 year WM. Body weight (BW), body composition, leptin concentration, attitude towards eating (measured with the Three Factor Eating Questionnaire), physical activity and the polymorphisms of the PPAR $\gamma 2, \mathrm{GRL}$ and CNTF genes were determined.

Results: BW loss was $7.0 \pm 3.1 \mathrm{~kg}$. After $1 \mathrm{y}, 21$ subjects showed successful WM $(<10 \%$ regain) and 99 unsuccessful WM ( $\geq 10 \%$ regain). Compared to the unsuccessful subjects, successful subjects showed a higher increase in their dietary restraint over time $(4.8 \pm 5.0$ vs. $1.8 \pm 3.9, p<0.01)$, whereas their general hunger feelings were significantly reduced $(-4.0 \pm 4.9$ vs. $-1.2 \pm 2.7, p<0.05)$. The successful subjects showed a significantly different frequency distribution for the PPAR $\gamma 2(p=0.05)$ and GRL genes $(p<0.05)$. In addition, the relatively more successful genotypes showed a higher baseline BMI (PPAR 2 , GRL) and waist circumference (PPAR 2 ), a higher decrease in disinhibition/emotional eating during the first 3 months (GRL) and less feelings of hunger during weight loss (GRL). The $\mathrm{G} / \mathrm{G}$ genotype (GRL) was an independent predictor for successful WM.

Conclusion: The different genotypes of the PPAR $\gamma 2$ and GRL genes contribute to WM, either directly (GRL) or indirectly via baseline BMI and waist circumference, and a change in the Three Factor Eating Questionnaire scores. 


\section{INTRODUCTION}

Overweight and obesity are emerging as major health problems. Weight control methods often produce short-term success, but sustained weight maintenance (WM) is difficult to reach (1-3). Strategies to improve the maintenance of weight loss have resulted in behavior modification such as changes in diet and increased physical activity (4-6). With respect to weight loss maintenance strategies, we observed that the category of subjects with increased dietary restraint (control over food intake to influence body weight and shape) during weight loss showed best WM (7). Furthermore WM was predicted by high initial BMI, waist circumference, fat mass, and sparing fat-free mass (7). Obesity or the failure to maintain weight loss may also be explained by genetic factors or an interaction between genetic and environmental factors (8). Peroxisome proliferator-activated receptors (PPARs) are members of the nuclear hormone receptor subfamily of ligand-dependent transcription factors. The isoform, PPAR 2 , is mainly expressed in adipose tissue where it modulates the expression of target genes involved in adipocyte differentiation. The Pro12Ala PPAR $\gamma 2$ gene missense mutation has been associated with higher BMI's and greater weight regain $(9,10)$. We therefore hypothesize that subjects homozygous for the Pro allele would show greater WM. The glucocorticoid receptor (GRL) gene has an important role in the metabolism of adipose tissue and in the regulation of abdominal fat distribution (11). Variation in the GRL gene demonstrated by a BcII restriction fragment length polymorphism is present in intron 2, 646 nucleotides downstream from exon 2. Two restriction fragments of 2.3 ( $C$ allele) and 4.5 ( $\mathrm{G}$ allele) $\mathrm{kb}$ can be distinguished (12). The $\mathrm{G}$ allele was found to be associated with an elevated BMI, a higher abdominal visceral fat and an increased waist to hip ratio $(13,14)$. However, contradictory results have also been reported (12). The neurocytokine ciliary neurotrophic factor (CNTF) exerts its multiple effects through a receptor complex whose sequence, localization and mode of signal transduction share remarkable similarities with the receptor for leptin (15). In the human CNTF gene, a mutation in the first intron creates a new splice acceptor site, with the resulting mRNA coding for an aberrant protein (16). Recently, O'Dell and colleagues (2002) (17) found significantly higher body weight (BW) and BMI for males homozygous with this naturally occurring null mutation. Others have reported no association $(15,18)$. Therefore, in the present study we assessed the possible relationships between the GRL, CNTF and the PPAR 2 genotypes and WM after a period of weight loss.

\section{SUBJECTS AND METHODS}

\section{Subjects}

Subjects were recruited by advertisements in local newspapers. 150 subjects complied with the selection criteria: BMI $>25 \mathrm{~kg} / \mathrm{m}^{2}$ and age between 20 and 65 years. The exclusion criteria were: use of other research medication or diet up to 30 days prior to the study, and participation in another scientific study up to 30 days prior to this study. 133 subjects started with a Very Low Calorie Diet (VLCD) for six weeks. Before the start of the VLCD, 17 subjects had withdrawn for several reasons (e.g. lack of motivation). The 133 subjects (age: $48.1 \pm 9.5$ y, BMI: $31.1 \pm 3.7 \mathrm{~kg} / \mathrm{m}^{2}$ ) who completed the VLCD had measurements made before and after weight loss, and at three months and one year after the end of the weight loss period. At three months WM, another 13 subjects dropped-out for several reasons. The dropouts did not significantly change the baseline 
characteristics of the subjects. Data have been analyzed for the 120 subjects (age: $49.0 \pm 9.8 \mathrm{yr}$, BMI $31.0 \pm 3.8 \mathrm{~kg} / \mathrm{m}^{2}$ ) who completed the entire study. Subjects gave their written informed consent to participate in the study, which was approved by the Medical Ethical Committee of Maastricht University.

\section{Study design}

Part of the study design, i.e. the weight loss and the WM protocol has been described previously (7). In short, the study consisted of a dietary weight loss intervention under free-living circumstances of six weeks and a WM period of 1 year. The VLCD (Modifast, Novartis Nutrition, Brussels, Belgium) consisted of $2.1 \mathrm{MJ} / \mathrm{d}(500 \mathrm{kcal} / \mathrm{d})$ given in three sachets per day. It provided $50 \mathrm{~g}$ carbohydrates, $52 \mathrm{~g}$ protein, $7 \mathrm{~g}$ fat and a vitaminsand minerals content which meets the Dutch recommended daily allowance. The VLCD was dissolved in water to make a soup, milkshake or dessert. In addition to the VLCD, subjects were allowed to consume two pieces of fruit and an unrestricted amount of vegetables every day, without sauces or vinaigrettes.

Measurements of body weight, body composition, leptin concentration, attitude towards eating, and physical activity took place before the VLCD (to), immediately after the VLCD $(\mathrm{t} 1), 3$ months after to (t2), and one year after to (t3). At to one blood sample was taken and stored for DNA analysis.

\section{Measurements}

\section{Anthropometry}

Height was measured using a wall-mounted stadiometer (Seca, model 220, Hamburg, Germany) and body weight (BW) was measured using a digital balance accurate to 0.1 kg (Sauter D7470, Ebingen, Germany). Measurements were executed in underwear, after an overnight fast and after voiding the bladder. BMI was calculated by BW/height ${ }^{2}$ $\left(\mathrm{kg} / \mathrm{m}^{2}\right)$. The waist circumference was measured at the site of the smallest circumference between the rib cage and the ileac crest, with the subjects in standing position.

\section{Body composition}

Body composition was measured using the deuterium dilution technique. ${ }^{2} \mathrm{H}_{2} \mathrm{O}$ dilution was used to measure total body water (TBW). Subjects were asked to collect a urine sample in the evening just before drinking the deuterium-enriched water solution. After ingestion of this solution, no further consumption was allowed. Ten hours after drinking the water solution, another urine sample was collected. The dilution of the deuterium isotope is a measure of the TBW of the subject. Deuterium was measured in the urine samples with an isotope ratio mass spectrometer (VG-Isogas Aqua Sira, VG Isogas, Middlewich, Cheshire, England). TBW was obtained by dividing the measured deuterium dilution space by 1.04 . Fat free mass (FFM) was calculated by dividing TBW by the hydration factor 0.73 (19-21).

\section{Attitude towards eating}

The Three Factor Eating Questionnaire (TFEQ) is a self-report measure of eating behaviors that are believed to be particularly relevant to the development and maintenance of obesity. The TFEQ has been widely used in obesity treatment and includes three subscales: cognitive dietary restraint (Factor 1), inhibition of dietary 
restraint (disinhibition) and emotional eating (Factor 2) and hunger (Factor 3) $(22,23)$. The factor cognitive dietary restraint is regarded as the best tool available for the psychometric assessment of restrained eating (24). It determines control over food intake to influence body weight and body shape (e.g. "I consciously hold back at meals to keep from gaining weight") (25). It was observed that e.g. restrained eaters consumed less energy, took fewer meals, and showed higher preferences for low-calorie foods than did the complementarily defined unrestrained group $(26,27)$. Correspondingly, the adjusted energy expenditure was found to be significantly lower, which may indicate that restrained eaters have a balance below the biologically given level (27). The factor inhibition of restraint eating refers to the tendency to lose control over eating when feeling hungry or when exposed to external stimuli (e.g. "Sometimes when I start eating, I just can't seem to stop") and emotional eating refers to the propensity to overeat in relation to negative mood states, e.g. when feeling lonely, anxious, or depressed (25). The factor hunger measures a person's general subjective feeling of hunger. Because a subset of the subjects from this study $(n=40)$ participated in earlier studies in our lab, we were able to correlate earlier measured TFEQ data at baseline to the present measured TFEQ data at baseline. All three factors were significantly correlated (Factor 1: $r=0.4, p<0.01$, Factor 2: $r=0.7, p<0.001$, Factor 3: $r=0.4, p<0.05)$, which indicates the reliability of this questionnaire. For the present study we used a validated Dutch translation of the TFEQ (23).

\section{Physical activity}

An estimation of the physical activity level was determined using the validated Baecke questionnaire (28). The Baecke questionnaire consists of a work index, a sports index, a leisure time index and the total index (29).

\section{Leptin}

Blood samples were taken following a 12-h overnight fast. Serum leptin concentrations were measured with a double-antibody, sandwich-type enzyme-linked immunosorbent assay that used a monoclonal antibody specific for human leptin. The lower limit of detection is $0.5 \mu \mathrm{g} / \mathrm{L}$ and the upper limit is $50 \mu \mathrm{g} / \mathrm{L}$. The intra- and interassay CVs were $9 \%$ and $12 \%$, respectively. The leptin concentrations of normal-weight subjects range from 2 to $12 \mu \mathrm{g} / \mathrm{L}$.

\section{Determination of the genotypes}

The genomic DNAs of 119 subjects were isolated from peripheral blood leukocytes using a QIAamp kit from Qiagen.

\section{Peroxisome Proliferator-Activated Receptor $\gamma 2$ (PPAR $\gamma 2$ ) genotyping}

A 270 bp fragment of the PPAR 22 gene was generated from genomic DNA by PCR using forward primer 5'-GCCAATTCAAGCCCAGTC-3' and mutagenic reverse primer 5'GATATGTTTGCAGACAGTGTATCAGTGAAGGAATCGCTTTCCG-3' which introduces a BstU-I restriction site only when the $\mathrm{C}->\mathrm{G}$ substitution at nucleotide 34 is present related to the Pro12Ala polymorphism (30). The PCR products were digested with BstU-I at $60^{\circ} \mathrm{C}$ for 60 minutes, electrophoresed on a $2.5 \%$ agarose gel and stained with ethidium bromide. The expected products after digestion with BstU-I are 270 bp for $P / P$ homozygotes, 227 and 43 bp for A/A homozygotes and 270, 227 and 43 bp for P/A heterozygotes. 
Glucocorticoid receptor (GRL) genotyping

A 87 bp fragment of the GRL gene was generated from genomic DNA by PCR using forward primer 5'-GCTCACAGGGTTCTTGCCATA-3' and reverse primer 5'TTGCACCATGTTGACACCAAT-3', which includes a C/G polymorphism in intron 2, 646 nucleotides downstream from exon 2 (12). The PCR products were digested with BcII at $50^{\circ} \mathrm{C}$ for 60 minutes, electrophoresed on a $3 \%$ agarose gel and stained with ethidium bromide. The expected products after digestion with BclI are 87 bp for $\mathrm{G} / \mathrm{G}$ homozygotes, 47 and 40 bp for $\mathrm{C} / \mathrm{C}$ homozygotes and 87,47 and 40 bp for $\mathrm{G} / \mathrm{C}$ heterozygotes.

\section{Ciliary Neurotrophic Factor (CNTF) genotyping}

A 134 bp fragment encompassing the null mutation at position -6 before the second exon of the CNTF gene was generated from genomic DNA by PCR using forward primer 5'-CCAGAGAGATGAGTGAGATTITGT-3' and reverse primer 5'CAGGTTGATGTTCTTGTTCATGCC-3' (16). The PCR products were digested with HaeIII at $37^{\circ} \mathrm{C}$ for 60 minutes, electrophoresed on a $2.5 \%$ agarose gel and stained with ethidium bromide. The expected products after digestion with HaeIII are 94 and 40 bp for normal homozygotes (G/G), 134 bp for null mutation homozygotes (A/A) and 134, 94 and $40 \mathrm{bp}$ for heterozygotes (G/A).

\section{Statistical analysis}

We used repeated measures ANOVA to test for differences between groups over time and two-sample t-tests for the differences in single variables between groups (Statview SE Graphics ${ }^{T M}$ for Macintosh). Relations between variables were evaluated as Pearson correlations and chi-square tests were used for the Hardy-Weinberg equilibrium. Associations between genotype and the outcome variable (un)successful WM were tested with exact Fisher tests. The relation of the outcome variable (un)successful WM to genotype was analyzed with correction for possible confounder variables using logistic regression (SPSS for windows, version 11.5). All statistical tests were two-sided, differences were considered significant at $p<0.05$. Values are expressed as mean \pm standard deviation (sd).

\section{RESULTS}

Subjects were categorized into 2 distinct groups according to either high or low rates of weight change over the follow-up period in order to identify factors that distinguish successful subjects from unsuccessful subjects. Based upon Weinsier's analysis we assessed relative success in WM using the $10 \%$ weight regain criterion (31). A distinct break below and above a $10 \%$ weight regain had appeared.

Table 1 shows the differences in changes of the subject's characteristics over time in the successful and unsuccessful groups. In addition, the baseline differences between the successful and unsuccessful subjects with respect to BMI, waist circumference and fat mass are indicated (Table 1) (7). There was a significant overall group $x$ time interaction $(p<0.001)$ based on a 2-factor repeated measures ANOVA for BW, BMI, waist circumference, $\%$ body fat, fat mass, dietary restraint and hunger feelings. With respect to BW, BMI, waist circumference, body fat, fat mass and dietary restraint, the successful group maintained their reduced values after weight loss for the period of 1 year, whereas the unsuccessful group showed a regain. 
The observations on WM were related to the genotype frequency distribution of the successful and unsuccessful groups as follows. With respect to the analysis of the PPAR $\gamma 2$, the GRL and the CNTF genotypes of 119 subjects (Table 2), the overall genotype frequencies were in Hardy-Weinberg equilibrium (data not shown). The genotype frequency distributions of the GRL gene was significantly different for the successful group as compared to the unsuccessful group $(p<0.05)$, for the PPAR $\gamma 2$ gene this tended to be significantly different $(p=0.05)$, while the genotype frequency distribution of the CNTF gene was not significantly different between the two groups (Table 2).

For the PPAR $\gamma 2$ genotype, the successful group had relatively few heterozygous subjects (P/A) $(9.5 \%$ as compared to $23.5 \%$ for the unsuccessful group) and more subjects with the homozygous Pro allele (P/P) $(85.7 \%$ as compared to $76.5 \%$ for the unsuccessful group). In addition, all subjects with the $P / P$ genotype showed a significantly higher baseline BW ( $91.9 \pm 15.9$ vs. $83.9 \pm 11.5, p=0.02)$, BMI ( $31.3 \pm 3.9$ vs. $29.7 \pm 3.0, p=0.05)$ and waist circumference $(102.9 \pm 12.2$ vs. $96.8 \pm 10.0, p=0.02)$ as compared to those with the P/A genotype. In general, a higher baseline BMI and waist circumference were associated with better WM (Table 1). Binary logistic regression analysis shows that when corrected for baseline BW, BMI and waist circumference the relatively more successful $\mathrm{P} / \mathrm{P}$ genotype had no direct association with better WM ( $p>0.05)$.

For the GRL genotype, it appeared that the successful group had relatively more homozygous carriers of the $\mathrm{G}$ allele as compared to the unsuccessful group $(28.6 \% \mathrm{vs}$. $8.2 \%$ respectively). Compared to the $\mathrm{C} / \mathrm{C}$ and $\mathrm{C} / \mathrm{G}$ genotypes, the $\mathrm{G} / \mathrm{G}$ genotypes had a significantly higher baseline BMI (32.9 \pm 4.3 vs. $30.2 \pm 3.1$ and $31.2 \pm 4.1$ respectively, $\mathrm{p}=0.05)$, showed a greater decrease in disinhibition/emotional eating during the first 3 months of the study $(-1.9 \pm 1.9$ vs. $-0.4 \pm 1.8$ and $-0.2 \pm 2.1$ respectively, $p<0.05)$, and showed significantly less feelings of hunger during weight loss $(-2.6 \pm 5.8$ vs. $-0.5 \pm 2.6$ and $-1.9 \pm 2.9$ respectively, $p<0.05)$. Binary logistic regression analysis shows that when corrected for the influence of baseline BMI, disinhibition/emotional eating and hunger the relatively more successful $G / G$ genotype appeared to be an independent predictor for successful WM (Odds ratio 5.032, $\mathrm{p}<0.05$ ) (Table 3 ). In addition, during weight loss, a change in dietary restraint score was inversely correlated with a change in disinhibition/emotional eating score $(r=-0.4, p<0.001)$, as well as with a change in hunger score during the whole study period $(r=-0.36, p<0.0001)$ and during WM $(r=-$ $0.25, p<0.01)(7)$. Indeed, subjects with the $G / G$ genotypes had significantly less weight regain as compared to subjects with the $C / C$ and the $C / G$ genotypes (23.3 \pm 51.8 vs. $61.3 \pm 52.0$ and $60.8 \pm 56.7$ respectively, $p=0.05$ ).

For the CNTF gene, the frequency distribution of the genotypes was not statistically different between the successful and unsuccessful groups. Nevertheless, the successful group seemed to show relatively more G/A genotypes as compared to the unsuccessful group (38.1\% vs. $24.5 \%$ respectively), which did not reach statistical significance. However, compared to subjects with the G/G genotype, subjects with the G/A genotype showed a significantly lower baseline serum leptin concentration (21.2 \pm 12.5 vs. $28.5 \pm 17.5, \mathrm{p}<0.05)$ and a lower delta leptin concentration during weight loss $(-13.4 \pm 9.6$ vs. $-19.3 \pm 14.5, p<0.05)$. Moreover, during 1 year WM the successful subjects had a significantly smaller change in leptin concentrations as compared to the unsuccessful subjects $(3.4 \pm 4.6$ vs. $8.8 \pm 5.7, p<0.05)(7)$. In general, in the whole group leptin was correlated positively with fat mass at all measured time points (baseline, after VLCD and after 1 year: $r=0.6, p<0.001$, and after 3 months: $r=0.7, p<0.001)$ and the change in leptin concentrations during WM was positively correlated with \%BW regain at 1 year $(r=0.2, p=0.01)$ and with the change in fat mass during WM $(r=0.3, p<0.01)(7)$. 
Table 1: Characteristics (mean \pm sd) of successful $(S)(n=21)$ and unsuccessful $(U)(n=99)$ subjects on baseline, after VLCD, after 3 months and after 1 year (7).

\begin{tabular}{lccccc}
\hline & & $\begin{array}{c}\text { Baseline } \\
(\mathrm{t} 0)\end{array}$ & $\begin{array}{c}\text { After } \\
\text { VLCD }(\mathrm{t} 1)\end{array}$ & $\begin{array}{c}\text { After 3 months } \\
(\mathrm{t} 2)\end{array}$ & $\begin{array}{c}\text { After 1 year } \\
(\mathrm{t} 3)\end{array}$ \\
\hline BW $(\mathrm{kg})^{1}$ & $\mathrm{~S}$ & $94.7 \pm 19.6$ & $87.1 \pm 18.5$ & $85.3 \pm 19.1^{4,5}$ & $85.3 \pm 19.4^{6,7,8}$ \\
& $\mathrm{U}$ & $89.3 \pm 14.2$ & $82.1 \pm 12.5$ & $83.3 \pm 12.9$ & $87.0 \pm 13.9$ \\
BMI $\left(\mathrm{kg} / \mathrm{m}^{2}\right)^{1}$ & $\mathrm{~S}$ & $32.7 \pm 4.9^{2}$ & $30.1 \pm 4.8$ & $29.4 \pm 5.0^{4,5}$ & $29.4 \pm 4.9^{6,7,8}$ \\
& $\mathrm{U}$ & $30.7 \pm 3.5$ & $28.2 \pm 3.2$ & $28.6 \pm 3.3$ & $29.9 \pm 3.6$ \\
Waist circumference & $\mathrm{S}$ & $106.5 \pm 14.0^{2}$ & $98.7 \pm 14.0$ & $96.6 \pm 14.2^{4,5}$ & $96.6 \pm 14.2^{6,7,8}$ \\
$(\mathrm{~cm})^{1}$ & $\mathrm{U}$ & $100.6 \pm 11.2$ & $93.4 \pm 10.2$ & $94.2 \pm 10.3$ & $95.8 \pm 11.3$ \\
Body Fat $(\%)^{1}$ & $\mathrm{~S}$ & $38.0 \pm 6.9$ & $35.6 \pm 7.0$ & $33.1 \pm 8.2^{4,5}$ & $33.0 \pm 8.2^{6,7,8}$ \\
& $\mathrm{U}$ & $36.7 \pm 6.3$ & $34.3 \pm 6.6$ & $32.2 \pm 6.4$ & $35.6 \pm 6.4$ \\
Fat mass $(\mathrm{kg})^{1}$ & $\mathrm{~S}$ & $35.6 \pm 10.6^{3}$ & $30.7 \pm 9.4$ & $28.2 \pm 12.1^{4,5}$ & $28.0 \pm 11.2^{6,7,8}$ \\
& $\mathrm{U}$ & $32.1 \pm 6.6$ & $27.6 \pm 6.2$ & $25.9 \pm 5.6$ & $30.1 \pm 6.4$ \\
& $\mathrm{~S}$ & $58.1 \pm 13.6$ & $55.3 \pm 12.8$ & $54.6 \pm 11.8$ & $55.5 \pm 12.4$ \\
Fat free mass $(\mathrm{kg})$ & $\mathrm{U}$ & $55.7 \pm 11.1$ & $53.3 \pm 10.2$ & $55.2 \pm 11.0$ & $55.0 \pm 10.8$ \\
& $\mathrm{~S}$ & $7.7 \pm 4.9$ & $10.1 \pm 5.8$ & $13.1 \pm 4.2^{4,5}$ & $12.5 \pm 4.1^{6,7}$ \\
Dietary restraint & $\mathrm{U}$ & $8.6 \pm 4.3$ & $10.7 \pm 4.5$ & $11.2 \pm 4.4$ & $10.3 \pm 4.5$ \\
(F1 of TFEQ) $^{1}$ & $\mathrm{~S}$ & $4.9 \pm 2.9$ & $4.0 \pm 2.5$ & $4.6 \pm 2.8$ & $4.5 \pm 2.5$ \\
Disinhibition & $\mathrm{U}$ & $5.7 \pm 2.6$ & $5.3 \pm 2.5$ & $5.0 \pm 2.5$ & $5.2 \pm 2.7$ \\
(F2 of TFEQ) $_{\text {Hunger }}$ & $\mathrm{S}$ & $6.9 \pm 4.6$ & $3.5 \pm 2.7$ & $2.8 \pm 2.5^{4}$ & $2.9 \pm 2.8^{6}$ \\
(F3 of TFEQ) $^{1}$ & $\mathrm{U}$ & $5.2 \pm 3.6$ & $4.1 \pm 3.2$ & $3.5 \pm 3.1$ & $3.9 \pm 3.1$ \\
Physical activity & $\mathrm{S}$ & $7.9 \pm 1.2$ & $8.1 \pm 1.5$ & $8.2 \pm 1.3$ & $8.3 \pm 1.4$ \\
(Baecke) $_{\text {Leptin }(\mathrm{ng} / \mathrm{ml})}$ & $\mathrm{U}$ & $8.3 \pm 1.2$ & $8.5 \pm 1.2$ & $8.5 \pm 1.2$ & $8.4 \pm 1.3$ \\
& $\mathrm{~S}$ & $28.1 \pm 18.3$ & $10.1 \pm 6.7$ & $15.3 \pm 12.5$ & $13.3 \pm 8.8$ \\
& $\mathrm{U}$ & $26.6 \pm 16.6$ & $8.7 \pm 5.5$ & $14.6 \pm 7.7$ & $17.5 \pm 8.4$ \\
\hline
\end{tabular}

${ }^{1}$ There was a significant overall group $x$ time interaction $(\mathrm{p}<0.001)$ based on a 2 -factor repeated measures ANOVA

${ }^{2} \mathrm{p}<0.05$ (t-test, group $\mathrm{S}$ versus $\mathrm{U}$ at baseline)

${ }^{3} \mathrm{p}=0.06$ (t-test, group $\mathrm{S}$ versus $\mathrm{U}$ at baseline)

${ }_{5}^{4} \mathrm{p}<0.01$ (2-factor repeated measures ANOVA with group $x$ time interaction from t0-t2 respectively)

${ }^{5} \mathrm{p}<0.01$ (2-factor repeated measures ANOVA with group $x$ time interaction from $\mathrm{t} 1$ - $\mathrm{t} 2$ respectively)

${ }^{6} \mathrm{p}<0.01$ (2-factor repeated measures ANOVA with group $x$ time interaction from t0-t3 respectively)

$7 \mathrm{p}<0.01$ (2-factor repeated measures ANOVA with group $x$ time interaction from $\mathrm{t} 1$ - $\mathrm{t} 3$ respectively)

$8 \mathrm{p}<0.01$ (2-factor repeated measures ANOVA with group $\mathrm{x}$ time interaction from $\mathrm{t} 2$ - $\mathrm{t} 3$ respectively)

Table 2: Frequency distribution of the genotypes of 3 groups: all subjects together $(n=119)$, successful weight maintenance $(<10 \%$ regain over 1 year) $(n=21)$ and unsuccessful weight maintenance $(\geq 10 \%$ regain over 1 year) $(n=98)$.

\begin{tabular}{lcccc}
\hline & Genotype & $\begin{array}{c}\text { Frequency } \\
\text { All }(\mathrm{n}=119)\end{array}$ & $\begin{array}{c}\text { Frequency } \\
\text { Successful }(\mathrm{n}=21)\end{array}$ & $\begin{array}{c}\text { Frequency } \\
\text { Unsuccessful }(\mathrm{n}=98)\end{array}$ \\
\hline${\text { PPAR } \gamma 2^{1}}^{1}$ & P/P & $93(78.2 \%)$ & $18(85.7 \%)$ & $75(76.5 \%)$ \\
& P/A & $25(21.0 \%)$ & $2(9.5 \%)$ & $23(23.5 \%)$ \\
GRL $^{2}$ & A/A & $1(0.8 \%)$ & $1(4.8 \%)$ & $0(0 \%)$ \\
& C/C & $49(41.2 \%)$ & $6(28.6 \%)$ & $43(43.9 \%)$ \\
& C/G & $56(47.0 \%)$ & $9(42.9 \%)$ & $47(48.0 \%)$ \\
CNTF & G/G & $14(11.8 \%)$ & $6(28.6 \%)$ & $8(8.2 \%)$ \\
& G/G & $85(71.4 \%)$ & $13(61.9 \%)$ & $72(73.5 \%)$ \\
& G/A & $32(26.9 \%)$ & $8(38.1 \%)$ & $24(24.5 \%)$ \\
& G/A & $2(1.7 \%)$ & $0(0 \%)$ & $2(2.0 \%)$ \\
\hline
\end{tabular}

${ }^{1} p=0.05$, successful vs. unsuccessful (Fisher exact test)

$2 \mathrm{p}<0.05$, successful vs. unsuccessful (Fisher exact test) 
Table 3: Results of binary logistic regression analysis with successful weight maintenance as the categorical outcome variable and GRL genotype, baseline BMI, disinhibition and hunger as independent variables.

\begin{tabular}{lcccc}
\hline & Odds ratio & \multicolumn{2}{c}{$95 \%$ C.I. } & P-value \\
& & Lower & Upper & \\
\hline BMI $\left(\mathrm{kg} / \mathrm{m}^{2}\right)$ & 1.110 & 0.979 & 1.258 & 0.102 \\
Disinhibition (F2 of TFEQ) & 1.234 & 0.943 & 1.616 & 0.126 \\
Hunger (F3 of TFEQ) & 0.792 & 0.671 & 0.934 & 0.006 \\
GRL (G/G vs. C/C and C/G) & 5.032 & 1.140 & 22.205 & 0.033 \\
\hline
\end{tabular}

\section{DISCUSSION}

Subjects were categorized into 2 distinct groups (successful and unsuccessful WM) according to either high or low rates of weight change over the follow-up period. A break below and above a $10 \%$ weight regain had appeared. Subjects with the homozygous P/P genotype for the PPAR 22 gene and subjects with the homozygous G/G genotype for the GRL gene (which genotype frequencies were relatively more present in the successful group) appeared to have a higher baseline BMI as compared to the other genotypes in both genes. Moreover, subjects with the P/P genotype had a significantly higher waist circumference as compared to the other 2 genotypes in the PPAR $\gamma 2$ gene. Subjects with a relatively high baseline BMI, waist circumference and fat mass (FM), appeared to lose relatively more weight and body fat, while at the same time they showed better WM, related to effective changes in body composition (7); these characteristics were more frequently present in subjects with the homozygous genotype P/P for the PPAR 22 gene and in subjects with the homozygous G/G genotype for the GRL gene. Both genes have an important role in the metabolism of adipose tissue, i.e. the PPAR $\gamma 2$ gene modulates the expression of target genes involved in adipocyte differentiation (9) and the GRL gene is involved in the regulation of abdominal fat distribution (11), and therefore may be related to WM. The PPAR 2 gene was no independent predictor for better weight maintenance, when corrected for baseline BW, BMI and waist circumference.

As previously shown (32-35), leptin was strongly dependent on FM in (both successful and unsuccessful) obese subjects. Variation in the CNTF genotype was of no influence on better WM, but the different genotypes were in fact related to leptin concentration. Compared to subjects with the CNTF G/G genotype, subjects with the G/A genotype appeared to have a smaller decrease in leptin concentration during weight loss. A smaller decrease in leptin concentration may contribute to better WM; both animal and human studies indicate that low baseline or decreased (as observed during fasting) leptin levels act as a peripheral signal of starvation, which subsequently may be a trigger to increase weight, thereby ensuring survival of the species (36).

Similar to previously reported observations $(2,37)$, subjects that were able to increase their dietary restraint during the whole study period were better able to control or maintain their weight (Table 3). McGuire and colleagues (2001) found that increases in dietary restraint in the WM period were related to decreases in body weight (38). An increase in dietary restraint is often related to a decrease in disinhibition (39-41). In this study we found this inverse correlation as well (7). Moreover, weight gainers appear to be low in dietary restraint and high in disinhibition $(39,42,43)$. This implies that WM may 
only be sustained with high dietary restraint scores in combination with low scores on disinhibition. Furthermore, in this study we found that successful subjects appeared to increase dietary restraint and at the same time reduced their general hunger feelings over time. Thus, subjects that do not suffer from hunger may not be vulnerable to inhibit dietary restraint and therefore they sustain or even increase dietary restraint, and consequently maintain their BW. In addition, compared to the other two genotypes the homozygous carriers of the G allele of the GRL gene showed significant decreases over time in their disinhibition/emotional eating scores and their hunger scores, which may result in decreased food intake. Moreover, independently of these variables the GRL gene had a direct influence on WM, in that the $G / G$ genotype was an independent predictor for successful WM, subjects with the G/G genotype had a 5 times higher chance on success. To summarize the above mentioned, we speculate that due to environmental changes every individual may become overweight. But having the 'right' genes may contribute to successful WM, a more favorable body composition (which allows more BW flexibility) as well as less feelings of hunger, disinhibition and emotional eating. Therefore, individuals with these particular genotypes may be more sensitive for certain treatments, since the treatment is more rewarded and the reduced body weight is maintained (and vice versa). In fact, these are the individuals may not necessarily 'need' to be overweight. For the PPAR 2 and GRL genes we have found that, compared to the unsuccessful subjects the successful subjects showed a significantly different genotype frequency distribution. For the PPAR 2 genotype the successful group had relatively less heterozygous subjects (P/A) as compared to the whole group. Similar results were reported by Nicklas and colleagues (2001), who found that mean weight regain during follow-up was greater in women with the Ala allele than women homozygous for the Pro allele ( $5.4 \pm 0.9$ vs. $2.8 \pm 0.4 \mathrm{~kg}, \mathrm{p}<0.01)(10)$. Also other studies found that greater weight gain was associated with the Ala allele $(44,45)$. For the GRL genotype we found that, as compared to the whole group, the successful group had relatively more homozygous carriers of the $\mathrm{G}$ allele. In addition, these homozygous $\mathrm{G}$ allele carriers had a significantly higher initial BMI compared to the $C$ allele carriers. The latter result was in accordance with the findings of Rosmond et al (2000) and Buemann et al $(1997)(13,14)$. Little research investigated the association of the CNTF genotype and obesity. O'Dell and colleagues (2002) found that males homozygous for the null mutation had a significantly higher BW and BMI as compared to males with the other genotypes, while other studies, including the present study, reported no or very little association with obesity.

A strength of the present study is that after weight loss there were two measurement periods, one after 3 months and one after 1 year WM. The successful group, in contrast to the unsuccessful group, showed no differences in the measured variables between the two measurement points, which indicates that being successful at 3 months WM seems to be a good predictor for being successful at 1 year.

Clearly, obesity is a multi-factorial disease. From the present study we conclude that after weight loss, genetic factors played a role in successful WM that mainly appeared in subjects that increased their dietary restraint, who were supported by characteristics such as a relatively high baseline BMI, waist circumference and FM and a more favorable body composition. The different genotypes of the PPAR $\gamma 2$ and GRL genes contribute directly or indirectly to weight maintenance in that they may induce different biological mechanisms e.g. fat cell differentiation (PPAR $\gamma 2$ and GRL) leading to a higher BMI and more BW flexibility; behavioral differences supported by physiological mechanisms (GRL) leading to a change in the Three Factor Eating Questionnaire scores, which all result in better WM. 


\section{ACKNOWLEDGEMENTS}

We thank our subjects for their thoughtful participation in this study. We gratefully thank Loek Wouters, Roy Langeveld, Joan Senden and Wendy Sluijsmans for their assistance and we acknowledge Dr. Natalie Luscombe-Marsh for editing the English text.

NV and MW designed the present study. The main investigator of this study was NV, who prepared for and carried out the main body of the work, collected and analyzed the data, and wrote the largest part of the manuscript. FB contributed to the practical work itself and wrote a part of the subjects and methods section. AK supervised the statistical analysis and reviewed the manuscript. KD reviewed the manuscript. Planning, processing the results and writing the manuscript were done under general supervision by EM and MW. The authors had no conflict of interest. 


\section{REFERENCES}

1. Pasman WJ, Rossner S, Westerterp-Plantenga MS, Saris WH. Body weight changes after treatment of obesity or pregnancy. Milan, Italy: Edra, 1999: Pages.

2. Westerterp-Plantenga MS, Kempen KP, Saris WH. Determinants of weight maintenance in women after diet-induced weight reduction. Int J Obes Relat Metab Disord 1998;22:1-6.

3. Pasman WJ, Saris WH, Westerterp-Plantenga MS. Predictors of weight maintenance. Obes Res 1999;7:43-50.

4. Anderson JW, Vichitbandra S, Qian W, Kryscio RJ. Long-term weight maintenance after an intensive weight-loss program. J Am Coll Nutr 1999;18:620-7.

5. Leermakers EA, Perri MG, Shigaki CL, Fuller PR. Effects of exercise-focused versus weight-focused maintenance programs on the management of obesity. Addict Behav 1999;24:219-27.

6. $\quad$ Ewbank PP, Darga LL, Lucas CP. Physical activity as a predictor of weight maintenance in previously obese subjects. Obes Res 1995;3:257-63.

7. Vogels N, Westerterp-Plantenga MS. Categorical strategies based on subject characteristics of dietary restraint and physical activity, for weight maintenance. Int J Obes Relat Metab Disord 2005;29:849-57.

8. Tremblay A, Bouchard L, Bouchard C, Despres JP, Drapeau V, Perusse L. Long-term adiposity changes are related to a glucocorticoid receptor polymorphism in young females. J Clin Endocrinol Metab 2003;88:3141-5.

9. Rosmond R, Chagnon M, Bouchard C. The Pro12Ala PPARgamma2 gene missense mutation is associated with obesity and insulin resistance in Swedish middle-aged men. Diabetes Metab Res Rev 2003;19:159-63.

10. Nicklas BJ, van Rossum EF, Berman DM, Ryan AS, Dennis KE, Shuldiner AR. Genetic variation in the peroxisome proliferator-activated receptor-gamma2 gene (Pro12Ala) affects metabolic responses to weight loss and subsequent weight regain. Diabetes 2001;50:2172-6.

11. Ukkola O, Rosmond R, Tremblay A, Bouchard C. Glucocorticoid receptor Bcl I variant is associated with an increased atherogenic profile in response to long-term overfeeding. Atherosclerosis 2001;157:221-4.

12. van Rossum EF, Koper JW, van den Beld AW, et al. Identification of the BclI polymorphism in the glucocorticoid receptor gene: association with sensitivity to glucocorticoids in vivo and body mass index. Clin Endocrinol (Oxf) 2003;59:585-92.

13. Rosmond R, Chagnon YC, Holm G, et al. A glucocorticoid receptor gene marker is associated with abdominal obesity, leptin, and dysregulation of the hypothalamicpituitary-adrenal axis. Obes Res 2000;8:211-8.

14. Buemann B, Vohl MC, Chagnon M, et al. Abdominal visceral fat is associated with a BcII restriction fragment length polymorphism at the glucocorticoid receptor gene locus. Obes Res 1997;5:186-92.

15. Munzberg $\mathrm{H}$, Tafel J, Busing B, et al. Screening for variability in the ciliary neurotrophic factor (CNTF) gene: no evidence for association with human obesity. Exp Clin Endocrinol Diabetes 1998;106:108-12.

16. Takahashi R, Yokoji H, Misawa H, Hayashi M, Hu J, Deguchi T. A null mutation in the human CNTF gene is not causally related to neurological diseases. Nat Genet 1994;7:7984.

17. O'Dell SD, Syddall HE, Sayer AA, et al. Null mutation in human ciliary neurotrophic factor gene confers higher body mass index in males. Eur J Hum Genet 2002;10:749-52.

18. Jacob AC, Zmuda JM, Cauley JA, et al. Ciliary neurotrophic factor (CNTF) genotype and body composition. Eur J Hum Genet 2004; 12:372-6.

19. van Marken Lichtenbelt WD, Westerterp KR, Wouters L. Deuterium dilution as a method for determining total body water: effect of test protocol and sampling time. $\mathrm{Br}$ J Nutr 1994;72:491-7.

20. Schoeller DA, van Santen E, Peterson DW, Dietz W, Jaspan J, Klein PD. Total body water measurement in humans with 180 and 2H labeled water. Am J Clin Nutr 1980;33:268693. 
21. Westerterp KR, Wouters L, van Marken Lichtenbelt WD. The Maastricht protocol for the measurement of body composition and energy expenditure with labeled water. Obes Res 1995;3 Suppl 1:49-57.

22. Stunkard AJ, Messick S. The three-factor eating questionnaire to measure dietary restraint, disinhibition and hunger. J Psychosom Res 1985;29:71-83.

23. Westerterp-Plantenga MS, Rolland V, Wilson SA, Westerterp KR. Satiety related to $24 \mathrm{~h}$ diet-induced thermogenesis during high protein/carbohydrate vs high fat diets measured in a respiration chamber. Eur J Clin Nutr 1999;53:495-502.

24. Laessle RG, Tuschl RJ, Kotthaus BC, Pirke KM. A comparison of the validity of three scales for the assessment of dietary restraint. J Abnorm Psychol 1989;98:504-7.

25. Neale BM, Mazzeo SE, Bulik CM. A twin study of dietary restraint, disinhibition and hunger: an examination of the eating inventory (three factor eating questionnaire). Twin Res 2003;6:471-8.

26. Laessle RG, Tuschl RJ, Kotthaus BC, Pirke KM. Behavioral and biological correlates of dietary restraint in normal life. Appetite 1989;12:83-94.

27. Tuschl RJ, Platte P, Laessle RG, Stichler W, Pirke KM. Energy expenditure and everyday eating behavior in healthy young women. Am J Clin Nutr 1990;52:81-6.

28. Philippaerts RM, Westerterp KR, Lefevre J. Doubly labelled water validation of three physical activity questionnaires. Int J Sports Med 1999;20:284-9.

29. Baecke JA, Burema J, Frijters JE. A short questionnaire for the measurement of habitual physical activity in epidemiological studies. Am J Clin Nutr 1982;36:936-42.

30. Yen CJ, Beamer BA, Negri C, et al. Molecular scanning of the human peroxisome proliferator activated receptor gamma (hPPAR gamma) gene in diabetic Caucasians: identification of a Pro12Ala PPAR gamma 2 missense mutation. Biochem Biophys Res Commun 1997;241:270-4.

31. Weinsier RL, Hunter GR, Desmond RA, Byrne NM, Zuckerman PA, Darnell BE. Free-living activity energy expenditure in women successful and unsuccessful at maintaining a normal body weight. Am J Clin Nutr 2002;75:499-504.

32. Sartorio A, Agosti F, Resnik M, Lafortuna CL. Effects of a 3-week integrated body weight reduction program on leptin levels and body composition in severe obese subjects. J Endocrinol Invest 2003;26:250-6.

33. Nagy TR, Davies SL, Hunter GR, Darnell B, Weinsier RL. Serum leptin concentrations and weight gain in postobese, postmenopausal women. Obes Res 1998;6:257-61.

34. Neuhauser-Berthold M, Herbert BM, Luhrmann PM, et al. Resting metabolic rate, body composition, and serum leptin concentrations in a free-living elderly population. Eur J Endocrinol 2000;142:486-92.

35. Sudi KM, Gallistl S, Borkenstein MH, et al. Effects of weight loss on leptin, sex hormones, and measures of adiposity in obese children. Endocrine 2001;14:429-35.

36. Havel PJ. Role of adipose tissue in body-weight regulation: mechanisms regulating leptin production and energy balance. Proc Nutr Soc 2000;59:359-71.

37. Lejeune MP, Van Aggel-Leijssen DP, Van Baak MA, Westerterp-Plantenga MS. Effects of dietary restraint vs exercise during weight maintenance in obese men. Eur J Clin Nutr 2003;57:1338-44.

38. McGuire MT, Jeffery RW, French SA, Hannan PJ. The relationship between restraint and weight and weight-related behaviors among individuals in a community weight gain prevention trial. Int J Obes Relat Metab Disord 2001;25:574-80.

39. Dykes J, Brunner EJ, Martikainen PT, Wardle J. Socioeconomic gradient in body size and obesity among women: the role of dietary restraint, disinhibition and hunger in the Whitehall II study. Int J Obes Relat Metab Disord 2004;28:262-8.

40. Hays NP, al. e. Eating behavior correlates of adult weight gain and obesity in healthy women aged 55-65 y. Am J Clin Nutr 2002;75:476-83.

41. Williamson DA, Lawson OJ, Brooks ER, et al. Association of body mass with dietary restraint and disinhibition. Appetite 1995;25:31-41.

42. Lawson OJ, Williamson DA, Champagne CM, et al. The association of body weight, dietary intake, and energy expenditure with dietary restraint and disinhibition. Obes Res 1995;3:153-61. 
43. McGuire MT, Wing RR, Klem ML, Lang W, Hill JO. What predicts weight regain in a group of successful weight losers? J Consult Clin Psychol 1999;67:177-85.

44. Douglas JA, Erdos MR, Watanabe RM, et al. The peroxisome proliferator-activated receptor-gamma2 Pro12A1a variant: association with type 2 diabetes and trait differences. Diabetes 2001;50:886-90.

45. Lindi V, Sivenius K, Niskanen L, Laakso M, Uusitupa MI. Effect of the Pro12Ala polymorphism of the PPAR-gamma2 gene on long-term weight change in Finnish nondiabetic subjects. Diabetologia 2001;44:925-6. 


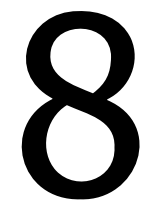

Discussion 


\section{GENERAL DISCUSSION}

The aim of the studies presented in this thesis was to identify physiological, behavioral and genetic determinants related to overweight and obesity in adults and children. According to the first law of thermodynamics, obesity is the consequence of a long-term imbalance between energy intake and energy expenditure (1). When energy intake equals energy expenditure, the body is in energy balance and body mass is stable. When energy intake exceeds energy expenditure, the body stores the extra energy as fat in the adipose tissue. Changes in body weight are mainly due to changes in body fat (2). Overweight individuals therefore have a different body composition as compared to lean individuals. Losing weight, by increasing energy expenditure or decreasing energy intake, or both, will change the body composition. Various physiological, behavioral and genetic determinants have an influence on the level of energy intake and energy expenditure and therefore on energy balance.

\section{PHYSIOLOGY AND BEHAVIOR}

\section{Eating behavior}

Changes in eating behavior, for example an increase in dietary restraint and a decrease in inhibition of restraint and the general feeling of hunger, have been related to successful weight maintenance in adults (3-5). We found that subjects who were triggered to increase their dietary restrained eating behavior during the diet, and moreover, who were able to keep this high level of restraint, showed better weight maintenance even after 1-8 years follow up (6-8). These subjects are 'successfully dietary restrained eaters' $(9,10)$, which means that their high restrained eating behavior helps them to control their weight effectively. Rather than a preventive method for becoming overweight or regaining weight, as present in adults (11), a high dietary restraint score in children may be interpreted as a consequence of being overweight, since lean children showed no dietary restrained eating behavior (12). We saw that the overweight children were significantly more dietary restraint, and also their inhibition of restraint was significantly higher as compared to the lean children (12). Both findings are consistent with previous observations $(13,14)$. The fact that they are overweight makes them more conscious about eating. During social events, when they may feel that others are observing them, they 'behave' and eat less than they would do otherwise (dietary restrained eating behavior) (15), whereas when they are alone or in a familiar environment they easily let go and eat what they like (inhibition of restraint) (12). In children, high restrained eating behavior, or a high focus on eating and dieting, may therefore be a risk factor to become even more overweight (13). Additionally, we have demonstrated that high restraint scores of the mother were significant predictors for overweight in children (12). The mother's eating behavior serves as a source of information for the child regarding what cues should trigger eating and how much to eat. Children subconsciously learn a lot about food and eating from the family environment. Especially mothers, as the primary caretaker, provide children with structure for meals by offering particular foods, and learn the child when and how much to eat (16). Highly restrained eating behavior is copied by the child as well. However, in children these dieting and weight concerns appear to have an adverse effect (12), at least in the Netherlands, where the environment is not considered very obesogenic, for example because the largest proportion of the meals is still cooked and consumed at 
home. To address this problem, parents should know about healthy food and food habits (e.g. portion-size, eat three meals a day, do not miss out breakfast, the importance of eating at home (17-20)). More importantly, parents should look after their own as well as their children's food choice and be aware that they act as a role-model for their children. They should understand their influence on the children's eating behavior and its association with overweight. In a very obesogenic environment, where there is an abundant and readily available supply of highly palatable foods and where a very large proportion of the meals are eaten outside home (20), a certain degree of restraint, even in children, is necessary to avoid overweight. However, also in these environments, parents have a large influence on and responsibility to their children to develop healthy food habits and prevent them from getting overweight. Future research should involve both parents and children, focusing on the influence of the parents on the children's eating behavior, in both very obesogenic and less obesogenic environments. Preferably, such studies should use longitudinal designs that can establish causal relations between parents' weight status and eating behavior and the development of children's eating behavior and overweight.

\section{Physical activity}

Changing activity behavior is a different way to influence energy balance. An increase in physical activity has frequently been related with successful weight maintenance (21, 22). Also, a relatively high regular physical activity level appears to be protective against obesity $(23,24)$. Comparable results were found in our children cohort (15). On the contrary, there are also studies that report no additional effect of physical activity $(3,25-$ 27). Different problems may arise during the measurement of physical activity and these problems may affect the interpretation of the results. The different terminology used to define physical activity and energy expenditure is the first. Total energy expenditure (TEE) consists of 3 components: basal metabolic rate (BMR) $(\sim 60-70 \%)$, diet induced thermogenesis (DIT) $(10-15 \%)$ and the most variable component, activity-related energy expenditure (AEE) (28). Measuring physical activity gives information about movements or physical activities and about the AEE. Besides, the physical activity level $(P A L=T E E / B M R)$ is a ratio indicating an individuals' activity level, which ranges from 1.22.5 for 'sustainable lifestyles' (29). Because of its complex nature, it is difficult to accurately assess physical activity under free-living conditions. One of the best techniques available to measure physical activities is tri-axial accelerometry, measuring accelerations in three different directions (30). In our children cohort, we therefore used this technique coupled with a validated questionnaire. We measured physical activities in free-living circumstances as well as in a controlled situation in overweight and lean children. In this way we were able to investigate whether the overweight children actually move less in free-living circumstances, or just move more slowly (e.g. taking more short breaks) in identical circumstances with programmed physical activities. We found that in their typical living environment, overweight children indeed moved significantly less, without being aware of it (15). Thus, compared to the lean children, in the overweight children the number of activity counts is unconsciously reduced. Since their movements per activity were the same as in lean children, when they were performing the same structured activities (15), and since it is known that energy expenditure per weight bearing activity is higher in overweight children due to their higher body mass (31), it may be that they drop the number of activities to compensate for the increased weight bearing activity-related energy expenditure. Obviously, a crosssectional design like this cannot prove whether an inactive lifestyle causes obesity or whether obesity leads to an inactive lifestyle. However, since the lean children moved 
significantly more than the overweight, the abovementioned theory seems possible, yet definite conclusions can only be drawn from longitudinal designs with different measurements over a long period of time. In addition, just using questionnaires to measure physical activity will over-estimate activity in the overweight. In conclusion, overweight children should move more in order to prevent childhood obesity. For future studies, physical activity would be best measured in free-living circumstances for longer periods of time on repeated occasions, which is feasible with tri-axial accelerometers.

\section{Subject specific strategies}

Different behavioral strategies may improve weight loss maintenance. Some people prefer to change their dietary habits while others prefer to become more physically active $(26,32,33)$. Strategies for weight maintenance differ between subjects and choosing these strategies according to the subjects' capability or preference may facilitate weight maintenance. To investigate the effect of these strategies, we categorized subjects according to their possible increase, during the first six weeks of the study, in dietary restraint, or physical activity, or both, or none of these. During one year, half of the subjects received subject specific guidelines according to their measured capability and half received guidelines opposite to their measured capability. The guidelines were based on scientific research about diet (e.g. portion size, meal frequency, energy density and macronutrient intake (34-37)), about exercise (e.g. activity intensity, activity-induced decrease in appetite (38-44)), about diet + exercise $(22,45)$, or about all other cues but diet + exercise (placebo or distraction from obsessive dieting) (46). The type of guidelines appeared to have no influence on weight maintenance (7). Independent of the guideline category, only the subjects that increased their dietary restraint during weight loss showed better weight maintenance and could also benefit from subject non-specific guidelines. Additionally, subjects receiving guidelines opposite to their preference showed better weight maintenance than subjects receiving preferred guidelines (7). As far as we know, very little research, concerning subject specific preference, has been done in this field. One study by Renjilian and colleagues (2001) observed no significant effects of treatment preference or the interaction of treatment preference by type of therapy (47). We speculate that new, unknown guidelines may have given subjects 'renewed' ideas on how to maintain their lower body weight, while the familiar guidelines that subjects apparently applied already, did not add anymore to weight maintenance. After all, subjects invent and apply their own strategies and increasing dietary restraint appeared to be most effective (7). Keeping this in mind, future research into effective weight maintenance strategies should select subjects that are able to increase and sustain dietary restraint, have a favorable genetic background (48), and the ability to spare fat free mass $(7,8)$. Due to these beneficial characteristics, these subjects may not necessarily prone to overweight. Effectively using their own strategies may therefore reduce the overall prevalence of overweight.

\section{Body composition and leptin}

Better weight maintenance was predicted by a higher fat mass at baseline and by a higher fat mass loss during weight loss $(7,8)$. When losing a large amount of fat, the body composition changes into a more usual ratio. This renewed ratio appeared to be more favorable and thus preserved by the body. Previously Dulloo et al. (1999) described this effect, in which the body composition of a given individual changed continuously towards a leaner body composition during the course of starvation (49). 
We found that large fat losses induced this fat free mass sparing effect, which subsequently was associated with better weight maintenance $(7,8)$. Another possible way to facilitate this fat free mass sparing effect is to increase the protein content in the diet, which has frequently been studied (50-53).

The amount of fat in the blood is a crucial measure for the brain to keep the body in energy balance. Part of the information about the energy stores is regulated by the hormone leptin (54). We observed a strong positive relationship between serum leptin concentration and fat mass $(r=0.76, p<0.01)$, at all measured time points, in both the subjects that showed successful weight maintenance and unsuccessful weight maintenance $(7,8)$. Because there was no clear difference in the correlations between the successful and unsuccessful groups, we could not explain a crucial role for leptin in this fat free mass sparing effect. Recently, another regulator of the body's energy storage has been discovered. The amount of malonyl coenzyme A (malonyl-CoA) present in the hypothalamus represents the amount of fatty acids in the blood. Fasting produces a state of negative energy balance in which hypothalamic malonyl-CoA is reduced and appetite is increased. Refeeding reverses these effects (55). Future research should focus on this direct pathway and its relation with human obesity. Generally, more research is required about the signals regulating energy intake and energy expenditure from the adipose tissue to the brain and vice versa.

\section{GENETIC ASPECTS}

A large number of genes have been related to the onset of obesity (56). Of these, we selected three relevant genes for our studies. Selection was based upon the relatively high allelic frequency distribution in our population and upon a proposed biological function. In adults, we found that certain genotypes of the peroxisome proliferatoractivated receptor (2 (PPAR(2) and the glucocorticoid receptor (GRL) genes were associated with better weight maintenance (48). The $\operatorname{PPAR}(2$ gene modulates the expression of target genes involved in adipocyte differentiation (57). The polymorphism in the PPAR(2 gene is located in an exon and changes an amino acid in the protein. The allelic forms may therefore have a slightly different functionality and consequently a different capacity to support adipocyte differentiation. The GRL gene is involved in the regulation of abdominal fat distribution (58). The polymorphism in the GRL gene is located in the second intron and therefore a defective protein is unlikely to occur. However, it is probably in linkage disequilibrium with an, as yet, unknown polymorphism, interfering with the rate of transcription of the gene. This may change the tissue GRL density for carriers of each of the alleles. As a result cortisol hormone sensitivity could be altered, which is associated with the regulation of the hypothalamicpituitary-adrenal (HPA) axis. Literature shows that elevated cortisol levels are related with stress-induced obesity (59).

Variation in the CNTF gene was not significantly related with successful weight maintenance. However, subjects with the null mutation for the CNTF gene, which leads to a defective protein, appeared to have a lower serum leptin concentration at baseline and a smaller drop in leptin concentration during weight loss. The CNTF receptor shares remarkable similarities with the receptor for leptin (60), suggesting that CNTF and leptin can compete for the same receptor. High, low or no CNTF may influence the availability of the receptor for leptin binding. Individuals with low CNTF may therefore be more sensitive for leptin. 
The genetic effects found in our adult cohort were not observed in the children cohort. The lack of a genetic effect in children (12) can be explained by the fact that there was no stimulated experimental situation, like exposure to a diet. Another possibility is the relatively small sample size or the small percentage of overweight children in this Dutch cohort. Cecil and colleagues (2005) investigated the role of different variants of the PPAR( gene on childhood obesity. They reported that no single variant of PPAR( was significantly associated with height, weight or BMI, despite the large sample size of 2454 children (61). Therefore, a more intriguing explanation is that childhood obesity may be mainly caused by physiological and behavioral influences, whereas in adults the hereditary factors become important.

\section{CONCLUSIONS}

Overweight in children was primarily related to physiological and behavioral factors, such as parental influences, high restraint eating behavior and low physical activity. These two latter factors can also be interpreted as consequences of overweight. Overweight will be maintained or even promoted by this vicious circle.

In adults, physiological, behavioral and genetic factors were associated with successful weight maintenance. After weight loss, genetic factors played a role in successful weight maintenance that mainly appeared in subjects that increased and sustained their dietary restrained eating behavior. These subjects were supported by characteristics such as a relatively high baseline fat mass and a large fat mass loss that induced a fat free mass sparing effect. The different genotypes of the PPAR(2 and GRL genes contributed directly or indirectly to weight maintenance. They influenced physiological mechanisms, such as fat cell differentiation (PPAR(2 and GRL) leading to a more favorable body composition. They also influenced behavioral functions that were supported by physiological mechanisms (GRL) and consequently leading to an increased restrained eating behavior. All of this resulted in better weight maintenance, independent of providing subject specific guidelines.

\section{FUTURE RESEARCH}

Weight loss may be difficult to achieve but maintaining the weight loss is an even greater challenge $(5,46,62)$. Obviously, successful weight maintenance requires physiological and behavioral changes. Most importantly, one needs to continuously maintain these changes for their lifetime $(21,63,64)$. Based on our results (7), as well as on those from others $(65,66)$, it appears that $~ 20 \%$ of overweight individuals are successful weight maintainers after weight loss. In fact, these are the very persons that are not necessarily prone to overweight. Due to their beneficial genetic background and related physiological and behavioral support they have a greater chance to successfully maintain a healthy weight after weight loss. A future protocol should select these particular subjects and make them aware that they do not need to be overweight. Treatment should focus on the strategies already used by these subjects. For example, they should be encouraged to write down their own invented strategies, and then further elaborate and refine these. Subjects should recognize the importance of these strategies and be stimulated to use them over their lifetime, particularly when they feel 
like their weight is increasing again. Furthermore, we suggest that these strategies could be combined with other strategies, such as increasing the protein content in the diet (50-53). The ultimate goal should be a lifelong change in their lifestyle. Executing longterm weight maintenance studies, with primary focus on these very subjects, and implementing these rather simple behavioral strategies, will treat $\sim 20 \%$ of overweight in the population and therefore prevent this section of the population from becoming obese. A very long duration of follow-up may be desirable, although it has been shown that subjects who kept their weight off for 2 years or more had markedly increased odds of continuing to maintain their weight over the following year (66). Unfortunately, the remaining $\sim 80 \%$ of overweight subjects will not benefit from rather simple strategies, and therefore they are very vulnerable to weight regain and subsequent obesity. For these subjects, the influence of other strategies, for example high protein diets should be investigated more elaborately $(50-53)$. The next step is to recommend pharmacological treatments (e.g. rimonabant, orlistat or sibutramine (67-69)). For morbid obese subjects, surgical treatment will still be required (70).

Since this thesis has examined valuable data regarding the development of childhood obesity from birth to post-puberty, the follow-up of this population is strongly recommended. In these children, important measurements on anthropometry and body composition were executed. Once the children reach the crucial period of puberty and their body composition is changing, follow-up measurements will ensure these changes are detected. It will be of interest to observe at which age a possible genetic expression related to body composition may appear. 


\section{REFERENCES}

1. Tremblay A, Perusse L, Bouchard C. Energy balance and body-weight stability: impact of gene-environment interactions. Br J Nutr 2004;92 Suppl 1:S63-6.

2. Kopelman PG. Obesity as a medical problem. Nature 2000;404:635-43.

3. Lejeune MP, Van Aggel-Leijssen DP, Van Baak MA, Westerterp-Plantenga MS. Effects of dietary restraint vs exercise during weight maintenance in obese men. Eur J Clin Nutr 2003;57:1338-44.

4. McGuire MT, Jeffery RW, French SA, Hannan PJ. The relationship between restraint and weight and weight-related behaviors among individuals in a community weight gain prevention trial. Int J Obes Relat Metab Disord 2001;25:574-80.

5. Westerterp-Plantenga MS, Kempen KP, Saris WH. Determinants of weight maintenance in women after diet-induced weight reduction. Int J Obes Relat Metab Disord 1998;22:1-6.

6. Vogels $\mathrm{N}$, Diepvens $\mathrm{K}$, Westerterp-Plantenga MS. Predictors of long-term weight maintenance. Obes Res 2005;13:2162-8.

7. Vogels N, Westerterp-Plantenga MS. Categorical strategies based on subject characteristics of dietary restraint and physical activity, for weight maintenance. Int J Obes Relat Metab Disord 2005;29:849-57.

8. Vogels N, Westerterp-Plantenga MS. Successful long-term weight maintenance, a $2 y$ follow-up. Obes Res 2006 (in revision).

9. Westerterp-Plantenga MS, Van den Heuvel E, Wouters L, ten Hoor F. Accuracy of estimates of forthcoming ingestion as a function of menu familiarity and dietary restraint. Appetite 1992; 18:101-9.

10. Yeomans MR, Tovey HM, Tinley EM, Haynes CJ. Effects of manipulated palatability on appetite depends on restraint and disinhibition scores from the Three-Factor Eating Questionnaire. Int J Obes Relat Metab Disord 2004;28:144-51.

11. Foster GD, Wadden TA, Swain RM, Stunkard AJ, Platte P, Vogt RA. The Eating Inventory in obese women: clinical correlates and relationship to weight loss. Int J Obes Relat Metab Disord 1998;22:778-85.

12. Vogels N, Posthumus DLA, Mariman ECM, et al. Determinants of overweight in a Dutch children cohort. AJCN 2006 (in press).

13. Shunk JA, Birch LL. Girls at risk for overweight at age 5 are at risk for dietary restraint, disinhibited overeating, weight concerns, and greater weight gain from 5 to 9 years. J Am Diet Assoc 2004;104:1120-6.

14. Edmunds $\mathrm{H}$, Hill AJ. Dieting and the family context of eating in young adolescent children. Int J Eat Disord 1999;25:435-40.

15. Vogels N, Westerterp KR, Posthumus DLA, Rutters F, Westerterp-Plantenga MS. Daily physical activity and activity-counts in lean and overweight Dutch children. BJN 2006 (in revision).

16. Cutting TM, Fisher JO, Grimm-Thomas K, Birch LL. Like mother, like daughter: familial patterns of overweight are mediated by mothers' dietary disinhibition. Am J Clin Nutr 1999;69:608-13.

17. Guthrie JF, Lin BH, Frazao E. Role of food prepared away from home in the American diet, 1977-78 versus 1994-96: changes and consequences. J Nutr Educ Behav 2002;34:140-50.

18. McConahy KL, Smiciklas-Wright H, Birch LL, Mitchell DC, Picciano MF. Food portions are positively related to energy intake and body weight in early childhood. J Pediatr 2002;140:340-7.

19. Siega-Riz AM, Popkin BM, Carson T. Trends in breakfast consumption for children in the United States from 1965-1991. Am J Clin Nutr 1998;67:748S-756S. 
20. St-Onge MP, Keller KL, Heymsfield SB. Changes in childhood food consumption patterns: a cause for concern in light of increasing body weights. Am J Clin Nutr 2003;78:1068-73.

21. McGuire MT, Wing RR, Klem ML, Hill JO. Behavioral strategies of individuals who have maintained long-term weight losses. Obes Res 1999;7:334-41.

22. Fogelholm M, Kukkonen-Harjula K, Oja P. Eating control and physical activity as determinants of short-term weight maintenance after a very-low-calorie diet among obese women. Int J Obes Relat Metab Disord 1999;23:203-10.

23. Brownson RC, Boehmer TK, Luke DA. Declining rates of physical activity in the United States: what are the contributors? Annu Rev Public Health 2005;26:421-43.

24. Williamson DF, Madans J, Anda RF, Kleinman JC, Kahn HS, Byers T. Recreational physical activity and ten-year weight change in a US national cohort. Int J Obes Relat Metab Disord 1993;17:279-86.

25. van Dale $D$, Schoffelen PF, ten Hoor F, Saris WH. Effects of addition of exercise to energy restriction on 24-hour energy expenditure, sleeping metabolic rate and daily physical activity. Eur J Clin Nutr 1989;43:441-51.

26. Leermakers EA, Perri MG, Shigaki CL, Fuller PR. Effects of exercise-focused versus weight-focused maintenance programs on the management of obesity. Addict Behav 1999;24:219-27.

27. Parsons TJ, Power C, Logan S, Summerbell CD. Childhood predictors of adult obesity: a systematic review. Int J Obes Relat Metab Disord 1999;23 Suppl 8:S1-107.

28. Westerterp-Plantenga MS, Steffens A, Tremblay A. Regulation of food intake and energy expenditure. Milano: EDRA, 1999.

29. Black $A E$, Coward WA, Cole TJ, Prentice AM. Human energy expenditure in affluent societies: an analysis of 574 doubly-labelled water measurements. Eur J Clin Nutr 1996;50:72-92.

30. Plasqui $G$, Joosen $A M$, Kester $A D$, Goris $A H$, Westerterp KR. Measuring free-living energy expenditure and physical activity with triaxial accelerometry. Obes Res 2005;13:1363-9.

31. Ekelund U, Aman J, Yngve A, Renman C, Westerterp K, Sjostrom M. Physical activity but not energy expenditure is reduced in obese adolescents: a case-control study. Am J Clin Nutr 2002;76:935-41.

32. Anderson JW, Vichitbandra S, Qian W, Kryscio RJ. Long-term weight maintenance after an intensive weight-loss program. J Am Coll Nutr 1999;18:620-7.

33. Ewbank PP, Darga LL, Lucas CP. Physical activity as a predictor of weight maintenance in previously obese subjects. Obes Res 1995;3:257-63.

34. Westerterp-Plantenga MS, Pasman WJ, Yedema MJ, Wijckmans-Duijsens NE. Energy intake adaptation of food intake to extreme energy densities of food by obese and nonobese women. Eur J Clin Nutr 1996;50:401-7.

35. Westerterp-Plantenga MS, Rolland V, Wilson SA, Westerterp KR. Satiety related to $24 \mathrm{~h}$ diet-induced thermogenesis during high protein/carbohydrate vs high fat diets measured in a respiration chamber. Eur J Clin Nutr 1999;53:495-502.

36. Westerterp-Plantenga MS, Goris AH, Meijer EP, Westerterp KR. Habitual meal frequency in relation to resting and activity-induced energy expenditure in human subjects: the role of fat-free mass. Br J Nutr 2003;90:643-9.

37. Westerterp-Plantenga MS, Kovacs EM, Melanson KJ. Habitual meal frequency and energy intake regulation in partially temporally isolated men. Int J Obes Relat Metab Disord 2002;26:102-10.

38. Foster GD, Wadden TA, Kendrick ZV, Letizia KA, Lander DP, Conill AM. The energy cost of walking before and after significant weight loss. Med Sci Sports Exerc 1995;27:888-94.

39. Morris JN, Hardman AE. Walking to health. Sports Med 1997;23:306-32.

40. Blair SN, Kohl HW, Gordon NF, Paffenbarger RS, Jr. How much physical activity is good for health? Annu Rev Public Health 1992;13:99-126. 
41. Votruba SB, Horvitz MA, Schoeller DA. The role of exercise in the treatment of obesity. Nutrition 2000;16:179-88.

42. Westerterp KR. Pattern and intensity of physical activity. Nature 2001;410:539.

43. Westerterp KR. Obesity and physical activity. Int J Obes Relat Metab Disord 1999;23 Suppl 1:59-64.

44. Westerterp-Plantenga MS, Verwegen CR, Ijedema MJ, Wijckmans NE, Saris WH. Acute effects of exercise or sauna on appetite in obese and nonobese men. Physiol Behav 1997;62:1345-54.

45. Van Aggel-Leijssen DP, Saris WH, Hul GB, Van Baak MA. Long-term effects of lowintensity exercise training on fat metabolism in weight-reduced obese men. Metabolism 2002; 51:1003-10.

46. Pasman WJ, Saris WH, Westerterp-Plantenga MS. Predictors of weight maintenance. Obes Res 1999;7:43-50.

47. Renjilian DA, Perri MG, Nezu AM, McKelvey WF, Shermer RL, Anton SD. Individual versus group therapy for obesity: effects of matching participants to their treatment preferences. J Consult Clin Psychol 2001;69:717-21.

48. Vogels N, Mariman EC, Bouwman FG, Kester AD, Diepvens K, Westerterp-Plantenga MS. Relation of weight maintenance and dietary restraint to peroxisome proliferator-activated receptor gamma2, glucocorticoid receptor, and ciliary neurotrophic factor polymorphisms. Am J Clin Nutr 2005;82:740-6.

49. Dulloo AG, Jacquet J. The control of partitioning between protein and fat during human starvation: its internal determinants and biological significance. $\mathrm{Br}$ ] Nutr 1999;82:339-56.

50. Layman DK, Walker DA. Potential importance of leucine in treatment of obesity and the metabolic syndrome. J Nutr 2006;136:319S-23S.

51. Lejeune MP, Kovacs EM, Westerterp-Plantenga MS. Additional protein intake limits weight regain after weight loss in humans. Br J Nutr 2005;93:281-9.

52. Westerterp-Plantenga MS, Lejeune MP. Protein intake and body-weight regulation. Appetite 2005;45:187-90.

53. Westerterp-Plantenga MS, Lejeune MP, Nijs I, van Ooijen M, Kovacs EM. High protein intake sustains weight maintenance after body weight loss in humans. Int J Obes Relat Metab Disord 2004;28:57-64.

54. Friedman JM. The function of leptin in nutrition, weight, and physiology. Nutr Rev 2002;60:S1-14; discussion S68-84, 85-7.

55. Dowell P, Hu Z, Lane MD. Monitoring energy balance: metabolites of fatty acid synthesis as hypothalamic sensors. Annu Rev Biochem 2005;74:515-34.

56. Perusse L, Rankinen T, Zuberi A, et al. The human obesity gene map: the 2004 update. Obes Res 2005;13:381-490.

57. Rosmond R, Chagnon M, Bouchard C. The Pro12Ala PPARgamma2 gene missense mutation is associated with obesity and insulin resistance in Swedish middle-aged men. Diabetes Metab Res Rev 2003;19:159-63.

58. Ukkola O, Rosmond R, Tremblay A, Bouchard C. Glucocorticoid receptor Bcl I variant is associated with an increased atherogenic profile in response to long-term overfeeding. Atherosclerosis 2001;157:221-4.

59. Bjorntorp P, Rosmond R. Obesity and cortisol. Nutrition 2000;16:924-36.

60. Munzberg $\mathrm{H}$, Tafel J, Busing B, et al. Screening for variability in the ciliary neurotrophic factor (CNTF) gene: no evidence for association with human obesity. Exp Clin Endocrinol Diabetes 1998;106:108-12.

61. Cecil JE, Fischer B, Doney AS, et al. The Pro12Ala and C-681G variants of the PPARG locus are associated with opposing growth phenotypes in young schoolchildren. Diabetologia 2005;48:1496-502.

62. Hill JO, Thompson $\mathrm{H}$, Wyatt $\mathrm{H}$. Weight maintenance: what's missing? J Am Diet Assoc 2005;105:S63-6. 
63. Perri MG, Sears SF, Jr., Clark JE. Strategies for improving maintenance of weight loss. Toward a continuous care model of obesity management. Diabetes Care 1993;16:200-9.

64. McGuire MT, Wing RR, Klem ML, Lang W, Hill JO. What predicts weight regain in a group of successful weight losers? J Consult Clin Psychol 1999;67:177-85.

65. McGuire MT, Wing RR, Hill JO. The prevalence of weight loss maintenance among American adults. Int J Obes Relat Metab Disord 1999;23:1314-9.

66. Wing RR, Phelan S. Long-term weight loss maintenance. Am J Clin Nutr 2005;82:222S$225 \mathrm{~S}$.

67. Despres JP, Golay A, Sjostrom L. Effects of rimonabant on metabolic risk factors in overweight patients with dyslipidemia. N Engl J Med 2005;353:2121-34.

68. Mathus-Vliegen EM. Long-term maintenance of weight loss with sibutramine in a GP setting following a specialist guided very-low-calorie diet: a double-blind, placebocontrolled, parallel group study. Eur J Clin Nutr 2005;59 Suppl 1:S31-8; discussion S39.

69. Mathys M. Pharmacologic agents for the treatment of obesity. Clin Geriatr Med 2005;21:735-46, vii.

70. van Gemert WG, Adang EM, Kop M, Vos G, Greve JW, Soeters PB. A prospective costeffectiveness analysis of vertical banded gastroplasty for the treatment of morbid obesity. Obes Surg 1999;9:484-91. 



\section{SUMMARY}

Obesity is a complex multi-factorial chronic disorder, associated with several major public health problems, such as cardiovascular disease and type 2 diabetes. The studies described in this thesis encompass different physiological, behavioral and genetic determinants associated with the etiology, prevention and treatment of obesity in both adults and children.

From a large cohort of Dutch children valuable anthropometrical data from birth till seven years of age were available. A follow-up study was performed in 2004, when the children had the mean age of 12 years. $15 \%$ of the children were classified as overweight and $85 \%$ as lean. Even in this homogenous cohort of normal weight to moderately overweight children, tracking of BMI during childhood took place from the first year of life. A large body weight increase during the first year of life, a high BMI of the father and high restraint scores of the mother were significant predictors for overweight at $12 y$. No genetic relationship was observed. In addition, overweight was positively associated with the dietary restraint score of the child and negatively associated with the child's activity score (chapter 2 ).

To investigate whether overweight children actually move less, or less intensive, daily physical activities at home, and activities performed according to the same instructed protocol, were measured with tri-axial accelerometers (Tracmor-4) and validated questionnaires, in lean and overweight children. In their typical living environment, mean Tracmor counts/day were significantly lower for the overweight children than for the lean, while reported activities were not significantly different. When performing the same instructed activities, there was no difference in mean Tracmor counts. To conclude, as compared to lean children, overweight children moved less without being aware of it; yet performed the same movements per activity (chapter 3 ).

The Maastricht Weight Maintenance Study is an ongoing longitudinal study of healthy men and women living in the south of the Netherlands. All subjects followed a very low calorie diet (VLCD) in order to lose weight. After a follow-up of at least 2 years, subjects were re-measured. The best predictors for weight maintenance after weight loss were an increase in dietary restraint during weight loss, a high baseline resting metabolic rate, a relatively high baseline fat mass favoring a fat free mass sparing effect during weight loss, a rather stable body weight, and a low frequency of dieting (chapter 4).

To investigate the effect of subject specific strategies for weight maintenance, 120 overweight subjects followed a VLCD for six weeks in a free-living situation. During the following 1-year weight maintenance period, subjects received guidelines (dietary, activity or placebo), according to their capability measured during weight loss and their preference for particular guidelines. After weight loss, the type of guidelines was not related to weight maintenance, whereas guidelines opposite to the subject's capability and preference were related. These only reached successful weight maintenance in originally dietary disciplined subjects, who were supported by characteristics such as a relatively high baseline BMI, waist circumference and fat mass, together with the ability to spare fat free mass (chapter 5).

To find predictors for long-term weight maintenance, the same subjects were measured again after 2-years of follow-up. Characteristics such as a relatively high baseline fat mass, the ability to spare fat free mass and more importantly, an increased and sustained high level of dietary restraint, again predicted successful long-term weight maintenance (chapter 6), which appeared to be very consistent with the 1-year results. 
Of the same group of subjects, three relevant genetic polymorphisms were measured and related to obesity and subsequently linked with the physiological and behavioral findings described in the previous chapters. Genetic factors played a role in successful weight maintenance after weight loss. The different genotypes of the PPAR $\gamma 2$ and GRL genes contributed directly or indirectly to weight maintenance. They influenced physiological mechanisms, such as fat cell differentiation (PPAR $\gamma 2$ and GRL) leading to a more favorable body composition. They also influenced behavioral functions that were supported by physiological mechanisms (GRL) and consequently leading to an increased restrained eating behavior (chapter 7 ).

To conclude, rather than an effective method to lose and maintain weight, as present in adults, a high dietary restraint score in children can be better interpreted as a consequence of being overweight, and may therefore be a risk factor to become even more overweight. In addition, a high BMI of the father and high restraint scores of the mother significantly predicted overweight in children. Parents should therefore look after their own as well as their children's food choice and be aware that they act as a rolemodel for their children. Also, a low physical activity level in overweight children is a risk factor to become even more overweight. Instead of moving less, overweight children should initiate at least the same number of movements than lean children, in order to prevent obesity. In adults, we found that subjects who increased dietary restraint using their own strategies appeared to be most successful during weight maintenance. In all, the ultimate goal should be a lifelong change in the individual's lifestyle. Moreover, large fat losses inducing a fat free mass sparing effect, supported weight maintenance considerably. 


\section{SAMENVATTING}

Obesitas, of extreem overgewicht, is een chronische aandoening die geassocieerd wordt met verschillende ziektebeelden zoals hart- en vaatziekten en type- 2 diabetes. Dit proefschrift richt zich op bepaalde fysiologische, gedragsmatige en erfelijke eigenschappen die invloed hebben op het ontstaan, de preventie en de behandeling van obesitas bij volwassenen en kinderen.

Bij een Nederlands kindercohort zijn vanaf de geboorte tot en met de leeftijd van 7 jaar jaarlijks lengte en gewicht gemeten. In 2004 waren deze kinderen gemiddeld 12 jaar en werden ze gevraagd om mee te doen aan een follow-up meting. 15\% bleek overgewicht te hebben en $85 \%$ had een normaal gewicht. Tevens bleek dat de BMI op 12 jarige leeftijd gerelateerd was aan de BMI op 1 jarige leeftijd. Dit is opmerkelijk, gegeven het lage percentage overgewicht in dit cohort. Andere voorspellende variabelen voor overgewicht op 12 jarige leeftijd waren een snelle groei tijdens het eerste levensjaar, een hoge BMI van de vader en een hoge mate van geremd eetgedrag van de moeder. Verder bleek dat, vergeleken met de kinderen met een normaal gewicht, de kinderen met overgewicht duidelijk meer geremd eetgedrag en minder activiteiten vertoonden (hoofdstuk 2).

Om te achterhalen of kinderen met overgewicht daadwerkelijk minder bewegen of dat ze de bewegingen die ze doen minder intensief uitvoeren, hebben we het bewegingpatroon van een groep kinderen met overgewicht vergeleken met een groep kinderen met een normaal gewicht. De activiteit werd gemeten met 3-dimensionale bewegingsmeters (Tracmor) en een gevalideerde vragenlijst. De bewegingen werden eerst in hun dagelijkse omstandigheden gemeten, waarbij ze vrij waren in hun doen en laten, en nadien tijdens een gecontroleerde situatie, waarbij er oefeningen en spelen werden uitgevoerd volgens een standaard activiteiten protocol. In hun eigen leefomgeving bleken de gemiddelde Tracmor counts/dag (objectieve maat) van de kinderen met overgewicht significant minder te zijn dan van de kinderen met een normaal gewicht, terwijl ze wel gelijk scoorden op de bewegingsvragenlijst (subjectieve maat). Tijdens de gecontroleerde situatie bleek er geen verschil te zijn in Tracmor counts tussen de twee groepen (hoofdstuk 3).

De 'Maastricht Weight Maintenance Study' is een longitudinale studie van gezonde mannen en vrouwen woonachtig in het zuiden van Nederland. Om gewicht te verliezen hebben al deze mensen onder begeleiding een dieet gevolgd. Na ten minste 2 jaar werden zij opnieuw benaderd, en werden lichaamsgewicht en andere relevante parameters weer bepaald. De beste voorspellers voor succesvol gewichtsbehoud op langere termijn na gewichtsverlies bleken een verhoging van het geremde eetgedrag tijdens het dieet, een hoog rustmetabolisme bij aanvang van de studie, en een aanvankelijk hoge vetmassa en relatief veel vetmassaverlies tijdens gewichtsverlies wat zorgde voor een gunstige lichaamssamenstelling. Verder waren een stabiel lichaamsgewicht en een lage dieetfrequentie gecorreleerd met succesvol gewichtsbehoud (hoofdstuk 4).

Hoofdstuk 5 beschrijft het effect van persoonsspecifieke adviezen op gewichtsbehoud. Als je mensen gedragsadviezen geeft die in overeenstemming zijn met hun kunnen, zou het gemakkelijker kunnen zijn om na gewichtsverlies het lagere gewicht te behouden. 120 proefpersonen met overgewicht volgden een 6 weken durend dieet, waarna tijdens een periode van 1 jaar persoonspecifieke of niet-persoonspecifieke adviezen werden aangeboden (dieet, activiteit, afleiding of combinaties daarvan). Gewichtsbehoud bleek niet afhankelijk van het soort advies. Wel leidde, tegen onze verwachting in, een niet 
persoonspecifiek advies tot beter gewichtsbehoud. Ongeacht het advies waren mensen die hun geremd eetgedrag verhoogden en die een aanvankelijk hoge vetmassa hadden, waardoor ze veel vet verloren wat leidde tot een meer gunstige lichaamssamenstelling, het meest succesvol in het behouden van hun gewicht na gewichtsverlies (hoofddstuk 5).

Na 2 jaar werd deze zelfde groep mensen opnieuw benaderd om de effecten op langere termijn vast te stellen. De resultaten bleken consistent met de resultaten na 1 jaar en opnieuw waren de mensen die hun geremd eetgedrag tijdens het dieet verhoogden en bij wie het na 2 jaar ook nog steeds hoog was het meest succesvol. Ook een aanvankelijk hoge vetmassa, en groot vetmassaverlies en dus een gunstigere lichaamssamenstelling, bleek gecorreleerd met succesvol gewichtsbehoud na 2 jaar (hoofdstuk 6).

Er werd bij deze mensen eveneens gekeken naar 3 genetische eigenschappen en de relatie met fysiologische en gedragsmatige determinanten van overgewicht. De verschillende genotypen van de peroxisome proliferator-activated $\gamma 2$ (PPAR $\gamma 2$ ) en glucocorticoid receptor (GRL) genen bleken direct of indirect gecorreleerd te zijn met gewichtsbehoud. PPAR $\gamma 2$ en GRL waren gecorreleerd met het vetvrije massa sparende effect, waardoor de lichaamssamenstelling veranderd werd. GRL was ook gerelateerd aan gedragsmatige mechanismen, zoals een veranderde houding ten opzichte van eten, resulterend in geremd eetgedrag en verminderde disinhibitie (hoofdstuk 7).

Geconcludeerd wordt dat een verhoging van het geremde eetgedrag bij volwassenen een effectieve methode voor succesvol gewichtsbehoud is. Bij kinderen lijkt deze sterke focus op eten en diëten juist een nadelige consequentie te zijn van het dik zijn en daardoor een risicofactor om nog meer aan te komen. Een hoog geremd eetgedrag van de moeder en daarnaast een hoge BMI van de vader zijn belangrijke voorspellers voor overgewicht bij kinderen. Het is om bovengenoemde redenen belangrijk dat ouders letten op hun eigen eetgedrag en dat van hun kind en beseffen dat ze zelf als voorbeeld fungeren. Verder vonden we dat kinderen met overgewicht minder bewegen dan de kinderen met een normaal gewicht, terwijl ze, om verder overgewicht te voorkomen, ten minste evenveel zouden moeten bewegen. Bij volwassenen blijkt dat mensen met een gunstige genetische achtergrond, een gunstige verandering van de lichaamsamenstelling tijdens gewichtsverlies, en die als eigen strategie het verhogen van het geremd eetgedrag hebben, het beste in staat zijn het lagere gewicht te behouden. Voor succesvol gewichtsbehoud op de lange termijn is deze levenslange aanpassing van levensstijl noodzakelijk. 


\section{DANKWOORD}

Het blijft een beetje onwerkelijk, maar hier ligt 'ie dan, mijn proefschrift! Het resultaat van 4 bijzondere jaren die werkelijk voorbij zijn gevlogen. Daar hebben natuurlijk verschillende mensen een bijdrage aan geleverd, die ik bij deze allemaal ontzettend wil bedanken.

Allereerst Margriet. Een paar voorbeelden. Als ik weer een stuk bij je inleverde zei je altijd: "Dank je wel! Heb ik vanavond weer wat leuks te lezen!" en hooguit een dag later had ik het dan weer terug en kon ik weer verder. Of de vele congressen in binnen en buitenland waar je ons altijd vol enthousiasme mee naar toe nam. En de gezellige etentjes voor onze verjaardagen.. En ondanks mijn regelmatige twijfels ben je altijd in me blijven geloven. Bedankt!

Edwin, bedankt voor het lezen van mijn papers, voor je 'genetische' inbreng en uitleg en dat ik altijd zomaar binnen kon wandelen met vragen. De beoordelingscommissie wil ik bedanken voor het kritisch lezen van mijn manuscript. Kathleen and Natalie, thank you very much for editing the English text of my articles.

Dan mijn directe (ex)collega's: Marcel, Stijn, Femke, Natalie, Margriet, Ananda, Anneke, Caroline, Annemiek, Joost, Freddy, Guy, Gijs, Joris, Tanja, Marieke en Marleen bedankt voor de vele gezellige 'Koffie/thee/limonade?!' uurtjes, feestjes en lunchpauzes. Voor Astrid, Mirjam en mijn 'back-up paranimfen' :) Lydia en Manuela een speciaal woordje: met jullie ben ik toch het meeste opgetrokken de afgelopen 4 jaar en daar heb ik enorm van genoten. Jullie kennen me inmiddels, zowel op werk als op privé gebied, door en door en dat heeft nogal eens voor hilarische taferelen gezorgd.. Jullie adviezen, meningen en luisterende oren heb ik altijd ontzettend gewaardeerd! Bovenstaande heeft ook betrekking op mijn kamergenootje en paranimf Kristel: ik denk dat wij een perfect koppel waren (zelfs samen een bed delen op congressen was geen probleem!). Ondanks je drukke schema was je altijd opgewekt en aanwezig, maar we konden ook heel goed samen stil zijn als dat nodig was. Super!

Freek, Klaas, Gerard, Daniëlle, Sandra, Marloes, Krista, Roy, Paul, Loek, Joan, Jos en Wendy wil ik bedanken voor het mogelijk maken van mijn studies, de uitvoering van verschillende analyses of als ik weer eens niet begreep hoe mijn computer werkte...

Natuurlijk niet te vergeten de secretaresses van Humane Biologie, Claudia, Ilona en Larissa, bedankt voor jullie medewerking en de herhaalde hulp bij het faxapparaat..

Verder wil ik alle andere mensen van Humane Biologie die ik nog niet genoemd heb (het zijn er inmiddels zo veel..) ook enorm bedanken voor de 4 leuke jaren die ik op deze vakgroep heb gehad.

Mijn lieve vriendinnetjes, Inge, Merel, Martine, Janneke, Cathelijne, Manja, Mariëlle, Lydia, Esther en Veronique en in het bijzonder natuurlijk mijn tweede paranimf, en allerbeste vriendinnetje, Marloes, bedankt dat jullie er altijd voor me waren en nog steeds zijn! Het heeft me ontzettend geholpen hoe vol lof jullie altijd over mij en mijn werk waren, ook al kon ik t zelf vaak moeilijk geloven. That's what friends are for.. En natuurlijk Sander niet te vergeten: veel praten en ondertussen heerlijk eten, een perfecte combi. Weet zeker dat ik jullie ook na Maastricht nog ga blijven zien, waar we allemaal ook terecht gaan komen! 
Dirk, GJ, Tim, Hugo, Marijn, Harm, Fede, Aline, Karine, Bruno en Kirsten, al ken ik jullie nog maar kort, jullie hebben het laatste jaar tot een heel bijzonder jaar gemaakt voor mij. In het bovenstaand rijtje ontbreekt zeker nog een persoon. Bram, super bedankt voor het helpen met de omslag van dit boekje. Alleen had ik dit never-nooit voor elkaar gekregen, en door jou was het in een paar uurtjes gepiept.. In een woord: geweldig!

Papa, Joke, mama, Rose, Wannes en Neeltje: altijd enorm trots en geïnteresseerd (bedankt voor het bijhouden van het NRC!). Jullie hielpen me vol te houden en te relativeren tijdens de mindere momenten. Ben super blij met jullie allemaal en ontzettend dankbaar dat jullie, wat er ook gebeurt, altijd achter me zullen staan!

"Blonde haren, blauwe ogen, uit een sprookjesboek geslopen.."

Het laatste jaar beleefde ik inderdaad als in een sprookje.. Lieve Jochen, bedankt dat je bent wie je bent. Hoe blij ik ben dat ik jou ruim een jaar geleden op het Onze Lieve Vrouwe plein ben tegengekomen is met geen pen te beschrijven! Nu weet ik dat $1+1$ inderdaad 3 kan zijn.. 


\section{PUBLICATIONS}

\section{Full papers}

1. Egger G, Vogels N, Westerterp KR. Estimating human movement levels over time. Med J Aus 2001; 175: 635-636.

2. Vogels N, Egger G, Plasqui G and Westerterp KR. Estimating changes in daily physical activity levels over time: implication for health interventions from a novel approach. Int J Sports Med 2004; 25(8): 607-10.

3. Vogels N, Nijs IMT, Westerterp-Plantenga MS. The effect of grape-seed extract on $24 \mathrm{~h}$ energy intake in humans. Eur J Clin Nutr 2004; 58(4):667-73.

4. Vogels $\mathrm{N}$ and Westerterp-Plantenga MS. Categorical strategies based on subject specific characteristics of dietary restraint and physical activity, for weight maintenance. Int J Obes 2005; 29:849-857.

5. Vogels N, Mariman ECM, Bouwman FG, Kester ADM, Diepvens $K$ and Westerterp-Plantenga MS. Relation of weight maintenance and dietary restraint with peroxisome proliferator-activated $\gamma 2$, glucocorticoid receptor and ciliary neurotrophic factor polymorphisms. Am J Clin Nutr 2005; 82:740-6.

6. Vogels N, Diepvens K and Westerterp-Plantenga MS. Predictors of long-term weight maintenance. Obes Res 2005;13:2162-2168.

7. Diepvens K, Kovacs EM, Nijs IM, Vogels N, Westerterp-Plantenga MS. Effect of green tea on resting energy expenditure and substrate oxidation during weight loss in overweight females. Br J Nutr 2005; 94(6):1026-34.

8. Diepvens K, Kovacs EM, Vogels N, Westerterp-Plantenga MS. Metabolic effects of green tea and of phases of weight loss. Physiol Behav 2006; 87(1):185-91.

9. Vogels N, Posthumus DLA, Mariman ECM, Bouwman FG, Rump P, Hornstra G and Westerterp-Plantenga MS. Determinants of overweight in a Dutch children cohort. Am J Clin Nutr (in press)

10. Vogels $\mathrm{N}$ and Westerterp-Plantenga MS. Successful long-term weight maintenance, a $2 y$ follow-up. Obes Res (in revision)

11. Vogels N, Westerterp KR, Posthumus DLA, Rutters F and Westerterp-Plantenga MS. Daily physical activity and activity-counts in lean and overweight Dutch children. BJN (in revision) 


\section{Abstracts}

1. Vogels N, Egger G, Plasqui G and Westerterp KR. Changes over time in physical activity level and effect on body weight. Appetite 2002; 39(1): 104

2. Vogels N, Nijs IMT, Westerterp-Plantenga MS. Grape seed affects energy intake in humans. Appetite 2003; 40(3): 365

3. Vogels $\mathrm{N}$, Westerterp-Plantenga MS. Predictors of weight maintenance after weight loss. Appetite 2004; 42(3):407

4. Vogels N, Westerterp-Plantenga MS. Subject specific treatment of obesity. IJO 2004; 28(1):S224

5. Vogels $\mathrm{N}$, Westerterp-Plantenga MS. Predictors of weight maintenance after weight loss. IJO 2004; 28(1):S173

6. Vogels N, Westerterp-Plantenga MS. Subject specific treatment of obesity. Appetite 2004; 42(3):406

7. Vogels N, Mariman ECM, Bouwman FG and Westerterp-Plantenga MS.

Relationship of weight maintenance and dietary restraint with PPAR $\gamma 2$, GRL and CNTF polymorphisms. Obes Rev 2005; 6(suppl 1):149

8. Vogels N, Westerterp-Plantenga MS. Childhood obesity: BMI tracking and parental influences. Appetite 2005; 44(3):386 


\section{CURRICULUM VITAE}

Neeltje Vogels was born on December 23th 1978 in Veghel, the Netherlands. In 1997, she completed secondary school at the 'Kruisheren College' in Uden. In the same year she started her study Health Sciences with specialization Biological Health Science at Maastricht University, where she graduated in December 2001. She did her master thesis entitled "Physical activity as measured by accelerometry: Changes over time and influence on body weight" at Sydney University, guided by Prof. dr. KR Westerterp and Dr. G Egger.

In February 2002, she started her PhD at the department of Human Biology, Maastricht University, guided by Prof. dr. MS Westerterp-Plantenga. In July 2002, she was awarded with a New Investigator Award for her presentation "Changes over time in physical activity level and effect on body weight" at the Annual Meeting for the Society for the Study of Ingestive Behavior in Santa Cruz, California, USA. In February 2006 she finished her thesis entitled "On the weighty issue of obesity: Physiological, behavioral and genetic aspects". 